DANIEL HUMBERTO GARCIA ESPINOSA

\title{
EFEITO DE LENTE TÉRMICA E NÃO-LINEARIDADES ÓPTICAS DO SILÍCIO AMORFO HIDROGENADO DOPADO COM FÓSFORO
}

Dissertação apresentada à Escola Politécnica da Universidade de São Paulo para obtenção do título de Mestre em Engenharia Elétrica.

São Paulo 
DANIEL HUMBERTO GARCIA ESPINOSA

\section{EFEITO DE LENTE TÉRMICA E NÃO-LINEARIDADES ÓPTICAS DO SILÍCIO AMORFO HIDROGENADO DOPADO COM FÓSFORO}

Dissertação apresentada à Escola Politécnica da Universidade de São Paulo para obtenção do título de Mestre em Engenharia Elétrica.

Área de Concentração: Microeletrônica

Orientador: Prof. Dr. Roberto Koji Onmori

São Paulo 
Este exemplar foi revisado e alterado em relação à versão original, sob responsabilidade única do autor e com a anuência de seu orientador.

São Paulo, 16 de junho de 2011.

Assinatura do autor

Assinatura do orientador

\section{FICHA CATALOGRÁFICA}

Espinosa, Daniel Humberto Garcia

Efeito de lente térmica e não-linearidades ópticas do silício amorfo hidrogenado dopado com fósforo / D.H.G. Espinosa. -ed. rev. -- São Paulo, 2011.

$83 \mathrm{p}$.

Dissertação (Mestrado) - Escola Politécnica da Universidade de São Paulo. Departamento de Engenharia de Sistemas Eletrônicos.

1. Filmes finos 2. Óptica 3. Processos de microeletrônica I. Universidade de São Paulo. Escola Politécnica. Departamento de Engenharia de Sistemas Eletrônicos II. t. 


\section{DEDICATÓRIA}

À minha querida esposa Alessandra, que em todos os momentos me incentivou, com paciência, amor e carinho, a realizar este trabalho. 


\section{AGRADECIMENTOS}

Ao Prof. Dr. Roberto K. Onmori, pela amizade e orientação neste trabalho. Seus ensinamentos sempre me ajudaram a acreditar na possibilidade de realização deste trabalho.

Ao Prof. Dr. Antônio Martins Figueiredo Neto, pelo suporte, treinamento e tutoria nos laboratórios do Grupo de Fluídos Complexos do IFUSP.

À Prof. ${ }^{a}$ Dr. ${ }^{a}$ Sarah Alves, ao Prof. Dr. Marcelo Martinelli e ao Prof. Dr. Sérgio Zílio, pelas importantes discussões e ensinamentos em Óptica Não-Linear. trabalho.

Ao Prof. Dr. Marco Alayo Chávez, pelas críticas para melhoria deste

Aos amigos Odair Martins e Roger Yokoyama, pelas valiosas conversas técnicas, científicas, políticas e filosóficas.

Ao amigo Celso Manoel da Silva, por estar sempre disposto a me auxiliar na realização deste trabalho. Sem dúvida nenhuma, é uma pessoa admirável.

Aos amigos e integrantes do LME: André, Taís, Carlos, Tereza, Cristina, Marcos, João e Rita, pelas discussões e pelas importantes contribuições na sala limpa, e aos colegas da Poli: Alexandre Lopes, pelo auxílio com o reator PECVD e Ricardo Rangel, pelo auxílio com o elipsômetro.

Ao Dr. Diogo Soga e ao Dr. Lenardo de Boni, por me auxiliarem com as discussões sobre a técnica de varredura-Z.

Aos amigos e integrantes do Grupo de Fluídos Complexos do IFUSP: Celso, Marco, Dennys, Igino, Priscila, Luiz, Ellen, Alex, Fernando, Tatiana, Tiago, Cleidi, Eduardo, Társis, Ângelo, Amarildo e José Paulino, e aos professores do GFCx, Suhaila, Cristiano e Elisabeth, que de alguma forma contribuíram para minha formação técnica e científica.

À minha esposa Alessandra. Sem seu amor, seu apoio e sua ajuda, esse trabalho não seria concluído.

Aos meus pais-avós, Gino e Anita, e à minha mãe Sandra, por me educarem, pelo incentivo e pelo carinho. Às minhas irmãs Karla e Karen, pelo apoio e compreensão. Aos meus segundos-pais, Aliseu e Elza, pela compreensão e por desejarem meu sucesso.

A todos aqueles que colaboraram com este trabalho e não foram listados aqui, e a todos aqueles que, de algum modo, puderem ser beneficiados com este trabalho. 


\section{RESUMO}

Efeitos ópticos não-lineares foram estudados em filmes finos de silício amorfo hidrogenado através da técnica de varredura-Z, que utiliza um único feixe de luz laser de onda contínua, modulado na escala de tempo de milissegundos. Em tal técnica, amostras do material foram deslocadas ao longo da região focal de um feixe com perfil de intensidade gaussiano e comprimento de onda de $532 \mathrm{~nm}$, enquanto a transmitância da luz foi medida no campo distante. Os filmes foram depositados sobre vidro pela técnica PECVD a baixas temperaturas (entre $50{ }^{\circ} \mathrm{C}$ e $200{ }^{\circ} \mathrm{C}$ ) e foi utilizado fósforo como impureza dopante: variando-se a concentração do gás fosfina durante a deposição do material, obtêm-se diferentes quantidades de fósforo incorporado no Si-a:H. Durante a realização da varredura-Z, foi observado o efeito de lente térmica no sinal da transmitância e a resolução temporal do sinal medido possibilitou o ajuste dos dados experimentais ao Modelo de Lente Térmica. A partir dos parâmetros desse ajuste, foi possível determinar a difusividade térmica das amostras $\left(D \sim 3 \times 10^{-3} \mathrm{~cm}^{2} / \mathrm{s}\right)$ e estimar sua condutividade térmica $\left(K \sim 5 \times 10^{-3} \mathrm{~W} / \mathrm{Kcm}\right)$ e seu coeficiente de temperatura do caminho óptico ( $\mathrm{d} s / \mathrm{d} T)$. Além disso, os valores dos deslocamentos de fase do feixe $(\theta)$ e dos tempos característicos de formação da lente térmica $\left(t_{c 0}\right)$ foram obtidos. Efeitos ópticos de origem térmica geralmente são indesejados em dispositivos fotônicos e, para evitá-los, o estudo e o conhecimento das propriedades ópticas não-lineares dos materiais que compõem tais dispositivos são de grande importância. Ademais, aplicações em microssensores podem ser baseadas nas propriedades do Si-a:H estudadas neste trabalho, como, por exemplo, sua condutividade térmica.

Palavras-chave: Silício amorfo hidrogenado. PECVD. Efeito de lente térmica.

Técnica de varredura-Z. Óptica não-linear. 


\begin{abstract}
Nonlinear optical effects have been studied in hydrogenated amorphous silicon films through the single beam Z-scan technique, using a modulated CW laser in the millisecond time-scale regime. In this technique, the samples were moved along the focal region of a focused gaussian laser beam with wavelength of $532 \mathrm{~nm}$, while the light transmittance in the far field was measured. The films were deposited on glass by low temperature PECVD technique (from $50{ }^{\circ} \mathrm{C}$ to $200{ }^{\circ} \mathrm{C}$ ) and phosphorus were used as a dopant impurity: during the material deposition, different concentrations of phosphine gas cause different amounts of incorporated phosphorus into a-Si:H. The thermal lens effect was observed in the transmittance signal, so the experimental data from the time-resolved Z-scan mode could be fitted in the Thermal Lens Model. It was possible to determine the samples' thermal diffusivity $\left(D \sim 3 \times 10^{-3} \mathrm{~cm}^{2} / \mathrm{s}\right)$ and to estimate their thermal conductivity $\left(K \sim 5 \times 10^{-3} \mathrm{~W} / \mathrm{Kcm}\right)$ and temperature coefficient of the optical path length change $(\mathrm{d} s / \mathrm{d} T)$ through those fittings. Besides, the phase shift $(\theta)$ and the thermal lens characteristic time $\left(t_{\mathrm{c} 0}\right)$ were achieved. Thermal optical effects are unwanted to photonics devices, therefore studying and knowing these effects is very important to avoid them. Moreover, applications to microsensor devices may use the a-Si:H properties studied in this work as, for example, its thermal conductivity.
\end{abstract}

Keywords: Hidrogenated amorphous silicon. PECVD. Thermal lens effect. Z-Scan technique. Nonlinear optics. 


\section{SUMÁRIO}

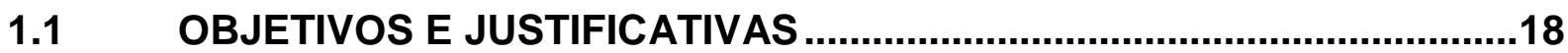

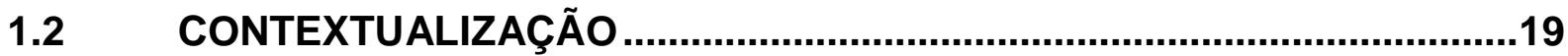

2 FUNDAMENTOS TEÓRICOS ..............................................23

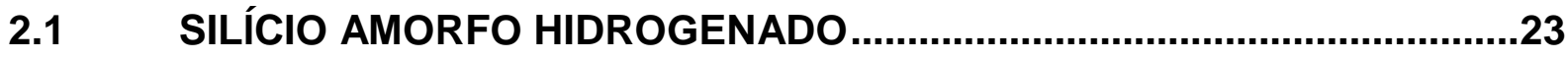

2.2 ESPECTRO DA RADIAÇÃO ELETROMAGNÉTICA …............................26

$2.3 \quad$ TÉCNICA DE DEPOSIÇÃO PECVD

2.4 TRANSMITÂNCIA E ABSORBÂNCIA EM MATERIAIS ...........................28

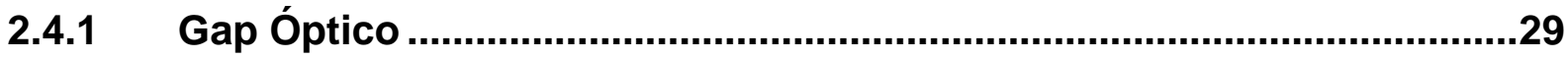

2.5 NÃO-LINEARIDADES ÓPTICAS DE MATERIAIS ...................................30

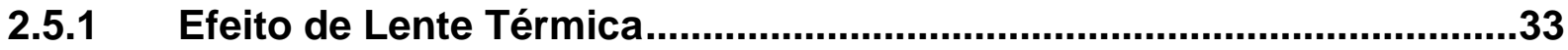

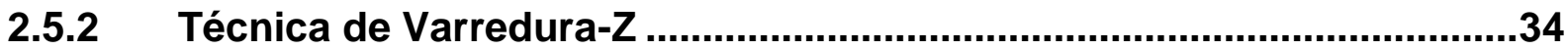

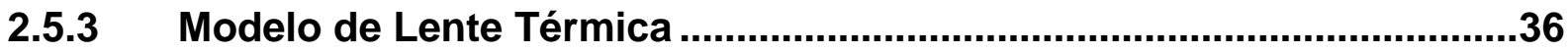

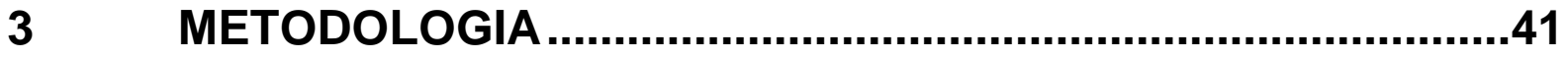

3.1 DEPOSIÇÕES DOS FILMES FINOS ………........................................

3.2 MEDIÇÕES DAS ESPESSURAS DOS FILMES.........................................46

3.3 MEDIÇÕES DOS ESPECTROS DE TRANSMISSÃO …............................47

3.4 COEFICIENTES DE ABSORÇÃO E GAPS ÓPTICOS ............................48

3.5 TÉCNICA DE VARREDURA-Z ..............................................................50

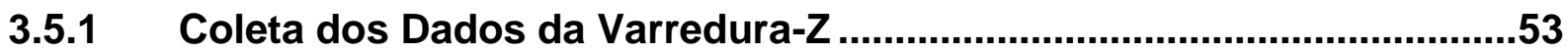

3.5.2 Medição do Perfil do Feixe e Determinação de $w_{0}$ e $z_{0}$...........................55 
4 RESULTADOS E DISCUSSÃO. .58

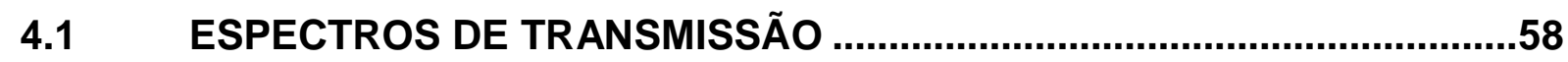

4.2 ESPESSURAS E COEFICIENTES DE ABSORÇÃO ……........................60

$4.3 \quad$ CINTURA DO FEIXE

4.4 VARREDURA-Z E LENTE TÉRMICA ..................................................65

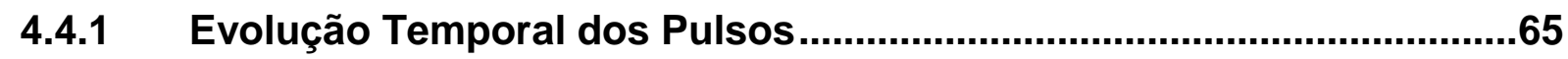

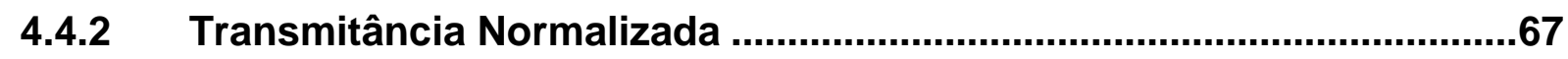

4.4.3 Desvios de Fase e Tempos Característicos ...........................................71

4.4.4 Propriedades Térmicas e Propriedades Ópticas Não-Lineares............74

$5 \quad$ CONCLUSÕES..................................................................

6 SUGESTÕES PARA TRABALHOS FUTUROS.......................79

7 REFERÊNCIAS BIBLIOGRÁFICAS ..................................80 


\section{LISTA DE FIGURAS}

Figura 1 - Principais aplicações do silício amorfo hidrogenado

Figura 2 - Tamanhos típicos dos grãos de cada tipo de silício (SUN; ROGERS, 2007) ...... 24

Figura 3 - Padrões de difração de elétrons do silício (RIBEIRO, 2009) ............................. 25

Figura 4 - Coeficiente de absorção linear $(\alpha)$ do silício (BASS et al., 1995) ....................... 26

Figura 5 - Esquema ilustrativo do espectro de radiação eletromagnética (VUOLO, 2004

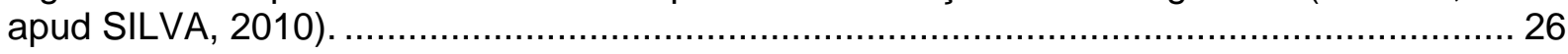

Figura 6 - Esquema ilustrativo da transmissão da luz através de uma amostra de material.28

Figura 7 - llustração do efeito de auto-focalização devido ao índice de refração não-linear. Nesse exemplo, $\Delta n>0$, produzindo um efeito de lente convergente (BOYD, 1992)........... 33

Figura 8 - Representação de um arranjo de varredura-Z ........................................... 35

Figura 9 - Efeito de lente térmica convergente ao longo da varredura-Z $(\Delta n>0) \ldots \ldots \ldots \ldots . . . .37$

Figura 10 - Efeito de lente térmica divergente ao longo da varredura-Z $(\Delta n<0) \ldots \ldots \ldots \ldots \ldots . \ldots 39$

Figura 11 - Espectro de transmissão da lâmina de vidro utilizada como substrato. O vidro é transparente na região do espectro entre 350 e $1000 \mathrm{~nm}$............................................... 41

Figura 12 - Imagens do reator PECVD do LME utilizado para a deposição dos filmes finos. Está destacada, na parte direita superior, a janela da câmara de deposição com o plasma e na parte direita inferior, o interior da câmara.

Figura 13 - Diagrama esquemático do reator PECVD utilizado para a deposição dos filmes finos. As letras em vermelho identificam os sistemas indicados pelas mesmas letras na figura 12 (RIBEIRO, 2009).

Figura 14 - Técnica de perfilometria. Em a), a ponteira do perfilômetro se move sobre o substrato de vidro. Em b), a ponteira se move sobre o filme fino. As dimensões estão fora de escala.

Figura 15 - Imagens do arranjo de espectrofotometria do GFCx. O sistema é composto pela fonte de radiação eletromagnética $(a)$, pelo porta-amostras (b) e pelos espectrômetros $(c)$. $O$ funcionamento interno do espectrômetro está ilustrado em (d).

Figura 16 - Diagrama ilustrativo do arranjo de varredura-Z utilizado para as medições das não-linearidades ópticas.

Figura 17 - Imagem do arranjo de varredura-Z do GFCx utilizado para as medições das nãolinearidades ópticas.

Figura 18 - Configuração do arranjo de varredura-Z através do software zscan_chopper_new. 
Figura 19 - Gráficos construídos pelo software zscan_chopper_new a partir dos dados coletados do osciloscópio.

Figura 20 - Perfil de intensidade da luz do laser. Em a), são apresentados a distribuição de intensidade no plano xy e os ajustes de curvas gaussianas nas componentes $x$ e y. Em b), é mostrado um diagrama tridimensional, no qual a altura representa a intensidade. 56

Figura 21 - Relação entre a cintura do feixe $w_{0}$ e o comprimento de Rayleigh $z_{0}$ 57

Figura 22 - Espectro de transmissão das amostras. Os parâmetros de deposição foram: a) $T_{\text {dep }}=50^{\circ} \mathrm{C}$ e fluxo de fosfina variando entre 2,5 e $40 \mathrm{sccm}$; b) fluxo de fosfina de $10 \mathrm{sccm}$ e $T_{\text {dep }}$ variando entre $50{ }^{\circ} \mathrm{C}$ e $200{ }^{\circ} \mathrm{C}$. Em C), são apresentados os espectros das amostras depositadas a $200^{\circ} \mathrm{C}$ sem dopantes (C2-200) e com fluxo de fosfina de $10 \mathrm{sccm}$ (D2-200).59

Figura 23 - Imagem de uma amostra de filme fino de Si-a:H depositada a $200{ }^{\circ} \mathrm{C}$. 60

Figura 24 - Gráfico da altura da ponteira do perfilômetro em função do seu deslocamento horizontal. A ponteira iniciou sua varredura na superfície do vidro e encontrou um degrau mecânico de Si-a:H após percorrer cerca de $1 \mathrm{~mm}$.

Figura 25 - Coeficiente de absorção das amostras. Os parâmetros de deposição foram: a) $T_{\text {dep }}=50^{\circ} \mathrm{C}$ e fluxo de fosfina variando entre 2,5 e $40 \mathrm{sccm}$; b) fluxo de fosfina de $10 \mathrm{sccm}$ e $T_{\text {dep }}$ variando entre $50{ }^{\circ} \mathrm{C}$ e $200{ }^{\circ} \mathrm{C}$. Em C), são apresentados os espectros das amostras depositadas a $200^{\circ} \mathrm{C}$ sem dopante (C2-200) e com fluxo de fosfina de $10 \mathrm{sccm}$ (D2-200). 62

Figura 26 - Determinação do gap óptico $E_{g}$ segundo o método de Tauc. Na figura são mostradas as extrapolações das retas das amostras que obtiveram menor gap óptico $(1,77$ eV) e maior gap óptico $(2,29 \mathrm{eV})$.

Figura 27 - Determinação da cintura do feixe $w_{0}$ com o ajuste das curvas de $w^{2}$ em função

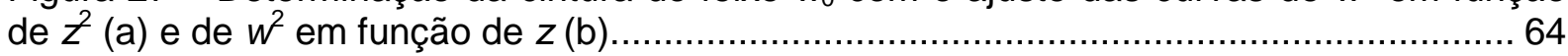

Figura 28 - Evolução temporal do sinal elétrico do fotodetector D1, para a amostra A2-2.5. Os círculos pretos correspondem à medida feita com a amostra posicionada longe do foco, enquanto os quadrados vermelhos correspondem à medida feita com a amostra posicionada próxima do foco. Em a) a amostra estava posicionada antes do foco $(z<0)$, enquanto em b) a amostra estava posicionada após o foco $(z>0)$. 66

Figura 29 - Resultado da varredura-Z da amostra A2-2.5, com $P=116 \mathrm{~mW}$ e $\lambda=532 \mathrm{~nm}$. Em a), apresenta-se a transmitância normalizada em função da posição $z$ para 0 fotodetector D1 (íris fechada). Em b), apresenta-se a transmitância normalizada em função da posição $z$ para o fotodetector D2 (íris aberta). Em c), apresenta-se a divisão da transmitância normalizada de a) pela de b). 68

Figura 30 - Resultado da varredura- $Z$ da amostra contendo apenas o substrato de vidro, com $P=116 \mathrm{~mW}$ e $\lambda=532 \mathrm{~nm}$. Em a), apresenta-se a transmitância normalizada em função da posição $z$ para o fotodetector D1 (íris fechada). Em b), apresenta-se a transmitância normalizada em função da posição $z$ para o fotodetector D2 (íris aberta). Em c), apresentase a divisão da transmitância normalizada de a) pela de b).

Figura 31 - Resultado da varredura-Z da amostra C2-200, com $\lambda=532 \mathrm{~nm}$. Os círculos pretos correspondem à medida feita com a potência de $45 \mathrm{~mW}$, enquanto os quadrados vermelhos correspondem à medida feita com a potência de $116 \mathrm{~mW}$. 71 
Figura 32 - Ajustes do modelo teórico aos dados de transmitância normalizada para a amostra A2-2.5. Os ajustes são representados pelas linhas contínuas. Em a), $t=30 \mathrm{~ms}$ e $T_{\mathrm{N}}$ é apresentada em função de $z$. Em b) e c), $z$ é fixo em -6,5 mm e 6,5 mm, respectivamente, e $T_{\mathrm{N}}$ é apresentada em função de $t$. 72

Figura 33 - Medidas do tempo característico no foco e da difusividade térmica para as amostras depositadas a $50{ }^{\circ} \mathrm{C}$. Em a), são apresentados os valores de $t_{\mathrm{co}}$ em função do fluxo de fosfina utilizado na deposição. Em b), são apresentados os valores de $D$ em função do fluxo de fosfina utilizado na deposição.

Figura 34 - Medidas do tempo característico no foco e da difusividade térmica para as amostras depositadas com fluxo de fosfina de $10 \mathrm{sccm}$. Em a), são apresentados os valores de $t_{\mathrm{c} 0}$ em função da temperatura de deposição, enquanto em b) são apresentados os valores de $D$ em função da temperatura de deposição. 


\section{LISTA DE QUADROS}

Quadro 2.1 - Mecanismos dos fenômenos de interação não-linear da luz com a matéria e tempos de resposta característicos (BOYD, 1992; MARTINELLI, 1998)............................ 32

Quadro 3.1 - Principais sistemas que compõem o reator PECVD do LME...................... 43

Quadro 3.2 - Características dos gases utilizados nas deposições. ................................. 45

Quadro 3.3 - Componentes do arranjo de varredura-Z do GFCx................................... 52 


\section{LISTA DE TABELAS}

Tabela 3.1 - Parâmetros utilizados em cada deposição. 46

Tabela 3.2 - Parâmetros fixos utilizados em todas as deposições. 46

Tabela 4.1 - Medidas das espessuras, transmitâncias, coeficientes de absorção linear e espessuras efetivas das amostras de Si-a:H, para o comprimento de onda de $532 \mathrm{~nm} . \ldots . . .61$

Tabela 4.2 - Resultados dos ajustes do modelo teórico aos gráficos de transmitância normalizada em função de $z$. São apresentados os valores do tempo característico $t_{\mathrm{c} 0}$ e do desvio de fase $\theta$ obtidos para cada amostra. Também são informados os valores da cintura do feixe e da potência utilizada na varredura-Z. 73

Tabela 4.3 - Propriedades ópticas não-lineares e propriedades térmicas das amostras de Si$\mathrm{a}: \mathrm{H}$ 


\section{LISTA DE ABREVIATURAS E SIGLAS}

\begin{tabular}{|c|c|}
\hline$A M-L C D$ & Active Matrix Liquid Crystal Display \\
\hline$C C D$ & Charge Coupled Device \\
\hline CMOS & Complementary-Metal-Oxide-Semiconductor \\
\hline $\mathrm{CO}_{2}$ & Dióxido de Carbono \\
\hline$C V D$ & Chemical Vapor Deposition \\
\hline$C W$ & Continuous Wave \\
\hline GFCx & Grupo de Fluídos Complexos \\
\hline $\mathrm{H}_{2}$ & Hidrogênio \\
\hline LME & Laboratório de Microeletrônica \\
\hline$L R O$ & Long Range Order \\
\hline$L V D T$ & Linear Variable Differential Transformer \\
\hline MEMS & Microelectromechanical Systems \\
\hline Nd:YAG & Neodímio em Cristais de $\mathrm{YAG}\left(\mathrm{Y}_{3} \mathrm{Al}_{5} \mathrm{O}_{12}\right)$ \\
\hline $\mathrm{Nd}: \mathrm{YVO}_{4}$ & Neodímio em Cristais de Vanadato de Ítrio $\left(\mathrm{YVO}_{4}\right)$ \\
\hline$P E C V D$ & Plasma Enhanced Chemical Vapor Deposition \\
\hline $\mathrm{PH}_{3}$ & Fosfina \\
\hline $\mathrm{RF}$ & Rádio-Frequência \\
\hline Si-a:H & Silício Amorfo Hidrogenado \\
\hline $\mathrm{SiH}_{4}$ & Silana \\
\hline $\mathrm{Si}-\mu \mathrm{C}: \mathrm{H}$ & Silício Microcristalino Hidrogenado \\
\hline SOI & Silicon-On-Insulator \\
\hline SRO & Short Range Order \\
\hline$T F T$ & Thin Film Transistor \\
\hline UV-VIS-NIR & Ultraviolet - Visible - Near-Infrared \\
\hline
\end{tabular}




\section{LISTA DE SÍMBOLOS}

\begin{tabular}{|c|c|}
\hline$A$ & absorbância \\
\hline$c$ & velocidade da luz no vácuo \\
\hline$c_{\mathrm{p}}$ & calor específico a pressão constante \\
\hline $\mathrm{d} n / \mathrm{d} T$ & coeficiente de temperatura do índice de refração \\
\hline $\mathrm{d} s / \mathrm{d} T$ & coeficiente de temperatura do caminho óptico \\
\hline$D$ & difusividade térmica \\
\hline$E_{f}$ & energia do fóton \\
\hline$E$ & energia do elétron \\
\hline$E_{g}$ & gap óptico \\
\hline$g(E)$ & densidade de estados eletrônicos de energia $E$ \\
\hline$h$ & constante de Planck \\
\hline I & intensidade da radiação eletromagnética \\
\hline$I_{0}$ & intensidade da luz incidente não refletida \\
\hline$I_{\mathrm{A}}$ & intensidade transmitida através da amostra \\
\hline$l_{\mathrm{abs}}$ & intensidade transmitida absorvida pela amostra \\
\hline$I_{\mathrm{R}}$ & intensidade transmitida através do material de referência \\
\hline$I_{\top}$ & intensidade da luz transmitida \\
\hline$I_{z}$ & intensidade de fundo \\
\hline$L$ & espessura da amostra \\
\hline$L_{\text {ef }}$ & espessura efetiva da amostra \\
\hline$n$ & índice de refração \\
\hline$n_{0}$ & índice de refração linear \\
\hline$n_{2}$ & índice de refração não-linear \\
\hline$n_{2}{ }^{t}$ & índice de refração não-linear de origem térmica \\
\hline$P$ & potência da luz incidente na amostra \\
\hline
\end{tabular}


caminho óptico normalizado pela espessura da amostra

$S$

$t$

$t_{\mathrm{c} 0}$

$T$

$\% T$

$T_{\text {dep }}$

$T_{\mathrm{N}}$

V

w

$w_{0}$

$x$

$z$

$z_{0}$

$\alpha$

$\Delta n$

$\Delta s$

$\Delta T$

$\theta$

K

$\lambda$

$\rho$

$\varphi$ caminho óptico

instante de tempo

tempo característico na posição focal

transmitância (em fração)

transmitância (em porcentagem)

temperatura de deposição

transmitância normalizada

velocidade da luz no material

raio do feixe

cintura do feixe

posição relativa da amostra $\left(x=z / z_{0}\right)$

posição da amostra

comprimento de difração (ou comprimento de Rayleigh) do feixe

coeficiente de absorção

variação do índice de refração

variação do caminho óptico

variação de temperatura induzida pela luz

desvio de fase

condutividade térmica

comprimento de onda da luz

densidade volumétrica de massa

eficiência quântica 


\section{INTRODUÇÃO}

Neste capítulo estão apresentados os objetivos do trabalho, suas justificativas e uma breve introdução ao material estudado, silício amorfo hidrogenado, bem como a técnica de medição de óptica não-linear, denominada varredura-Z.

\section{$1.1 \quad$ OBJETIVOS E JUSTIFICATIVAS}

Este trabalho teve como objetivos a obtenção de filmes finos de silício amorfo hidrogenado (Si-a:H), do tipo n, dopados com fósforo, e a medição de suas propriedades ópticas não-lineares e de suas propriedades térmicas, evidenciadas pelo fenômeno denominado de Efeito de Lente Térmica. Especificamente, este trabalho buscou medir a difusividade térmica $(D)$ e a condutividade térmica $(K)$ dos filmes, além de obter seu coeficiente de temperatura do caminho óptico ( $\mathrm{d} s / \mathrm{d} T)$, o desvio de fase do feixe $(\theta)$ e o tempo característico de formação da lente térmica $\left(t_{\mathrm{c} 0}\right)$.

Propriedades ópticas não-lineares de materiais despertam grande interesse por causa de suas aplicações no desenvolvimento de dispositivos optoeletrônicos. Esses dispositivos, por sua vez, são atualmente utilizados em diversas áreas tecnológicas, desde telecomunicações e informática, que os empregam nas fibras ópticas, monitores de tela plana de computadores, celulares e diversos aparelhos portáteis, moduladores eletro-ópticos e armazenamento e leitura ópticos de dados e até mesmo na medicina, em novos métodos de diagnóstico por imagens e cirurgias que utilizam fibras ópticas e lasers. Em particular, o silício amorfo hidrogenado é um material cujo uso na fabricação de guias de onda é intensamente pesquisado. Circuitos integrados totalmente ópticos poderão ser baseados nesses guias de onda, que substituirão a função das atuais interconexões metálicas dos circuitos optoeletrônicos. Entretanto, medidas dos efeitos termo- 
ópticos no Si-a:H através da técnica de varredura-Z não são muito exploradas na literatura e o estudo aqui proposto contribui para o aumento do conhecimento nessa área de pesquisa.

\subsection{CONTEXTUALIZAÇÃO}

O silício amorfo hidrogenado e o silício microcristalino hidrogenado (Si$\mu \mathrm{c}: H)$ são materiais semicondutores muito utilizados na indústria microeletrônica, para a fabricação de dispositivos como células solares fotovoltaicas, fotodiodos, transistores de filmes finos empregados em telas planas de mostradores de cristal líquido de matriz ativa (Active Matrix Liquid Crystal Display - AM-LCD), dispositivos fotônicos e optoeletrônicos e variados tipos de sensores, conforme ilustrações da figura 1.

\section{Aplicações do Si-a:H}

Células Solares

Transistores de Filmes Finos - TFT

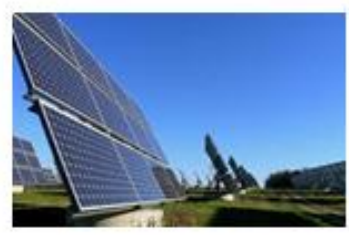

\section{Matriz Ativa de Telas de Cristal Líquido}

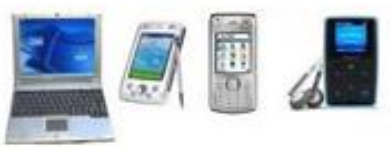

MEMS e Sensores

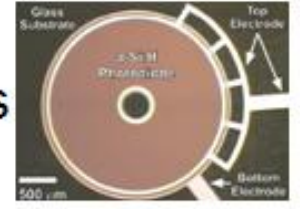

Eletrônica sobre Substratos Flexíveis

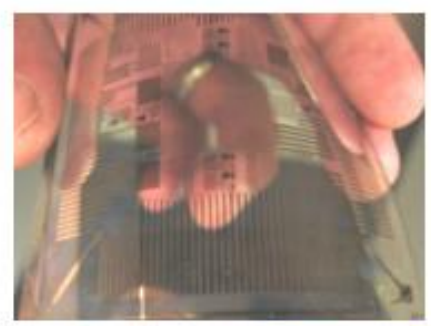

Dispositivos Fotônicos e Optoeletrônicos

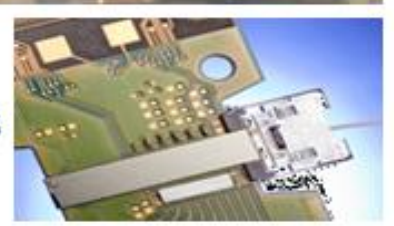

Figura 1 - Principais aplicações do silício amorfo hidrogenado. 
Os primeiros trabalhos a apresentarem técnicas de obtenção do silício amorfo hidrogenado a partir do gás silana por deposição química na fase vapor, através de uma descarga luminescente, foram realizados por Sterling e Swann (STERLING; SWANN, 1968). Em seguida, Si-a:H tipo $n$ e tipo $p$ foram obtidos por Spear e Le Comber (SPEAR; LE COMBER, 1976), o que tornou possível a primeira aplicação prática desse material pelos laboratórios RCA no mesmo ano, ao construir uma célula solar com a estrutura p-i-n (uma camada de Si-a:H dopado com boro tipo p, uma camada de Si-a:H intrínseco e uma camada de Si-a:H dopado com fósforo - tipo n) (CARLSON; WRONSKI, 1976). Como filmes finos de Si-a:H e de Si$\mu \mathrm{c}: \mathrm{H}$ podem ser obtidos através de processos envolvendo baixas temperaturas (inferiores a $150^{\circ} \mathrm{C}$ ), sua deposição sobre substratos poliméricos flexíveis tem sido, atualmente, alvo de grande interesse de pesquisa, além de sua utilização conjugada com polímeros em dispositivos eletrônicos orgânicos (NG et al., 2007; ONMORI et al., 1999; SUN; ROGERS, 2007).

Nos últimos anos, fez-se um grande investimento em pesquisa e desenvolvimento das propriedades ópticas do silício, com objetivo de aperfeiçoar suas aplicações em dispositivos optoeletrônicos integrados compatíveis com a já consolidada indústria microeletrônica (VLASOV; GREEN; XIA, 2008). O silício e o óxido de silício já são vastamente empregados nas tecnologias CMOS (ComplementaryMetal-Oxide-Semiconductor) e SOI (Silicon-On-Insulator) e a infraestrutura dos processos de fabricação que os utilizam também poderia ser aproveitada para a construção de circuitos integrados ópticos, onde fótons podem ser gerados, transportados, controlados, armazenados e detectados (SOREF, 2006). Processadores totalmente ópticos interligados, através de guias de onda, a memórias ópticas e dados transportados por fibras ópticas prometem aumentar a velocidade do processamento de dados para a faixa de Tera bits por segundo, pois eliminam a necessidade de conversão do sinal luminoso em sinal elétrico. Além disso, o consumo de energia diminuiria, já que, a dissipação de energia pelo efeito Joule que ocorre nos dispositivos eletrônicos não ocorreria nos dispositivos ópticos. Como exemplo de dispositivos construídos nessa linha de pesquisa, pode-se citar o modulador óptico da IBM a taxas de dados de $10 \mathrm{~Gb} / \mathrm{s}$ e consumo de $5 \mathrm{pJ} / \mathrm{bit}$ (GREEN, 2007). 
Para aplicações em guias de onda, o estudo das propriedades ópticas não-lineares do silício tem atraído bastante atenção, tornando o silício um forte candidato a material de fabricação de guias de onda integrados em um chip (DINU; QUOCHI; GARCIA, 2003; LIN; PAINTER; AGRAWAL, 2007). O silício é praticamente transparente para ondas eletromagnéticas de comprimentos de onda maiores que $1100 \mathrm{~nm}$, podendo guiá-las sem grandes perdas de potência. Além disso, o silício apresenta um alto índice de refração, o que é interessante para o confinamento das ondas eletromagnéticas em regiões sub-micrométricas, através da tecnologia SOI. E o silício apresenta não-linearidades de terceira ordem superiores à sílica atualmente utilizada nas fibras-ópticas, possibilitando a implementação de dispositivos ópticos em um chip interligados por guias de onda (LIN; PAINTER; AGRAWAL, 2007). Pode-se citar, como exemplo de dispositivos, chaves ópticas e moduladores ópticos (IKEDA; SHEN; FAINMAN, 2007; VLASOV; GREEN; XIA, 2008).

Entretanto, efeitos ópticos não-lineares de origem térmica podem diminuir a eficiência desses dispositivos, ou até mesmo impedir o projeto correto dos mesmos, se os efeitos forem desconhecidos. Nesse sentido, o estudo do efeito de lente térmica nos filmes finos de silício amorfo hidrogenado contribui para o estado da arte da pesquisa em fotônica e optoeletrônica.

Além disso, ao se estudar fenômenos ópticos não-lineares de origem térmica, é possível caracterizar o material, obtendo-se algumas de suas propriedades, como a condutividade e a difusividade térmica. $O$ conhecimento de como o material conduz calor é muito importante para o projeto de sensores baseados em diferenças de temperatura, como por exemplo, o microssensor de vazão de gases e líquidos, fabricado por Rodrigues e Furlan, no Laboratório de Microeletrônica da Escola Politécnica da USP (RODRIGUES; FURLAN, 2003).

Uma técnica atraente para a medição de não-linearidade causada por efeitos térmicos é a chamada técnica de varredura-Z ou "Z-scan", elaborada por Sheik-Bahae, Said e Stryland em 1989. Eles demonstraram o uso dessa técnica para medições do índice de refração não-linear de vários materiais, empregando lasers pulsados de $\mathrm{CO}_{2}$ e Nd:YAG (SHEIK-BAHAE; SAID; STRYLAND, 1989). Em 1990, Sheik-Bahae e colaboradores realizaram também medições de absorção não-linear pela técnica de varredura-Z (SHEIK-BAHAE et al., 1990). Nos últimos anos, essa 
técnica tem sido empregada para estudo de não-linearidades de diversos materiais, como ligas de silício amorfo hidrogenado com enxofre (AL-DALLAL et al., 2004), vidros a base de bismuto (HASEGAWA; NAGASHIMA; SUGIMOTO, 2005), filmes finos de silício amorfo hidrogenado intrínseco (IKEDA; SHEN; FAINMAN, 2007; MINAMIKAWA; TANAKA, 2006) e colóides magnéticos (SOGA et al., 2007; SOGA, 2007). 


\section{FUNDAMENTOS TEÓRICOS}

\subsection{SILÍCIO AMORFO HIDROGENADO}

Sólidos amorfos ou não-cristalinos são assim denominados para serem diferenciados dos sólidos cristalinos. Os sólidos cristalinos apresentam átomos ordenados dentro do material em padrões ou arranjos geométricos tridimensionais, que se repetem ao longo de várias distâncias atômicas. Essa repetição de padrões é denominada de Ordem de Longo Alcance (LRO - Long Range Order). Portanto, sólidos amorfos ou não-cristalinos podem ser definidos como sólidos cujos arranjos dos átomos não possuem ordem de longo alcance (CALLISTER, 2007). Mesmo sem a $L R O$, existe alguma ordenação de seus átomos em regiões próximas às suas vizinhanças, chamada de Ordem de Curto Alcance (SRO - Short Range Order). As características elétricas e ópticas desses materiais, utilizadas na maioria das aplicações tecnológicas, dependem da SRO.

O silício amorfo é um sólido semicondutor não-cristalino que apresenta, em sua estrutura, muitos defeitos chamados de ligações pendentes (ou dangling bonds). Suas propriedades eletrônicas, como a mobilidade dos portadores, são melhoradas quando a ele é adicionado hidrogênio, que se liga às ligações pendentes do silício, passivando, desse modo, alguns defeitos. O material obtido é então chamado de silício amorfo hidrogenado (STREET, 1991).

A adição de dopantes ao Si-a:H aumenta sua condutividade elétrica. Ao adicionar fósforo no $\mathrm{Si}-\mathrm{a}: \mathrm{H}$, elétrons fracamente ligados ao núcleo do fósforo se tornam livres, resultando em um aumento da mobilidade de elétrons. O material se torna, desse modo, um semicondutor do tipo n (cujos portadores majoritários são os elétrons).

O Si- $\mu \mathrm{c}: \mathrm{H}$, por sua vez, é formado por grãos cristalinos cujos tamanhos variam de $10 \mathrm{~nm}$ a $1 \mu \mathrm{m}$, enquanto o Si-a:H possui grãos de $0,1 \mathrm{~nm}$ a unidades de nanometros, conforme ilustrado na figura 2. As mobilidades dos portadores nesses materiais, em geral, aumentam com o aumento do tamanho dos grãos cristalinos, o 
que torna a condutividade elétrica do Si- $\mu \mathrm{c}: \mathrm{H}$ maior que a do Si-a:H (SUN; ROGERS, 2007).

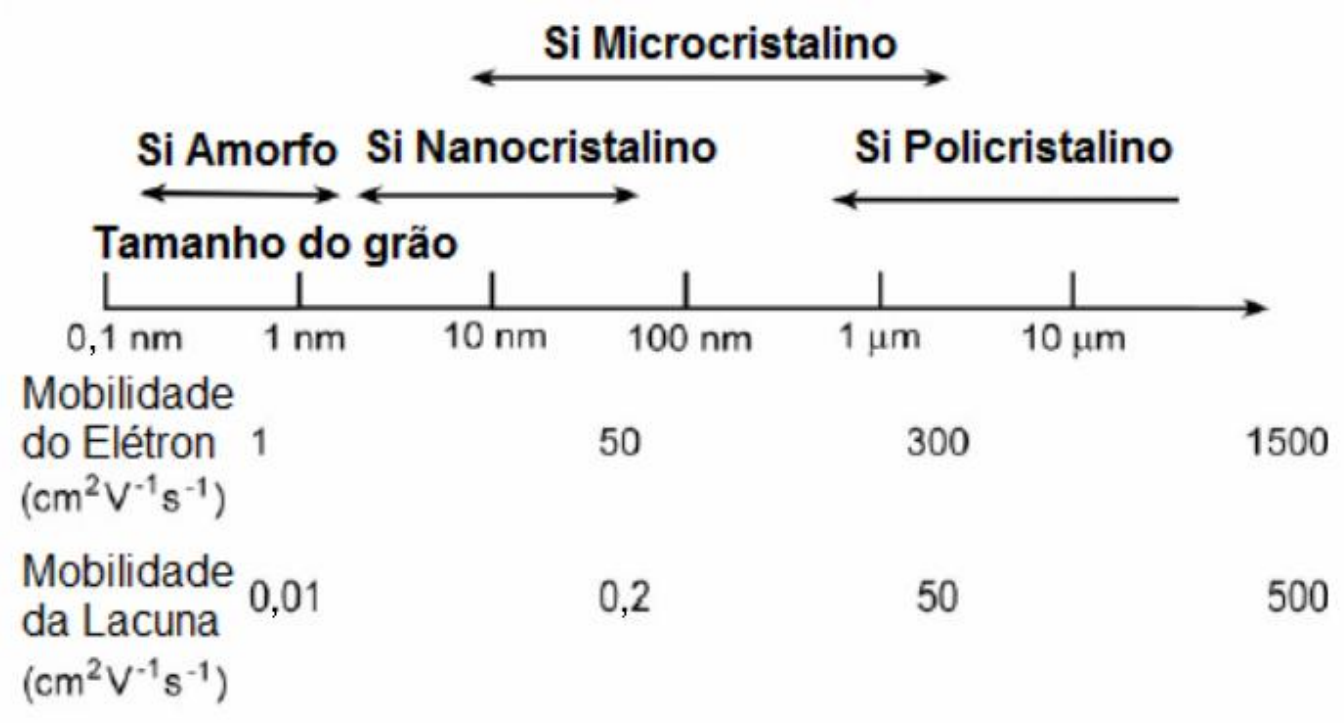

Figura 2 - Tamanhos típicos dos grãos de cada tipo de silício (SUN; ROGERS, 2007).

Uma técnica utilizada para a análise da estrutura do silício é a difração de elétrons em um microscópio eletrônico de transmissão. Através dessa técnica, é possível determinar se um material é amorfo ou possui grãos cristalinos. Um feixe de elétrons atravessa a amostra e sofre espalhamento durante esse processo. Além de serem partículas, os elétrons também apresentam uma natureza ondulatória, e por isso podem sofrer difração: a intensidade do feixe espalhado será maior quando houver interferência construtiva dos elétrons.

As condições para a ocorrência de interferência construtiva dependem diretamente das distâncias entre átomos, repetidas ao longo do material, em forma de arranjos atômicos tridimensionais, que espalham os feixes. Dependendo da geometria dos arranjos atômicos, feixes espalhados em algumas direções específicas estarão em fase entre si, sofrendo, portanto, interferência construtiva.

Nos materiais monocristalinos, ocorrerá interferência construtiva apenas para os feixes espalhados em algumas direções específicas. Quando o feixe transmitido incide sobre uma tela de fósforo, ocorre a formação de uma imagem chamada de "padrão de difração": o círculo mais intenso no centro da imagem 
corresponde ao feixe transmitido sem espalhamento, e pontos intensos equidistantes do centro são produzidos pelos feixes espalhados cujos elétrons sofreram interferência construtiva, conforme mostra a figura 3 (RIBEIRO, 2009).

Em materiais policristalinos, o feixe de elétrons incidente forma um ângulo com o plano cristalográfico diferente para cada grão cristalino. Por esse motivo, cada grão possui seu conjunto de direções de espalhamento que favorecem a interferência construtiva dos elétrons. Uma imagem de anéis concêntricos é formada, ao invés de pontos, como padrão de difração.

Em materiais amorfos, as direções de espalhamento são tantas que o padrão de difração apresenta apenas um halo difuso, conforme mostra a imagem da figura 3.
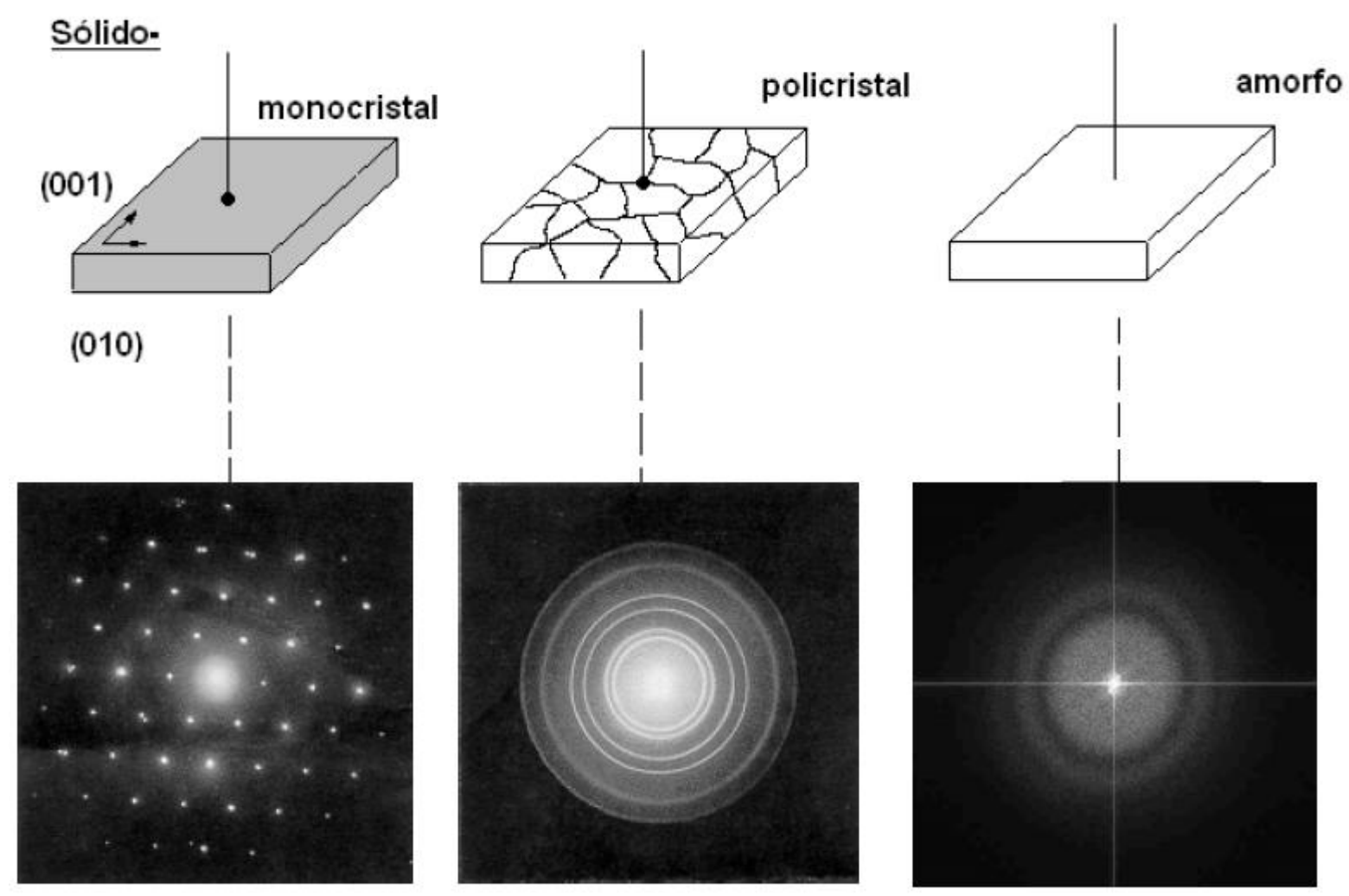

Figura 3 - Padrões de difração de elétrons do silício (RIBEIRO, 2009).

Além da difração de elétrons, o valor do coeficiente de absorção da luz pelo silício amorfo é superior ao do silício cristalino na região visível do espectro eletromagnético, conforme ilustrado na figura 4. 


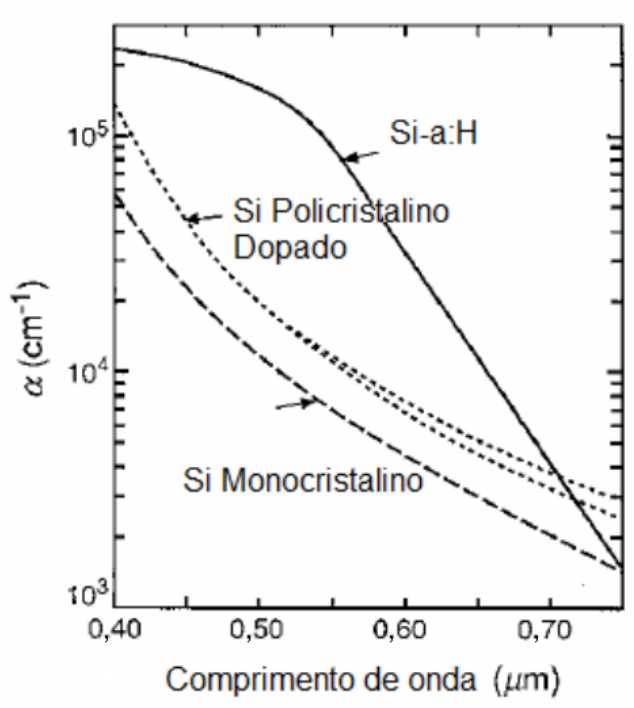

Figura 4 - Coeficiente de absorção linear ( $\alpha$ ) do silício (BASS et al., 1995).

\subsection{ESPECTRO DA RADIAÇÃO ELETROMAGNÉTICA}

A radiação eletromagnética possui um vasto espectro de frequência, desde ondas de rádio, micro-ondas, infravermelho, visível (chamada também de luz), ultravioleta, raios $x$ e raios $\gamma$. A figura 5 apresenta parte do espectro da radiação eletromagnética, com ênfase nos comprimentos de onda da radiação visível (comprimentos de onda de cerca de $400 \mathrm{~nm}$ a cerca de $700 \mathrm{~nm}$ ).

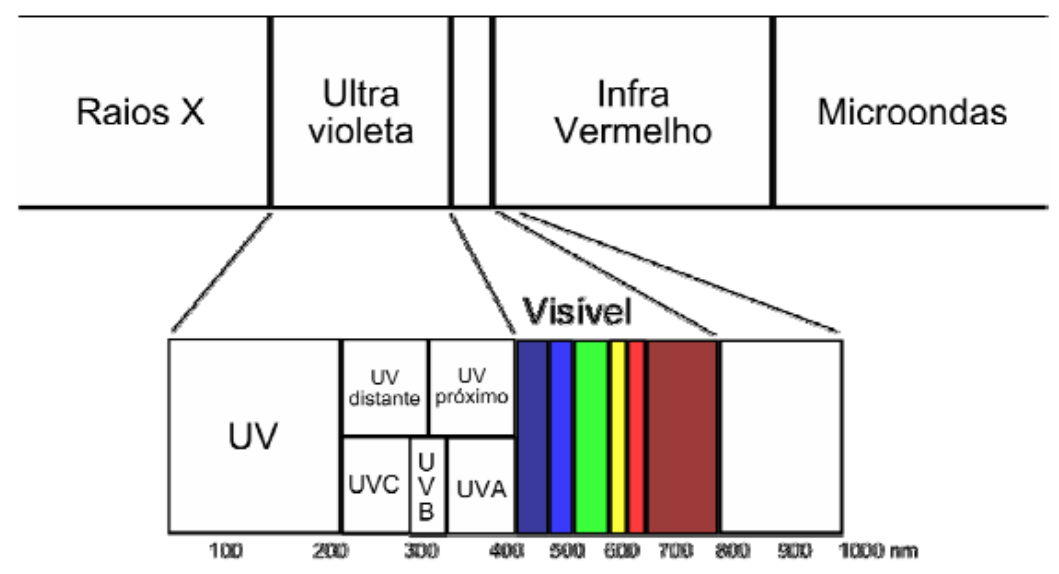

Figura 5 - Esquema ilustrativo do espectro de radiação eletromagnética (VUOLO, 2004 apud SILVA, 2010). 


\subsection{TÉCNICA DE DEPOSIÇÃO PECVD}

A técnica de deposição de filmes chamada Deposição Química na Fase Vapor Assistida por Plasma (PECVD - Plasma Enhanced Chemical Vapor Deposition) é utilizada para a produção de filmes finos sólidos sobre uma base, chamada substrato, a partir de gases precursores. Os gases sofrem reações químicas na superfície do substrato ou das camadas já depositadas do filme, formando, assim, o filme fino.

Os mecanismos de deposição do filme sobre o substrato são compreendidos pelas seguintes etapas:

a) difusão dos íons, moléculas e átomos para a superfície do substrato;

b) adsorção dos mesmos pela superfície do substrato (ou da camada de filme já depositada);

c) reações químicas, que ocorrem na superfície;

d) dessorção dos subprodutos das reações;

e) difusão dos subprodutos para longe da superfície.

Existem diversos tipos de reator $C V D$, entre eles, o PECVD. A diferença vantajosa do $P E C V D$ sobre os outros tipos é a formação de um plasma no interior da câmara onde se realizará a deposição. Com o plasma, além de moléculas e átomos ionizados, formam-se também radicais livres e fragmentos de moléculas, além dos átomos e moléculas em seus estados fundamentais. A interação entre essas partículas possibilita a ocorrência das reações químicas a temperaturas inferiores do que nos processos CVD sem a assistência do plasma. Além de simplificar o sistema de aquecimento do substrato, a vantagem de se trabalhar em temperaturas mais baixas é a possibilidade de deposição de filmes sobre substratos que não suportariam temperaturas altas. Baixas temperaturas de deposição viabilizam a deposição de filmes sobre polímeros (substratos flexíveis) ou mesmo sobre microcircuitos já fabricados, que necessitam da deposição de um filme fino como camada de passivação e encapsulamento (OHRING, 2001).

Os sistemas componentes do reator PECVD e o funcionamento dos mesmos serão detalhados na seção 3.1 . 


\subsection{TRANSMITÂNCIA E ABSORBÂNCIA EM MATERIAIS}

A figura 6 ilustra o que ocorre quando a luz é transmitida através de uma amostra absorvente: apenas uma fração da intensidade da luz é transmitida.

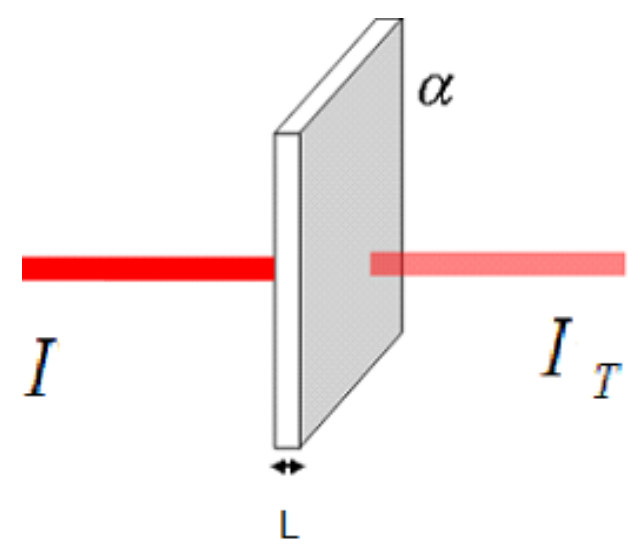

Figura 6 - Esquema ilustrativo da transmissão da luz através de uma amostra de material.

A divisão da intensidade da luz transmitida através do material $\left(l_{T}\right)$ pela intensidade da luz incidente não refletida $\left(I_{0}\right)$ é definida como a transmitância do material (T), conforme indica a equação 2.1 (CALLISTER, 2007):

$$
T=\frac{I_{T}}{I_{0}}=e^{-\alpha L}
$$

onde $L$ é a espessura da amostra e $\alpha$ é o chamado coeficiente de absorção da amostra. O valor de $T$ pode ser expresso apenas como uma fração ou em \%, e nesse último caso, multiplica-se o valor da transmitância da equação 2.1 por 100.

A absorbância de um material é então relacionada à sua transmitância pela equação 2.2 (CALLISTER, 2007):

$$
A=\log \left(\frac{1}{T}\right)
$$


Os valores da transmitância, absorbância e coeficiente de absorção de um determinado material, como definidas nas equações 2.1 e 2.2, dependem do comprimento de onda da luz incidente sobre ele. As medidas de $T$ e $A$ do material para cada comprimento de onda são denominadas de espectro de transmissão e espectro de absorção, respectivamente.

A absorção da luz pelo material pode ser descrita pela natureza corpuscular da luz. Os elétrons do material absorvem os fótons da luz incidente, sofrendo, por causa disso, uma transição de níveis de energia correspondente à energia do fóton absorvido.

\subsubsection{Gap Óptico}

O gap de energia um semicondutor é definido como a diferença entre o nível máximo de energia da banda de valência e o nível mínimo de energia da banda de condução (TAUC, 1974).

Em semicondutores cristalinos intrínsecos, a densidade de estados eletrônicos se torna praticamente nula para níveis de energia um pouco maiores que o nível máximo da banda de valência. O mesmo ocorre com a densidade de estados eletrônicos para níveis de energia um pouco menores que o nível mínimo da banda de condução. Por causa disso, a absorção de fótons com energia menor que o gap se torna praticamente nula e aumenta rapidamente quando a energia dos fótons se torna superior ao gap. Já em semicondutores amorfos, não existe um nível máximo de energia na banda de valência a partir do qual a densidade de estados se torna nula. Esse fenômeno é chamado de cauda da banda, e suas causas ainda são assunto de investigação (STREET, 1991). De forma semelhante, não existe um limite mínimo na banda de condução antes do qual a densidade de estados se torna nula. As caudas das bandas tornam difícil a definição de um gap de energia para esse tipo de material.

Para se definir o gap de energia para semicondutores amorfos é preciso, portanto, definir limites para os níveis de energia de suas bandas de valência e condução. Uma maneira de fazer tal definição foi proposta por Tauc, Grigorovici e 
Vancu em 1966 é conhecida como "método de Tauc" (TAUC; GRIGOROVICl; VANCU, 1966). A relação entre a densidade de estados eletrônicos e os níveis de energia da banda de valência segue um comportamento parabólico (exceto nas caudas de banda) e o mesmo ocorre com a relação entre a densidade de estados eletrônicos e os níveis de energia da banda de condução. Ou seja, $g(E)^{2} \sim E$, onde $g(E)$ é a densidade de estados de nível de energia $E$. Ao extrapolar esse comportamento parabólico para a região das caudas da banda, define-se o "gap óptico" como a diferença entre os níveis de energia da banda de valência e da banda de condução quando $g(E)$ de cada banda tende a zero (STREET, 1991).

O coeficiente de absorção do material é proporcional à densidade de estados do nível inicial e final da transição que o elétron sofre ao absorver os fótons da luz incidente. Ao se combinar a relação entre o coeficiente de absorção e as densidades eletrônicas com o modelo de bandas parabólico, Tauc, Grigorovici e Vancu chegaram à equação 2.3 (TAUC, 1974):

$$
\left(E_{f} \alpha\right)^{1 / 2}=A\left(E_{f}-E_{g}\right)
$$

onde $E_{f}$ é a energia do fóton incidente, relacionada com seu comprimento de onda através da constante de Planck e da velocidade da luz no vácuo $\left(E_{f}=h c / \lambda\right), E_{\mathrm{g}}$ é o gap óptico e $A$ é uma constante de proporcionalidade.

\subsection{NÃO-LINEARIDADES ÓPTICAS DE MATERIAIS}

Efeitos ópticos não-lineares em materiais são aqueles que dependem da intensidade da luz incidente sobre o mesmo. Segundo Boyd (1992): "Óptica nãolinear é o estudo da interação de luz laser intensa com a matéria".

Em particular, o índice de refração do material $(n)$, definido como a divisão da velocidade de propagação da luz no vácuo (c) pela velocidade da luz no material (v), poderá apresentar não-linearidades com radiações intensas, seguindo um comportamento descrito pela equação 2.4 (BOYD, 1992): 


$$
\Delta n(I)=n-n_{0}=n_{2} I
$$

onde $n$ corresponde ao índice de refração da amostra iluminada com luz de intensidade $I, n_{0}$ corresponde ao índice de refração linear e $n_{2}$ corresponde ao índice de refração não-linear. A variação no índice de refração do material $(\Delta n)$ descrita pela equação 2.4 é devida às oscilações da sua nuvem eletrônica com os altos valores de intensidade luminosa.

Para materiais que absorvem parte da luz sobre eles incidente, valores elevados de intensidade luminosa podem alterar sua temperatura, resultando em uma variação do seu índice de refração $(\Delta n)$. Esse fenômeno, denominado de nãolinearidade óptica de origem térmica, é descrito pela equação 2.5 :

$$
\Delta n(I)=n-n_{0}=\frac{d n}{d T} \Delta T(I)
$$

onde $n$ corresponde ao índice de refração da amostra iluminada com luz de intensidade $I, n_{0}$ corresponde ao índice de refração linear, $\mathrm{d} n / \mathrm{d} T$ corresponde ao coeficiente de temperatura do índice de refração e $\Delta T$ corresponde à variação de temperatura do material induzida pela alta intensidade luminosa (BOYD, 1992).

O mecanismo que dará origem à não-linearidade óptica depende do tempo de duração do pulso de luz, ou seja, possui um tempo de resposta característico para ocorrer. O quadro 2.1 apresenta valores típicos da magnitude de $n_{2}$ e o tempo característico de formação do mesmo.

O efeito da polarização eletrônica ocorre quando a luz induz distorções na distribuição espacial da nuvem eletrônica dos elétrons fortemente ligados aos núcleos dos átomos do material. A oscilação deve ser muito rápida para respeitar o princípio da incerteza (os níveis de energia distorcidos só podem existir por um intervalo de tempo curto). Por esse motivo, efeitos de polarização eletrônica ocorrem em regimes denominados de ultra-rápidos (femtossegundos).

A reorientação molecular, que acontece principalmente em líquidos compostos de moléculas anisotrópicas ou em colóides, é devida à tendência das moléculas em se alinharem com o campo elétrico da onda eletromagnética (BOYD, 
1992). Quando as moléculas se realinham, ocorrem uma mudança no índice de refração da amostra.

Quadro 2.1 - Mecanismos dos fenômenos de interação não-linear da luz com a matéria e tempos de resposta característicos (BOYD, 1992; MARTINELLI, 1998).

\begin{tabular}{|l|c|c|}
\hline \multicolumn{1}{|c|}{ Mecanismo } & $\begin{array}{c}\mathbf{n}_{2} \\
\left(\mathbf{c m}^{2} / \mathbf{W}\right)\end{array}$ & $\begin{array}{c}\text { Tempo de resposta } \\
(\mathbf{s})\end{array}$ \\
\hline Polarização eletrônica & $10^{-16}$ & $10^{-15}$ \\
\hline Reorientação molecular & $10^{-14}$ & $10^{-12}$ \\
\hline Eletrostricção & $10^{-14}$ & $10^{-9}$ \\
\hline Absorção atômica saturada & $10^{-10}$ & $10^{-8}$ \\
\hline Efeitos térmicos & $10^{-6}$ & $10^{-3}$ \\
\hline
\end{tabular}

$\mathrm{Na}$ eletrostricção, altas intensidades de onda eletromagnética provocam mudanças de densidade do material, podendo tanto aumentá-la, quanto diminui-la.

$\mathrm{Na}$ absorção atômica saturada, a absorção da luz pelos elétrons diminui após a saturação da sua população em estados excitados.

Por fim, nos efeitos térmicos, o aquecimento do material pela luz altera o perfil de temperatura do material, provocando uma mudança em seu índice de refração. Os efeitos térmicos serão investigados em mais detalhes nas seções 2.5.1 e 2.5.3 deste trabalho.

Há de se considerar que o efeito não-linear pode ser originado por mais de um tipo de mecanismo, caso a frequência dos pulsos (quantidade de pulsos por segundo) seja muito grande. Por exemplo, pulsos de largura de femtossegundos com freqüência da ordem de $\mathrm{kHz}$ (ou intervalo entre pulsos da ordem de milissegundos) podem apresentar efeitos térmicos, inclusive, sobrepujando os efeitos eletrônicos.

Robert Boyd (1992) utilizou um modelo de feixe de laser circular incidindo sobre uma amostra e resolveu a equação de transporte de calor no estado estacionário para chegar a uma equação onde $\Delta T$ é linear com $I$. Assim, ele reescreveu a equação 2.5 para ficar com a mesma forma da equação 2.4 , e estimou uma ordem de grandeza para $0 n_{2}{ }^{\mathrm{t}}$, de origem térmica. Esse valor de $n_{2}{ }^{\mathrm{t}}$, que está presente na última linha da tabela $2.1\left(10^{-6} \mathrm{~W} / \mathrm{cm}^{2}\right)$ é dependente da geometria do 
laser que ilumina a amostra, e não deve ser confundido com o índice de refração não-linear, também chamado de coeficiente do efeito Kerr óptico, $\left(n_{2}\right)$ da equação 2.4, que é uma propriedade do material. Entretanto, essa abordagem serve para mostrar que o efeito de origem térmica é dominante sobre outros efeitos, quando presente.

Efeitos refrativos não-lineares são responsáveis pelo fenômeno denominado auto-focalização da luz na amostra, onde o material da mesma pode produzir um efeito de lente convergente (se $\Delta n>0$ ) ou de lente divergente (se $\Delta n<$ $0)$, conforme ilustrado na figura 7.

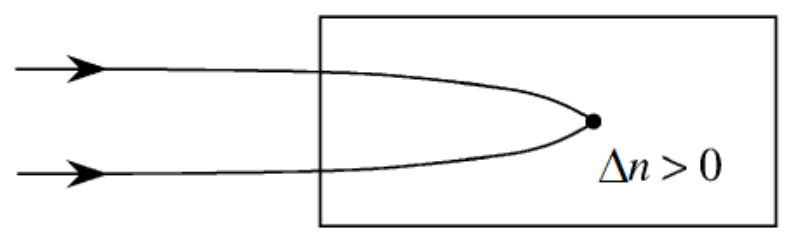

Figura 7 - llustração do efeito de auto-focalização devido ao índice de refração não-linear. Nesse exemplo, $\Delta \boldsymbol{n}>0$, produzindo um efeito de lente convergente (BOYD, 1992).

\subsubsection{Efeito de Lente Térmica}

Quando ocorre a absorção da luz por um material, conforme já citado na seção 2.4, do ponto de vista corpuscular, um fóton com energia $E_{f}=h c / \lambda$ é absorvido por um elétron do material (onde $h=4,136 \times 10^{-15} \mathrm{eVs}$ é a constante de Planck, $c=$ $3 \times 10^{8} \mathrm{~m} / \mathrm{s}$ é a velocidade da luz no vácuo e $\lambda$ é o comprimento de onda da luz). A energia $E_{\mathrm{f}}$, nesse momento, foi absorvida pelo material. Depois de um tempo, 0 elétron do material poderá voltar ao seu nível de energia inicial, e a energia $E_{f}$ poderá ser emitida novamente em forma de fóton (no caso do decaimento radiativo) ou pode ser transformada em energia de vibração dos átomos do material, quando $E_{f}$ é transferido a um fônon (no caso do decaimento não-radiativo).

Quando o elétron que absorveu a energia do fóton sofre um decaimento não-radiativo, a temperatura do material aumenta. Esse aumento de temperatura 
altera o índice de refração do material, produzindo, então, a chamada lente térmica (MESSIAS; ZANATTA; CATUNDA, 2004).

No caso de sólidos, a mudança no índice de refração devida ao aquecimento da amostra pela absorção da luz é acompanhada, simultaneamente, pela mudança em sua espessura, devida aos efeitos de dilatação térmica e de estresse térmico. Esses três efeitos, em conjunto, provocam a mudança no caminho óptico $S=n L$, onde $L$ é a espessura da amostra. Nesse caso, a equação 2.5 deve ser alterada para contemplar a mudança na espessura, conforme indica a equação 2.6:

$$
\Delta s(I)=\frac{d s}{d T} \Delta T(I)
$$

onde $s$ corresponde ao caminho óptico normalizado pela espessura da amostra e $\mathrm{d} s / \mathrm{d} T$ corresponde ao coeficiente de temperatura do caminho óptico. Para líquidos, o efeito é devido apenas à mudança no índice de refração com a temperatura $(\mathrm{d} s / \mathrm{d} T=$ $\mathrm{d} n / \mathrm{d} T$ e $\Delta s=\Delta n$ ) e a equação 2.5 pode ser utilizada (JACINTO et al., 2006).

\subsubsection{Técnica de Varredura-Z}

A técnica de varredura-Z é um experimento que permite a medição de efeitos não-lineares na transmitância da luz através de um material, utilizando uma fonte de luz laser com um perfil gaussiano (SHEIK-BAHAE et al., 1990; SHEIKBAHAE; SAID; STRYLAND, 1989).

A técnica consiste em medir a transmitância da luz através da amostra, enquanto a intensidade da luz é aumentada até valores onde ocorrem efeitos ópticos não-lineares no material. Ao passar por uma lente convergente, o raio do feixe do laser $(w)$ diminui ao longo do eixo de propagação do feixe (eixo z), até um valor mínimo $\left(w_{0}\right)$ no ponto focal (onde $z=0$ ), e depois volta a aumentar. O raio mínimo do feixe $w_{0}$ é também chamado de "cintura do feixe". A intensidade da luz, que varia 
com o inverso do quadrado de $w$, também varia ao longo do eixo $z$, atingindo o valor máximo em $z=0$, quando $w=w_{0}$, já que a potência do laser é mantida constante nesse experimento. A amostra é deslocada ao longo do eixo z (daí o nome de varredura-Z) na região próxima a $z=0$, onde os efeitos não-lineares ocorrem, e a transmitância da luz é medida em função de $z$.

O arranjo de varredura- $Z$ utilizado neste trabalho será apresentado em detalhes na seção 3.5. Todavia, a figura 8 esquematiza um arranjo genérico de varredura-Z, para apresentar uma introdução à técnica.

A fonte de luz laser, juntamente com o sistema aqui denominado de "geração / seleção dos pulsos", determinam quais fenômenos ópticos não-lineares podem ocorrer, conforme mostrado no quadro 2.1. Pode-se variar tanto a largura do pulso do laser (em alguns casos, a largura do pulso é uma característica do laser e para mudá-la, deve-se utilizar outro laser) quanto a taxa de repetição dos pulsos (ou freqüência dos pulsos), e desse modo, atingir os diferentes intervalos de tempo típicos de cada mecanismo óptico não-linear.

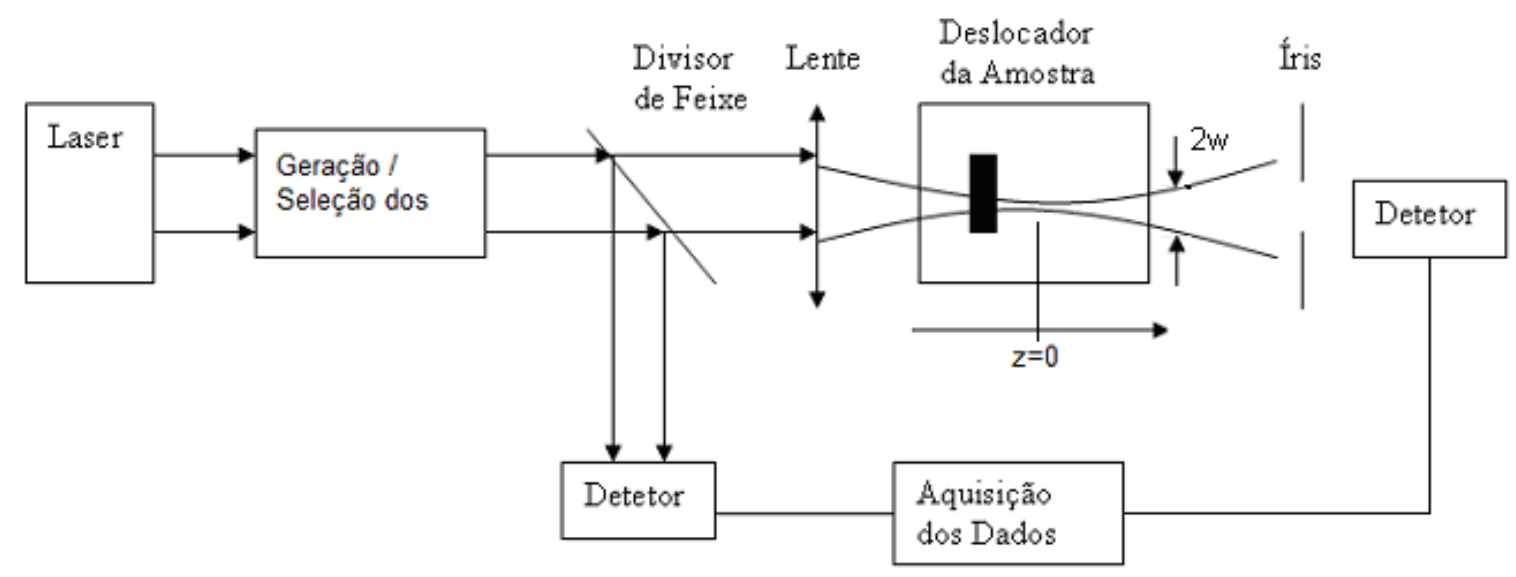

Figura 8 - Representação de um arranjo de varredura-Z.

Se o laser for de onda pulsada, utiliza-se um modulador eletro-óptico para diminuir a taxa de repetição dos pulsos. Se o laser for de onda contínua, o mesmo deverá atravessar um obturador mecânico (chopper) para a geração dos pulsos. Desse modo, o modulador eletro-óptico ou o chopper consistem no sistema de geração/seleção de pulsos. 
O divisor de feixe direciona parte do mesmo a um fotodetector de referência, para monitorar a estabilidade do laser. A outra parte do feixe incide numa lente convergente para sua focalização. Um deslocador faz a amostra se mover ao longo do eixo $z$ enquanto a luz a atravessa, e a luz transmitida incide sobre um segundo fotodetector, para a medição da transmitância. Com o sistema de aquisição de dados, obtêm-se a curva de transmitância normalizada em função de z.

A íris permite a escolha do tipo de não-linearidade a ser medida: a íris com uma abertura mínima torna o arranjo sensível aos efeitos não-lineares refrativos, pois permite a medição das distorções do perfil de intensidade dos raios paraxiais do feixe. Essa configuração é também chamada de íris fechada. Já a íris totalmente aberta (configuração íris aberta) permite ao detector medir a variação da potência da luz transmitida através da amostra, ou seja, torna o arranjo sensível aos efeitos não-lineares de absorção.

\subsubsection{Modelo de Lente Térmica}

A medição do efeito de lente térmica pela técnica de varredura-Z é realizada através da configuração de íris fechada, com a quantificação do efeito de auto-focalização da luz pela amostra.

A transmitância normalizada é calculada, em cada ponto $z$, e instante t, através da equação 2.7 (CUPPO et al., 2002):

$$
T_{N}(z, t)=\frac{I(z, t)}{I(z, 0)}
$$

A figura 9 mostra o princípio de funcionamento da técnica de varredura-Z, para um caso em que $\Delta \boldsymbol{n}>\mathbf{0}$. A transmitância normalizada é dada pela intensidade no final do pulso, $l(z, t)=A$, dividida pela intensidade no começo do pulso, $l(z, 0)=B$. Em a), como a intensidade de luz não é suficiente para aquecer a amostra, a lente térmica não se forma e $B=A$, ou seja, $T_{\mathrm{N}}=1$. Em b), c) e d), as linhas tracejadas 
a)

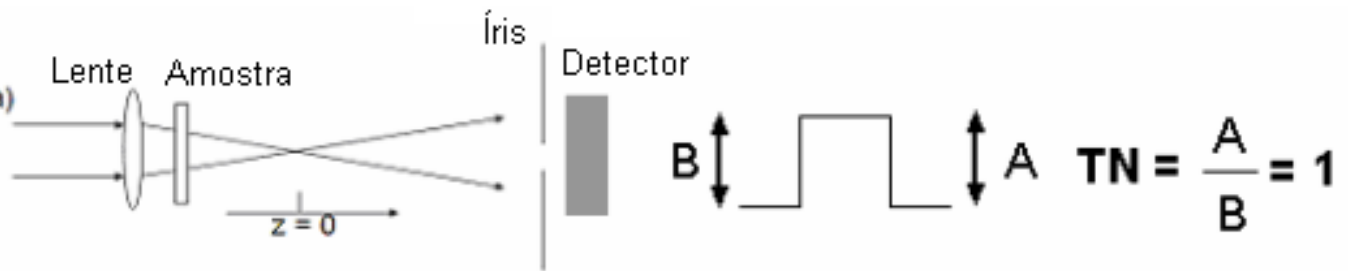

b)

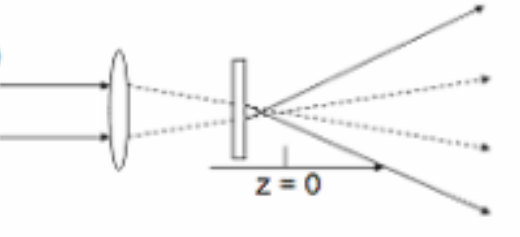

c)

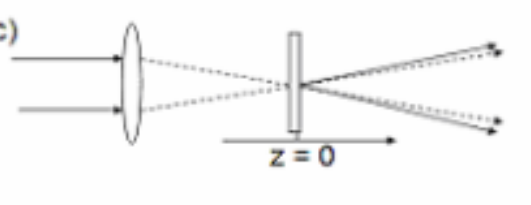

d)

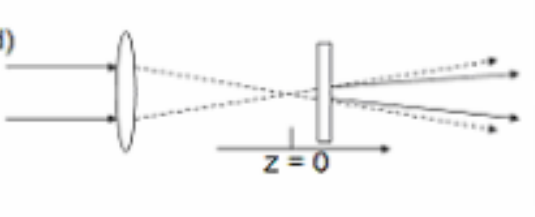

e)

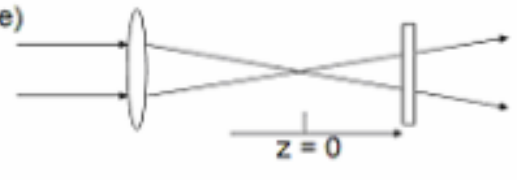

f)

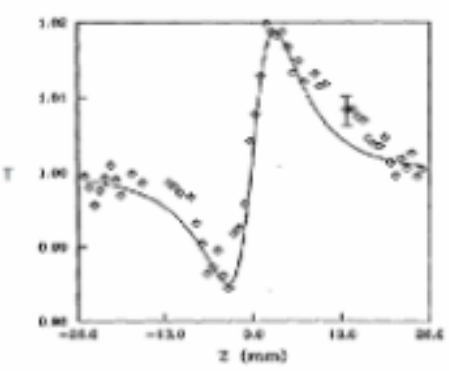

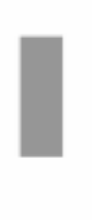
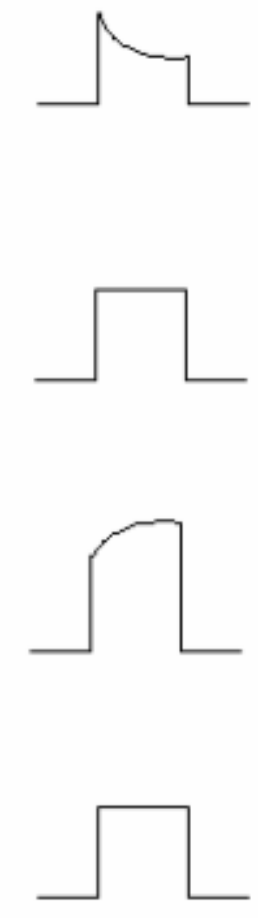

$\mathrm{TN}<1$

$\mathrm{TN}=1$

$\mathrm{TN}>1$

$\mathrm{TN}=1$

Figura 9 - Efeito de lente térmica convergente ao longo da varredura-Z $(\Delta n>0)$.

mostram o percurso que o feixe seguiria se não houvesse efeitos não-lineares, enquanto as linhas contínuas mostram o percurso do feixe desviado pela lente térmica formada na amostra. Em b), o efeito de lente convergente faz com que 0 feixe seja focalizado antes do ponto $z=0$, deixando, portanto, uma intensidade de luz menor passar pela abertura da íris. Em c), a transmitância volta a ser igual a um, 
por causa da posição da amostra sobre o foco. Em d), o efeito de lente convergente faz com que haja convergência do feixe na direção da íris, deixando, portanto, uma intensidade de luz maior passar. Em e), os efeitos não-lineares deixam de ocorrer, e $T_{\mathrm{N}}$ volta a ser igual a 1. Em f), ilustra-se o efeito da movimentação da amostra ao longo de $z$ no sentido positivo: ocorre um comportamento vale-pico com a curva da transmitância normalizada em função de $z$.

A figura 10 mostra o princípio de funcionamento da técnica de varredura$Z$, para um caso em que $\Delta \boldsymbol{n}<\mathbf{0}$. A transmitância normalizada também é dada pela equação 2.7. Em a), como a intensidade de luz não é suficiente para aquecer a amostra, a lente térmica não se forma e $B=A$, ou seja, $T_{N}=1$. Em b), c) e d), as linhas tracejadas mostram o percurso do feixe sem os efeitos não-lineares, enquanto as linhas contínuas mostram o percurso do feixe desviado pela lente térmica formada na amostra. Em b), o efeito de lente divergente faz com que o feixe seja focalizado após o ponto $z=0$, deixando, portanto, uma intensidade de luz maior passar pela abertura da íris. Em c), a transmitância volta a ser igual a um, por causa da posição da amostra sobre o foco. Em d), o efeito de lente divergente faz com que haja divergência do feixe na direção da íris, deixando, portanto, uma intensidade de luz menor passar. Em e), os efeitos não-lineares deixam de ocorrer, e $T_{N}$ volta a ser igual a 1. Em f), ilustra-se o efeito da movimentação da amostra ao longo de $z$ no sentido positivo: ocorre um comportamento pico-vale com a curva da transmitância normalizada em função de $z$.

A curva da transmitância normalizada em função de $z$ e de $t$ é dada pela equação 2.8 (CARTER; HARRIS, 1984; CUPPO et at., 2002):

$$
T_{N}(z, t)=\left\{1+\left[\frac{\theta}{1+\left(1+x^{2}\right) t_{c 0} / 2 t}\right] \frac{2 x}{1+x^{2}}+\left[\frac{\theta}{1+\left(1+x^{2}\right) t_{c 0} / 2 t}\right]^{2} \frac{1}{1+x^{2}}\right\}^{-1}
$$

onde $x=z / z_{0}$, sendo $z_{0} 0$ comprimento de difração do feixe, que será detalhado na seção 3.5.2, $t_{\mathrm{c} 0}$ é o tempo característico de formação da lente térmica e $\theta$ é o desvio de fase do feixe, devido ao efeito de auto-focalização causado pela lente térmica. 


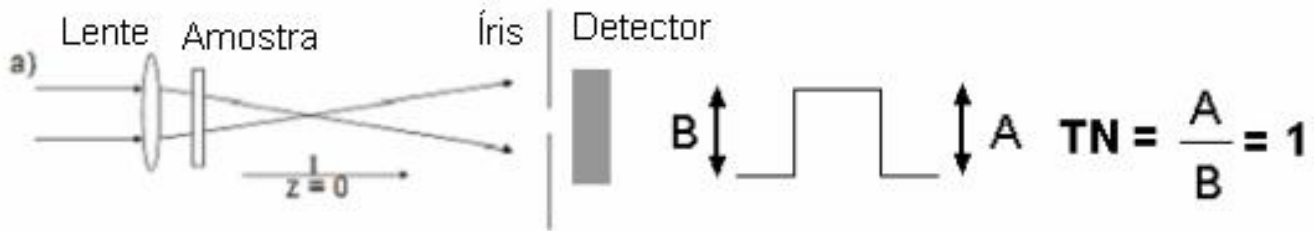

b)

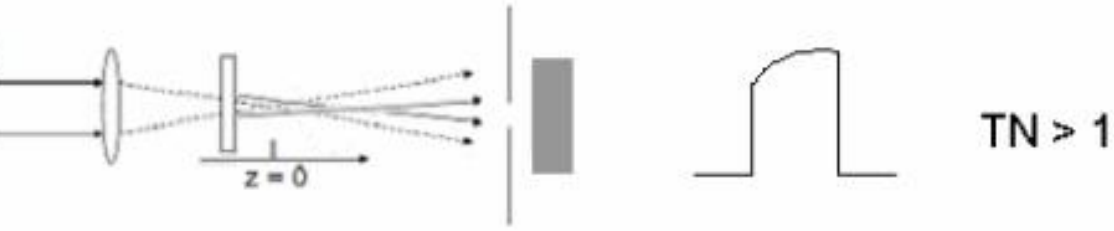

c)

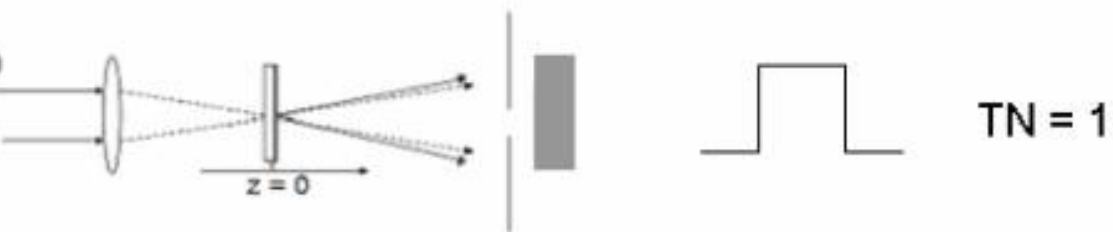

d)
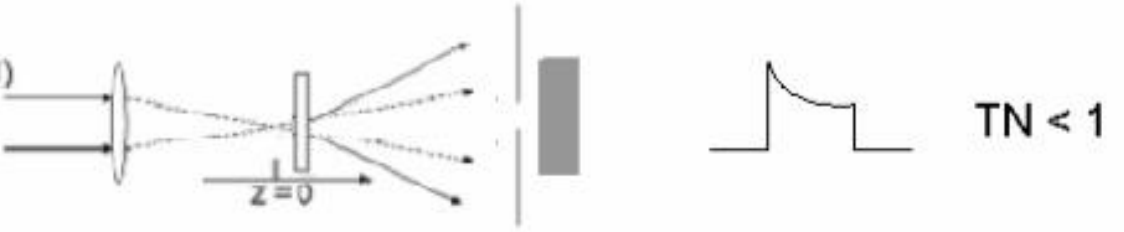

e)

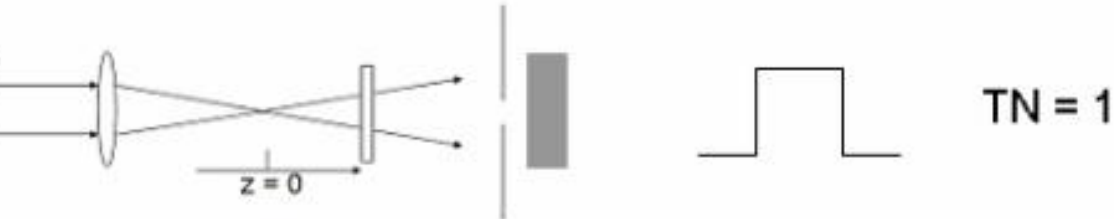

)

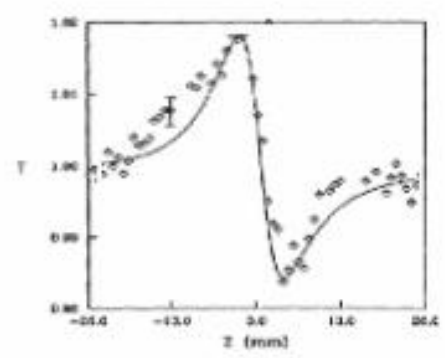

Figura 10 - Efeito de lente térmica divergente ao longo da varredura-Z $(\Delta n<0)$.

O tempo característico na posição focal $\left(t_{c 0}\right)$ está relacionado à difusividade térmica $D$ através da equação 2.9:

$$
D=\frac{w_{0}^{2}}{4 t_{c 0}}
$$


onde $w_{0}$ é o raio do feixe no foco (ou cintura do feixe).

O desvio de fase se relaciona com as propriedades do material através da equação 2.10 (CUPPO et al., 2002; JACINTO et al., 2006; MESSIAS; ZANATTA; CATUNDA, 2004):

$$
\theta=-\frac{\alpha P L_{e f}}{\lambda \mathrm{K}} \varphi \frac{d s}{d T}
$$

onde $\lambda$ é o comprimento de onda da luz, $\alpha$ é o coeficiente de absorção, $P$ é a potência da luz incidente na amostra, $L_{e f}=\left(1-\mathrm{e}^{-\alpha L}\right) / \alpha$ é a espessura efetiva da amostra, $K$ é a condutividade térmica, ds/dT é o coeficiente de temperatura do caminho óptico e $\varphi$ é a eficiência quântica, que vale aproximadamente 1 para o Sia:H, conforme Messias, Zanata e Catunda (MESSIAS; ZANATTA; CATUNDA, 2004).

A espessura efetiva pode ser entendida pelo seguinte raciocínio: sua multiplicação pelo coeficiente de absorção resulta na fração da intensidade de luz absorvida pela amostra, ou seja, $\alpha L_{e f}=1-\mathrm{e}^{-\alpha L}=1-T=I_{a b s} / I_{0}$. Como $\alpha$ depende do comprimento de onda, a espessura efetiva da amostra também varia $\operatorname{com} \lambda$.

A condutividade térmica está relacionada com a difusividade térmica através da equação 2.11 :

$$
\mathrm{K}=D \rho c_{p}
$$

onde $c_{p}$ é o calor específico à pressão constante do material e $\rho$ é sua densidade volumétrica de massa. 


\subsection{DEPOSIÇÕES DOS FILMES FINOS}

Os substratos sobre os quais os filmes finos foram depositados são lâminas de vidro para microscópio de $1 \mathrm{~mm}$ de espessura por $15 \mathrm{~mm}$ de largura e 26 mm de comprimento, de fabricação da Perfecta, código 200, do tipo lisa e lapidada. A figura 11 apresenta o espectro de transmissão de uma amostra desse vidro, medido por espectrofotometria (técnica que será apresentada na seção 3.3). O vidro é transparente para o espectro visível e infravermelho (até $\lambda \sim 1000 \mathrm{~nm}$ ), mas é absorvente para a radiação ultravioleta com $\lambda<350 \mathrm{~nm}$.

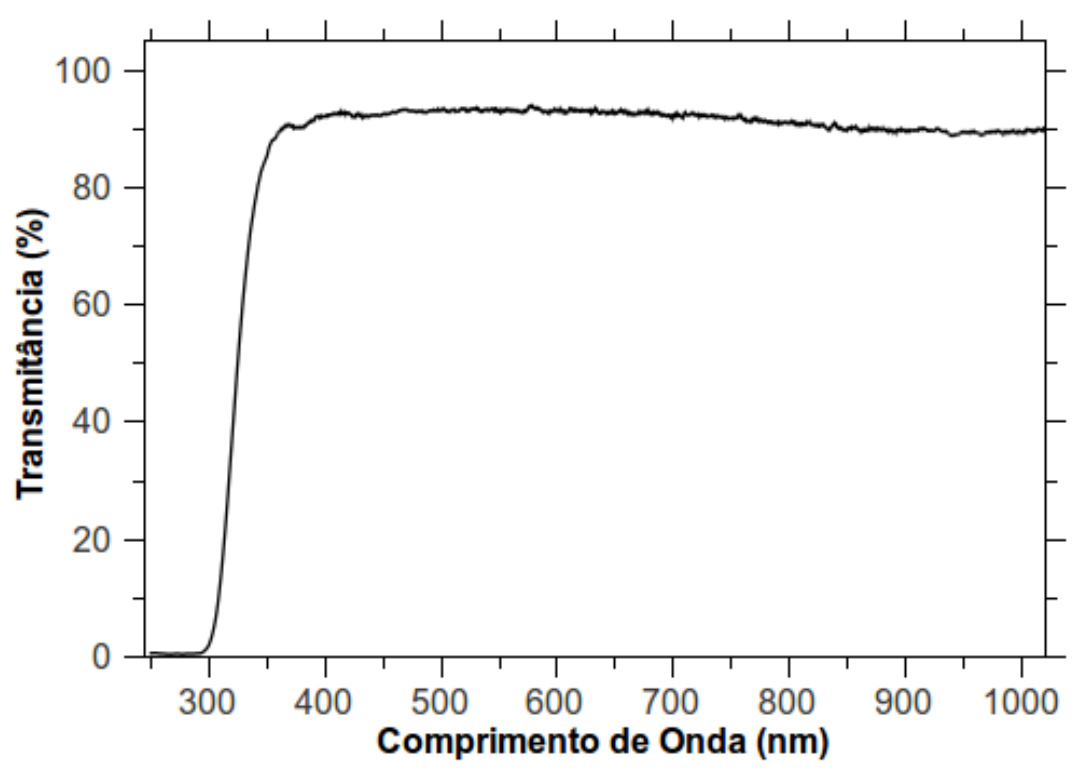

Figura 11 - Espectro de transmissão da lâmina de vidro utilizada como substrato. $O$ vidro é transparente na região do espectro entre 350 e $1000 \mathrm{~nm}$.

Para a deposição dos filmes finos de silício amorfo hidrogenado, foi utilizado o reator PECVD do Laboratório de Microeletrônica (LME) da Escola Politécnica da Universidade de São Paulo. 
O princípio de funcionamento do reator foi dividido, neste trabalho, em cinco etapas básicas, para que pudesse ser melhor explicado:

a) Preparativos pré-deposição;

b) Controle da temperatura do substrato;

c) Injeção dos gases precursores na câmara de deposição;

d) Ejeção dos gases da câmara de deposição;

e) Formação do plasma e deposição dos filmes.

A figura 12 apresenta imagens do reator, enquanto a figura 13 apresenta um diagrama esquemático para o mesmo (RIBEIRO, 2009). Cada sistema em particular foi identificado com a mesma letra na figura 12 e na figura 13, para que os sistemas representados no diagrama possam ser localizados nas imagens. Além disso, os fabricantes dos sistemas e seus respectivos modelos estão listados no quadro 3.1 .

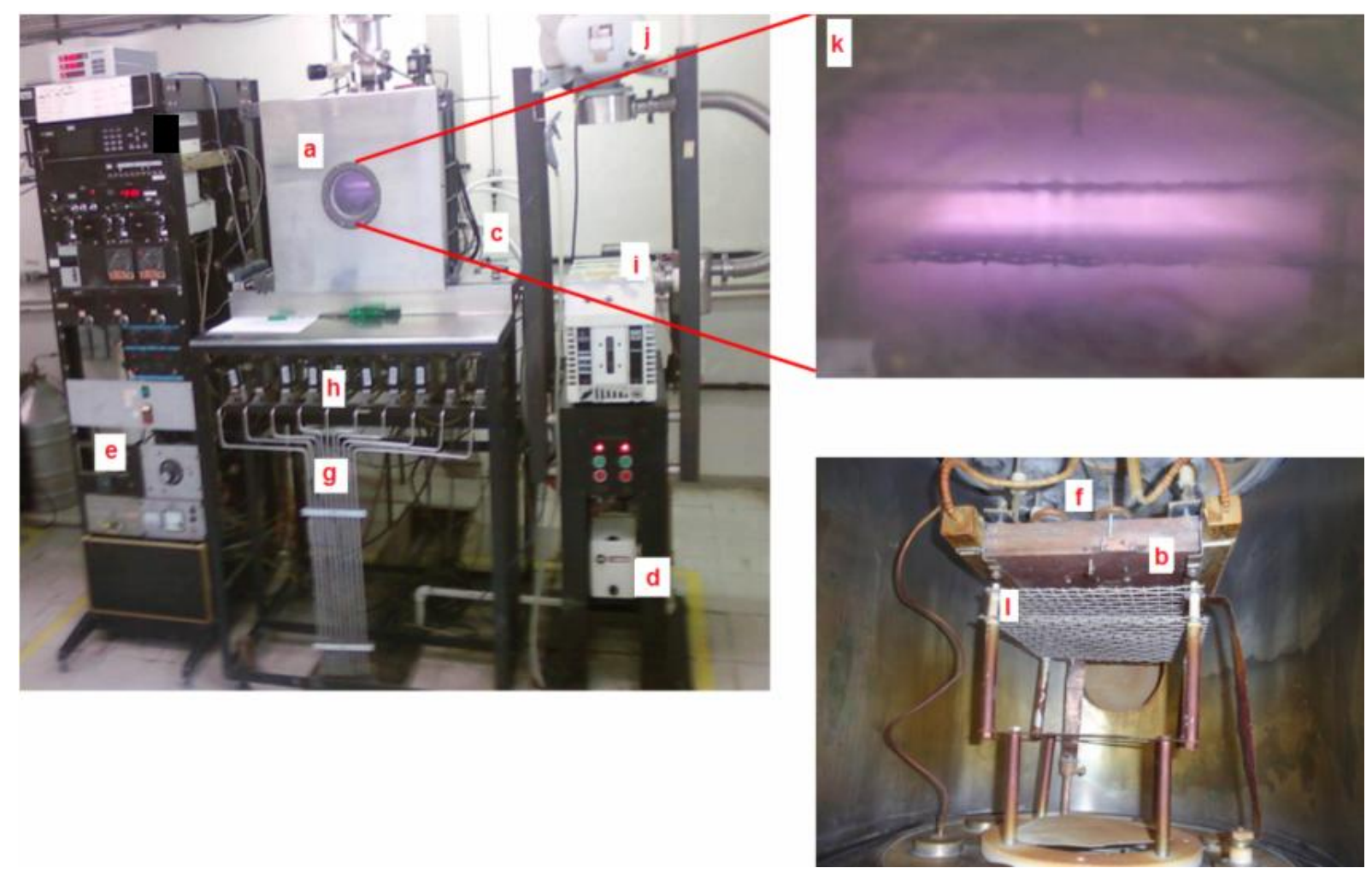

Figura 12 - Imagens do reator PECVD do LME utilizado para a deposição dos filmes finos. Está destacada, na parte direita superior, a janela da câmara de deposição com o plasma e na parte direita inferior, o interior da câmara. 


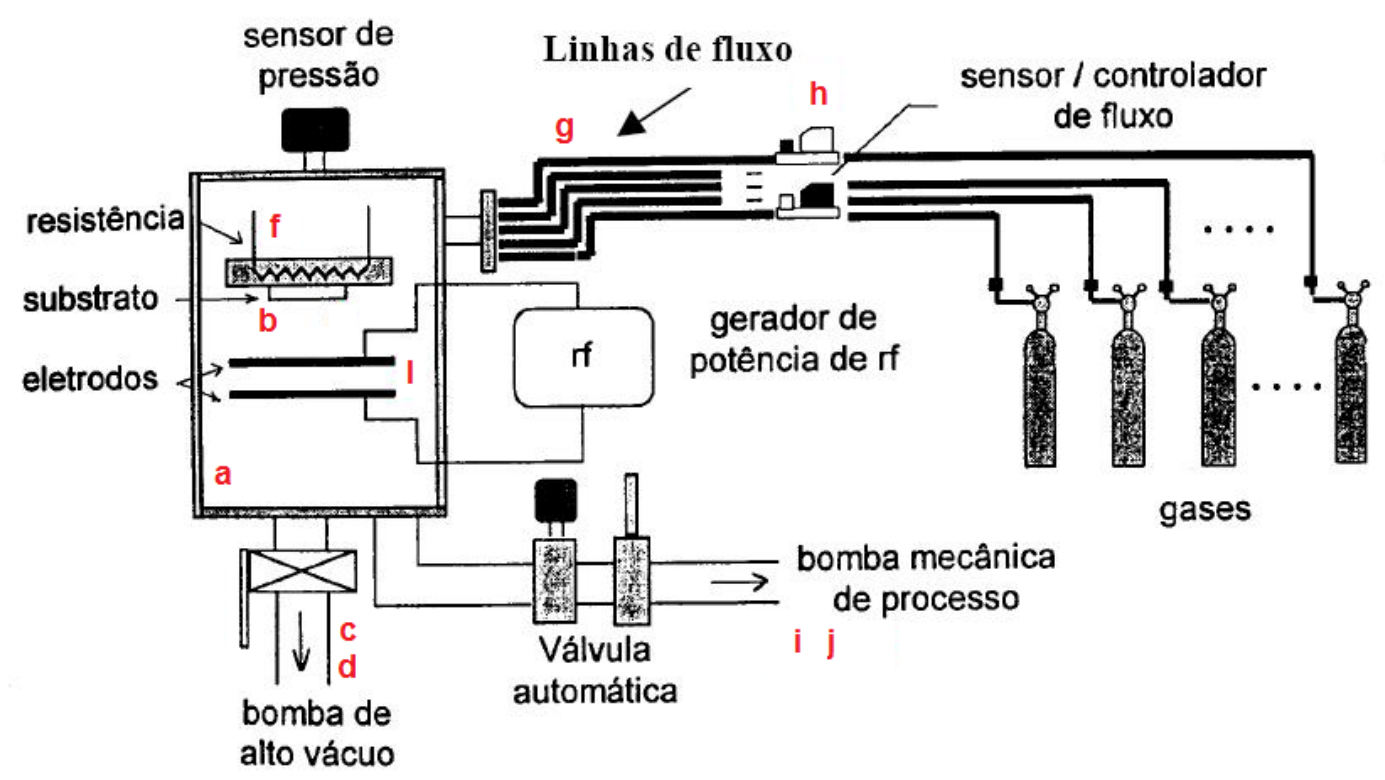

Figura 13 - Diagrama esquemático do reator PECVD utilizado para a deposição dos filmes finos. As letras em vermelho identificam os sistemas indicados pelas mesmas letras na figura 12 (RIBEIRO, 2009).

Quadro 3.1 - Principais sistemas que compõem o reator PECVD do LME.

\begin{tabular}{|c|c|c|c|}
\hline Equipamento / Sistema & Modelo & Fabricante & Identificação \\
\hline Bomba Termonuclear & V-450 & Varian & $\mathrm{c}$ \\
\hline Bomba Mecânica & SD-300 & Varian & $\mathrm{d}$ \\
\hline Controlador de Temperatura & 91 & Eurotherm & $\mathrm{e}$ \\
\hline Controlador de Fluxo de Gases & Mass Flow Meter 2258 & MKS & $\mathrm{h}$ \\
\hline Bomba Mecânica & TRIVAC D 65 B & Leybold-Heraeus & $\mathrm{i}$ \\
\hline Bomba Mecânica & RUVAC WAU 251 US & Leybold-Heraeus & $\mathrm{j}$ \\
\hline Fonte de RF & RFX-600 & Advanced Energy Corp & - \\
\hline
\end{tabular}

$\mathrm{Na}$ etapa dos preparativos pré-deposição, a câmara de 89 litros de volume (figura 12a) é aberta através de sua porta frontal, e os substratos são fixados na base de cobre de seu interior (figura 12b). Para evitar contaminação de partículas sob efeito gravitacional, a base de cobre é posicionada na parte superior da câmara e a superfície dos substratos fica voltada para baixo. A porta é então fechada e inicia-se a evacuação da câmara até o estabelecimento do regime de alto vácuo (pressão de cerca de $10^{-6}$ torr), por meio da bomba termonuclear em série com a bomba mecânica (figura 12, posicionada atrás da câmara e figura 12d, respectivamente). O regime de alto vácuo é importante para a minimização dos 
gases anteriormente presentes na câmara e, principalmente, vapor de água, evitando, desse modo, contaminações durante o processo de deposição (NARDES, 2002).

O controle de temperatura do substrato é iniciado juntamente com a evacuação da câmara e permanece durante todo o processo. As características estruturais dos filmes e a ocorrência das reações químicas que os formarão dependem do valor da temperatura do substrato (OHRING, 2001). Há, portanto, um controlador de temperatura (figura 12e) acoplado a um termômetro (termopar de cromel-alumel) e uma resistência elétrica de $1500 \mathrm{~W}$ em contato com a base de cobre para aquecimento do substrato (figura 12f).

Após o estabelecimento do regime de alto vácuo e a estabilização da temperatura do substrato no valor desejado, inicia-se a injeção dos gases precursores na câmara de deposição pelas linhas de fluxo (figura $12 \mathrm{~g}$ ). A quantidade correta do fluxo de cada gás é um fator determinante para a composição do filme depositado. Por isso, o sistema que controla os fluxos (figura 12h) é de grande importância para a reprodutibilidade dos resultados (NARDES, 2002). Além disso, o controlador também funciona como um dispositivo de segurança, pois, no caso de falta de alimentação elétrica, o sistema opera em modo "normalmente fechado", impedindo a circulação dos gases.

A pressão interna da câmara foi mantida em 100 mtorr durante todo 0 processo de deposição, através do equilíbrio dos fluxos de entrada e de saída dos gases. O sistema de ejeção dos gases da câmara de deposição tem a função da manutenção desse equilíbrio, e para isso utiliza duas bombas mecânicas ligadas em série (figura $12 \mathrm{i}, \mathrm{j}$ ), denominadas de "bombas de processo". Algo que requer atenção durante o projeto de construção do reator é o sistema de descarte de gases: geralmente, os gases precursores utilizados na microeletrônica são tóxicos, cancerígenos e inflamáveis, e um descarte seguro dos mesmos deve ser feito. Existem diferentes sistemas de descarte, como, por exemplo, a diluição dos gases expurgados da câmara com gás argônio ou gás nitrogênio e a utilização de filtros próprios para essa finalidade.

Com a formação do plasma se inicia a deposição dos filmes. As quebras, causadas pelo plasma, das moléculas dos gases geram espécies reativas que possibilitam a ocorrência de reações químicas, formadoras dos filmes, a 
temperaturas menores do que em outros processos (RIBEIRO, 2009). A figura 12k traz uma imagem do plasma visível através da janela da câmera, que é obtido por meio de uma fonte alternada de $\operatorname{RF}(13,56 \mathrm{MHz})$ de $25 \mathrm{~W}$ de potência (não aparente na figura 12) ligada aos eletrodos do tipo grade (figura 12l). Foi utilizada a configuração triodo para os eletrodos, para que os gases fossem decompostos numa região afastada do substrato, evitando, desse modo, o bombardeamento de íons e elétrons sobre o filme.

Os gases precursores utilizados para a obtenção do Si-a:H foram o hidrogênio $\left(\mathrm{H}_{2}\right)$, a silana $\left(\mathrm{SiH}_{4}\right)$ e a fosfina $\left(\mathrm{PH}_{3}\right)$, que sofrem reações químicas para a formação do filme fino. A dopagem do silício é realizada com átomos de fósforo provenientes da fosfina, ao mesmo tempo em que ele é depositado. O quadro 3.2 traz informações sobre a composição dos gases utilizados e seus fabricantes. Notase que a fosfina é diluída em $\mathbf{H}_{2}$. Neste trabalho, chama-se simplesmente de "fosfina" a fosfina diluída em hidrogênio na concentração especificada no quadro 3.2.

Quadro 3.2 - Características dos gases utilizados nas deposições.

\begin{tabular}{|c|c|c|c|c|}
\hline Gás & Fórmula & Composição & Fabricante & Pureza \\
\hline Hidrogênio & $\mathrm{H}_{2}$ & $100 \%$ & White Martins & $99,995 \%$ \\
\hline Silana & $\mathrm{SiH}_{4}$ & $100 \%$ & Scott & $99,999 \%$ \\
\hline Fosfina & $\mathrm{PH}_{3}$ & $4,94 \%$ em H & Linde Gas & $99,98 \%$ \\
\hline
\end{tabular}

Foram realizados nove processos PECVD, alterando-se um dos seguintes parâmetros em cada processo: a temperatura de deposição ou o fluxo de volume da fosfina (ou seja, a vazão da fosfina). A tabela 3.1 apresenta os valores do fluxo de fosfina em sccm (standard cubic centimeter per minute - centímetro cúbico padrão por minuto) e da temperatura, para cada deposição. Cada processo foi identificado com um código composto de uma letra e um número. A letra traz informações sobre a sequência em que as deposição foram feitas: primeiro a série $A$, depois a série $B$ e assim por diante. Os números trazem informações sobre algum parâmetro utilizado naquela deposição, de modo a facilitar sua identificação. Em cada processo de deposição, foram produzidas três amostras, que foram identificadas de acordo com o código do processo. Por exemplo, com o processo A-2.5 foram feitas as amostras 
A1-2.5, A2-2.5 e A3-2.5, e essa mesma metodologia de identificação foi adotada para os demais processos.

Tabela 3.1 - Parâmetros utilizados em cada deposição.

\begin{tabular}{ccc}
\hline Código do Processo & Temperatura de Deposição $\left({ }^{\circ} \mathbf{C}\right)$ & Fluxo de Fosfina (sccm) \\
\hline A-2.5 & 50 & 2,5 \\
A-10 & 50 & 10 \\
A-20 & 50 & 20 \\
A-40 & 50 & 40 \\
B-70 & 70 & 10 \\
B-90 & 90 & 10 \\
D-150 & 150 & 10 \\
D-200 & 200 & 10 \\
C-200 & 200 & 0 \\
\hline
\end{tabular}

A tabela 3.2 apresenta os demais parâmetros utilizados, que foram iguais para todas as deposições.

Tabela 3.2 - Parâmetros fixos utilizados em todas as deposições.

\begin{tabular}{ccc}
\hline Parâmetro & Valor & Unidade \\
\hline Fluxo de $\mathrm{H}_{2}$ & 250 & sccm \\
Fluxo de $\mathrm{SiH}_{4}$ & 10 & $\mathrm{sccm}$ \\
Duração da Deposição & 120 & minutos \\
Pressão da Câmara & 100 & mtorr \\
Potência do RF & 25 & W \\
\hline
\end{tabular}

\subsection{MEDIÇÕES DAS ESPESSURAS DOS FILMES}

As espessuras dos filmes finos depositados foram medidas com a utilização do perfilômetro AlphaStep 500, fabricado pela Tencor Instruments, que se encontra no Laboratório de Microeletrônica da Escola Politécnica da Universidade de São Paulo.

Para a realização da medição, as amostras necessitam de degraus mecânicos: a ponteira do perfilômetro se move na horizontal sobre a superfície do 
substrato de vidro (figura 14a), e quando encontra o degrau do filme a mesma se move na vertical e "sobe o degrau", passando então a se mover na horizontal sobre a superfície do filme (figura 14b). A ponteira de diamante é fixada a um núcleo de ferro, acoplado a um transformador diferencial variável linear (Linear Variable Differential Transformer - LVDT), ilustrado como um cilindro na figura 14. Quando a ponteira se move na direção vertical, o LVDT produz um sinal elétrico proporcional ao deslocamento do núcleo de ferro e, desse modo, a altura do degrau é medida e corresponde à espessura do filme (BATES, 1990).
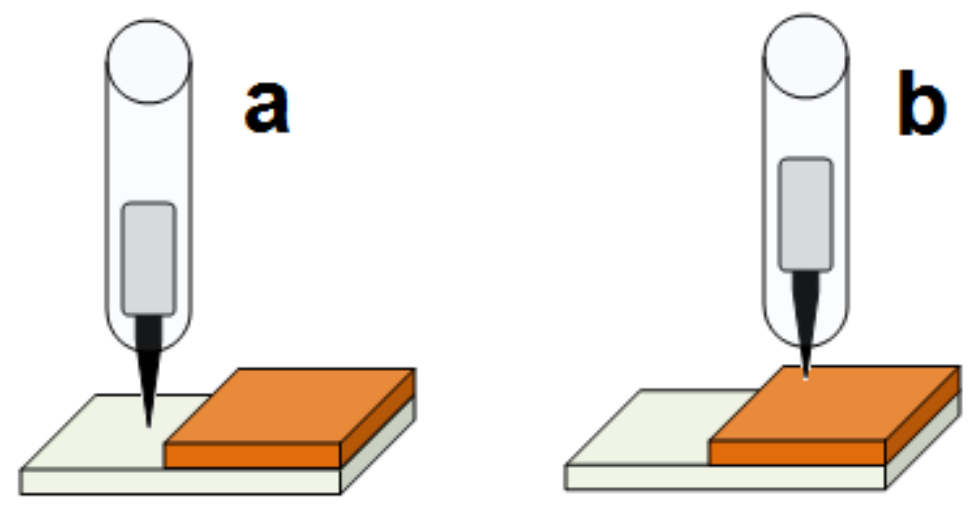

Figura 14 - Técnica de perfilometria. Em a), a ponteira do perfilômetro se move sobre o substrato de vidro. Em b), a ponteira se move sobre o filme fino. As dimensões estão fora de escala.

Os valores de deslocamento horizontal da ponteira utilizados neste trabalho variaram entre 3 e $5 \mathrm{~mm}$.

\section{3}

\section{MEDIÇÕES DOS ESPECTROS DE TRANSMISSÃO}

Para medir os espectros de transmissão das amostras foi utilizado o arranjo de espectrofotometria do Grupo de Fluídos Complexos (GFCx) do Instituto de Física da Universidade de São Paulo. A figura 15 mostra uma imagem do arranjo, formado pela fonte de radiação eletromagnética UV-VIS-NIR (ultravioleta-visívelinfravermelho próximo - figura 15a) modelo DH-2000-BAL, fabricada pela Mikropack, pelo porta-amostras (figura 15b) e por dois espectrômetros modelo USB4000, 
fabricados pela Ocean Optics (figura 15c). O sistema é interligado através de fibras ópticas, que transportam a radiação da fonte ao porta-amostras e do porta-amostras aos espectrômetros. Os dados são coletados dos espectrômetros e tratados pelo software "SpectraSuite" versão 1.4.2_09, da Ocean Optics.

A fonte é formada por uma lâmpada de deutério, que emite radiação com comprimentos de onda de cerca de $200 \mathrm{~nm}$ a cerca de $800 \mathrm{~nm}$ e por uma lâmpada de halogênio, que emite radiação com comprimentos de onda cerca de $500 \mathrm{~nm}$ a cerca de $1100 \mathrm{~nm}$. A intensidade da luz que foi transmitida através da amostra é medida pelos espectrômetros, onde a radiação é dispersa em um espectro e a intensidade de cada componente é transformada em sinal elétrico, medido via porta USB por um microcomputador (figura 15d). O software "SpectraSuite" utiliza a seguinte relação para determinar a transmitância $(\% T)$ da radiação de um determinado comprimento de onda $(\lambda)$ através da amostra:

$$
\% T(\lambda)=\frac{I_{A}(\lambda)-I_{Z}(\lambda)}{I_{R}(\lambda)-I_{Z}(\lambda)} \times 100 \%
$$

onde $I_{A}$ é a intensidade de radiação transmitida através da amostra, lz é a intensidade de fundo (correspondente ao zero de transmitância) e $I_{R}$ é a intensidade de radiação transmitida através do material de referência (correspondente ao 100\% de transmitância).

O valor de $I_{z}$ foi medido e armazenado pelo software quando não havia radiação chegando ao porta-amostras, enquanto o valor de $I_{R}$ foi medido $e$ armazenado pelo software quando a amostra constituía-se apenas da lâmina de vidro. A referência correspondente a $100 \%$ de transmitância foi, portanto, o vidro que serviu de substrato para os filmes de Si-a:H.

\subsection{COEFICIENTES DE ABSORÇÃO E GAPS ÓPTICOS}


Os coeficientes de absorção das amostras de Si-a:H foram determinados a partir de seus espectros de transmissão, medidos pela espectrofotometria, e de suas espessuras, medidas pela perfilometria.

Através das equações 2.1 e 3.1, chega-se à seguinte equação para o coeficiente de absorção $(\alpha)$ :

$$
\alpha(\lambda)=\frac{1}{L} \ln \left[\frac{100}{\% T(\lambda)}\right]
$$

onde \%T é a transmitância (em \%), L é a espessura da amostra.

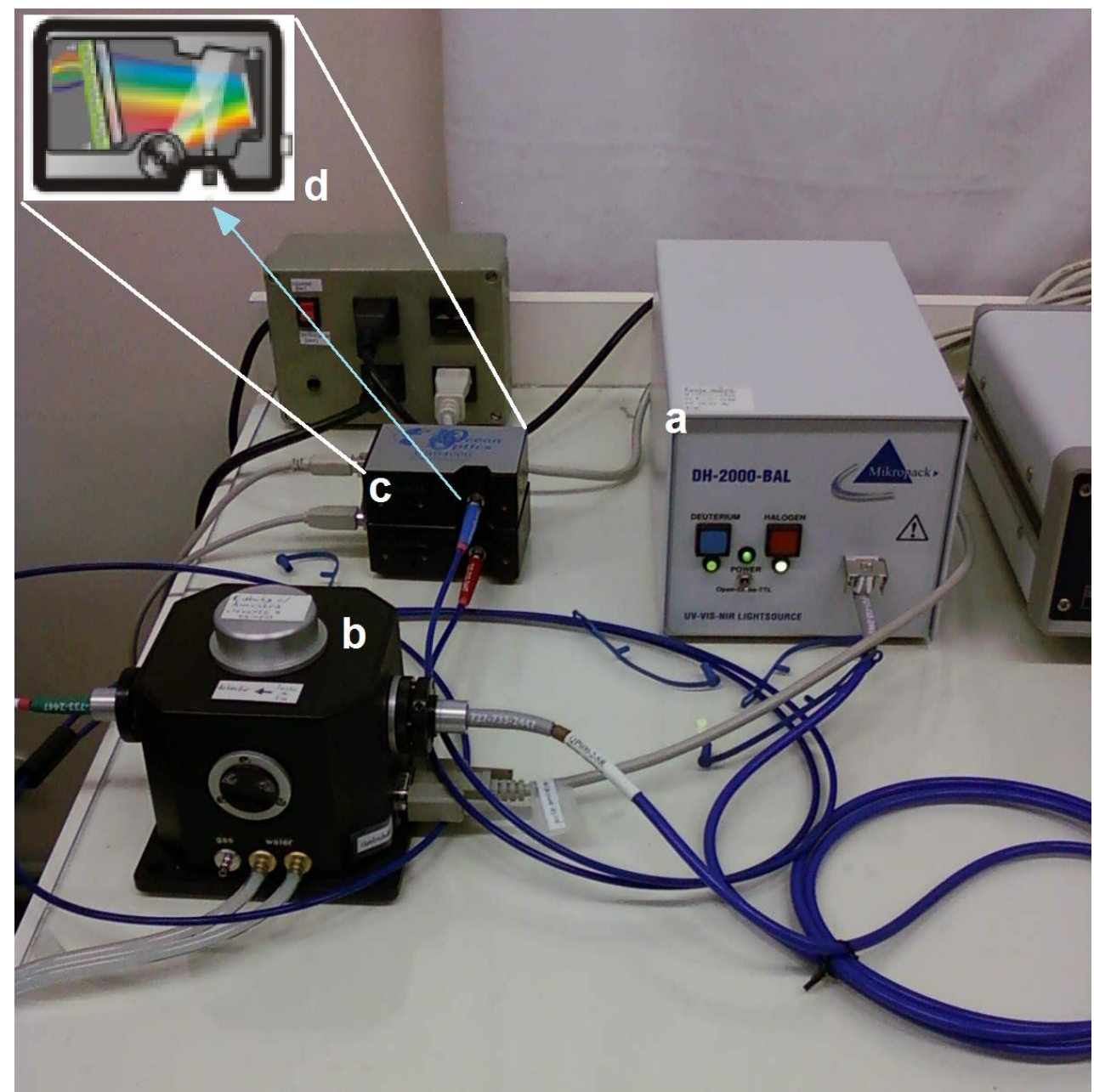

Figura 15 - Imagens do arranjo de espectrofotometria do GFCx. 0 sistema é composto pela fonte de radiação eletromagnética (a), pelo porta-amostras (b) e pelos espectrômetros (c). $O$ funcionamento interno do espectrômetro está ilustrado em (d). 
O gap óptico $\left(E_{g}\right)$ é obtido pelo método de Tauc, através da equação 2.3, para cada comprimento de onda. Ao extrapolar o trecho linear com o eixo das energias obtêm-se o valor do gap óptico $E_{\mathrm{g}}$.

\subsection{TÉCNICA DE VARREDURA-Z}

O arranjo da varredura-Z foi montado no Laboratório de Óptica do Grupo de Fluídos Complexos do Instituto de Física da Universidade de São Paulo, conforme esquematizado na figura 16.

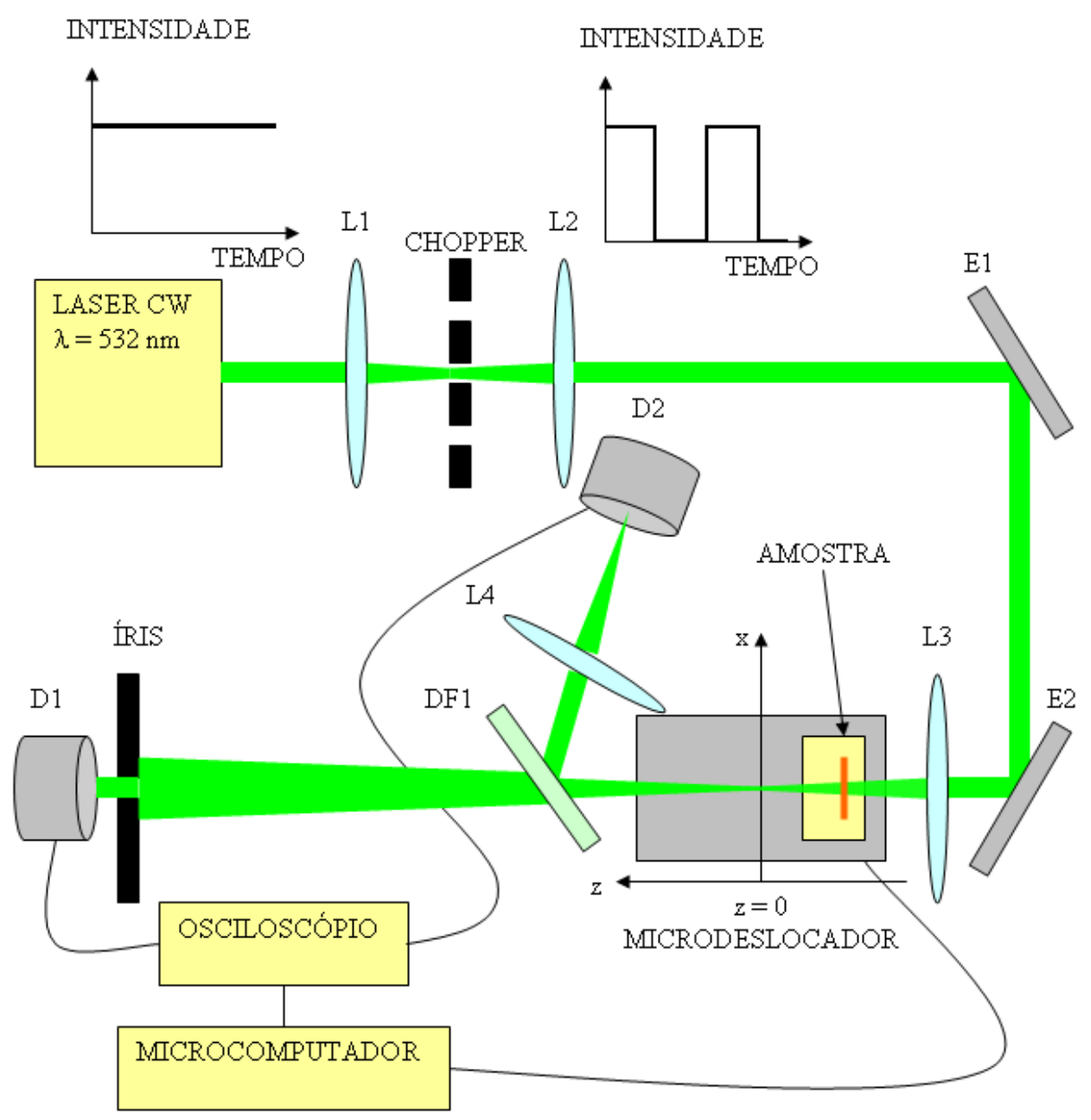

Figura 16 - Diagrama ilustrativo do arranjo de varredura-Z utilizado para as medições das não-linearidades ópticas. 
A figura 17 traz imagens do arranjo, com os elementos identificados com os mesmos códigos da figura 16, para facilitar a localização dos mesmos.

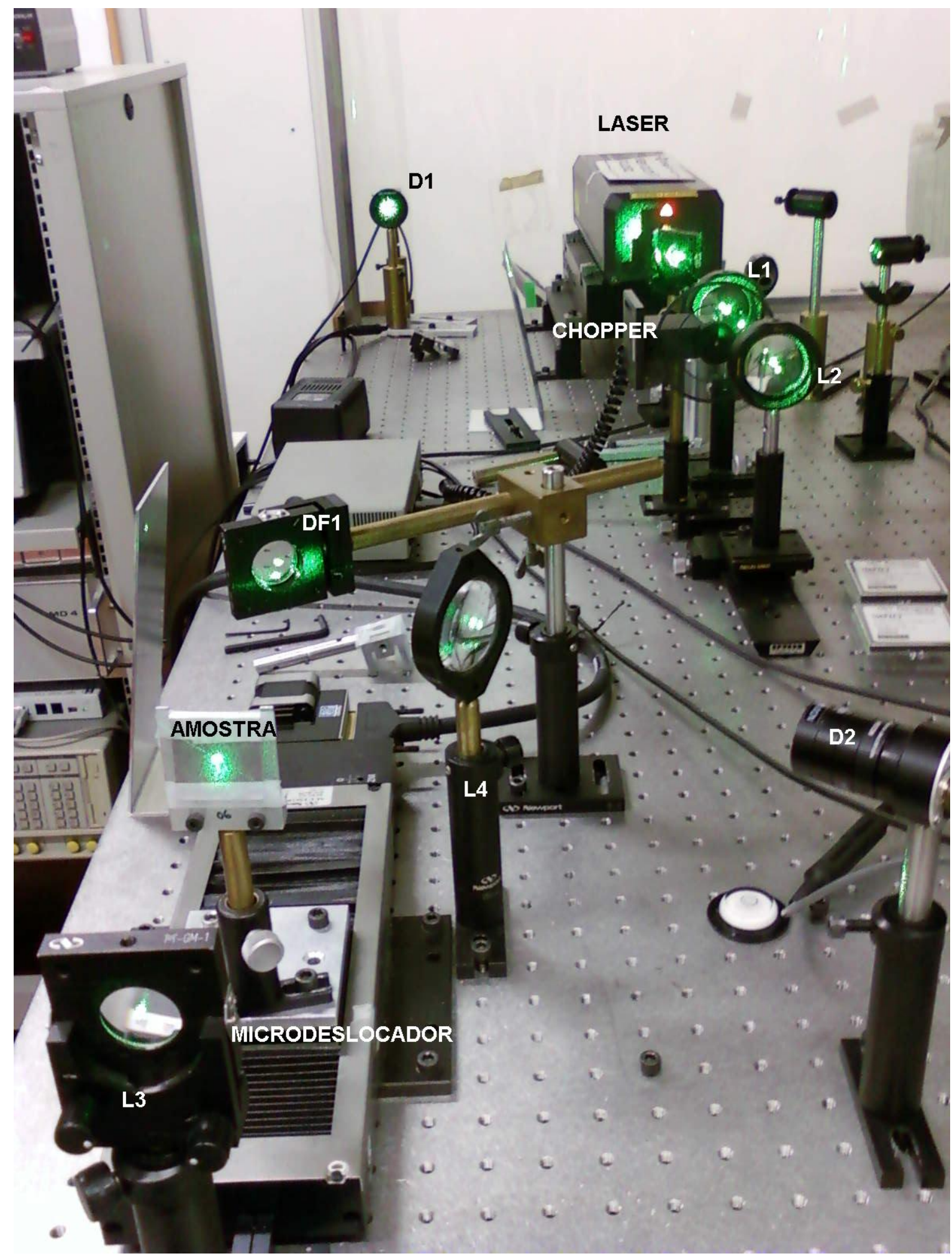

Figura 17 - Imagem do arranjo de varredura-Z do GFCx utilizado para as medições das não-linearidades ópticas. 
O quadro 3.3 traz as informações sobre os fabricantes dos equipamentos utilizados nesse arranjo, com seus respectivos modelos.

Quadro 3.3 - Componentes do arranjo de varredura-Z do GFCx.

\begin{tabular}{|c|c|c|c|}
\hline $\begin{array}{c}\text { Equipamento / } \\
\text { Elemento Óptico }\end{array}$ & Fabricante & Modelo & Características \\
\hline Laser & Coherent & Verdi V10 & $\lambda=532 \mathrm{~nm} ; \mathrm{CW}$; Perfil Gaussiano; Modo TEM 00 \\
\hline L1 & Newport & Lente Convergente & $\mathrm{f}=100 \mathrm{~mm} ; \mathrm{d}=50,8 \mathrm{~mm}$ \\
\hline L2 & Newport & Lente Convergente & $\mathrm{f}=80 \mathrm{~mm} ; \mathrm{d}=50,8 \mathrm{~mm}$ \\
\hline L3 & Newport & Lente Convergente & $\mathrm{f}=150 \mathrm{~mm} ; \mathrm{d}=25,4 \mathrm{~mm}$ \\
\hline L4 & Newport & Lente Convergente & $\mathrm{f}=125 \mathrm{~mm} ; \mathrm{d}=50,8 \mathrm{~mm}$ \\
\hline E1 & Newport & Espelho & $\mathrm{d}=25,4 \mathrm{~mm}$; espectro visível \\
\hline E2 & Newport & Espelho & $\mathrm{d}=25,4 \mathrm{~mm}$; espectro visível \\
\hline DF1 & Newport & Divisor de Feixe & $\mathrm{d}=25,4 \mathrm{~mm}$; espectro visível \\
\hline D1 & THORLABS & PDA50 & Fotodetector de Silício; Amplificado \\
\hline D2 & THORLABS & PDA55 & Fotodetector de Silício; Amplificado \\
\hline Microdeslocador & Newport & M-UTM 150PP.1 & Deslocamento máximo 150 mm \\
\hline Chopper & Stanford Research Systems & SR540 & Utilizado em 16,67 Hz \\
\hline Osciloscópio & Tektronix & TDS1002B & $60 \mathrm{MHz}$; Digital \\
\hline
\end{tabular}

A fonte de luz utilizada foi um laser verde $(\lambda=532 \mathrm{~nm})$ contínuo $(C W-$ Continuous Wave) de Nd:YVO 4 . Os pulsos de luz quadrados com período de cerca de 60 milissegundos foram produzidos com o modulador mecânico Chopper. As lentes convergentes L1 e L2 foram utilizadas para uma melhor resolução temporal dos pulsos quadrados.

O feixe de luz com perfil gaussiano focalizado na posição $z=0$, onde seu raio é mínimo $\left(w=w_{0}\right)$, é obtido com a utilização da lente convergente L3. A dependência de $w$ com $z$ é detalhada na seção 3.5.2. A amostra é deslocada ao longo do eixo $z$ pelo microdeslocador, controlado por microcomputador. A intensidade da luz incidente na amostra aumenta com o inverso do quadrado do raio do feixe, atingindo seu valor máximo em $z=0$.

A íris, localizada no campo distante (posição z muito maior que a distância focal de L3), possui um orifício que permite a passagem apenas dos raios paraxiais do feixe. A intensidade dos raios paraxiais é então convertida em sinal elétrico pelo fotodetector D1, ligado ao sistema de aquisição de dados (osciloscópio e microcomputador. A seção 3.5.1 traz mais detalhes). As instabilidades na potência 
do laser e os efeitos de absorção e espalhamento de luz que ocorrem próximas ao foco são medidas pelo fotodetector D2, que recebe, do divisor de feixes DF1, uma fração do feixe.

Nesse arranjo de varredura-Z, são feitas ao mesmo tempo as medições na configuração íris fechada e na configuração íris aberta: a medição da intensidade dos raios paraxiais da luz é realizada pelo fotodetector D1 (íris fechada), enquanto o fotodetector D2 mede todo o feixe, e não apenas os raios paraxiais (íris aberta). Para isso é utilizada a lente L4, que focaliza a luz no fotodetector D2.

A medição da potência do laser foi realizada com a utilização do Power Meter modelo 1815-C, de fabricação da Newport, juntamente com a cabeça detectora feita de fotodiodo de silício, modelo 818-SL, também fabricado pela Newport.

\subsubsection{Coleta dos Dados da Varredura-Z}

O sistema de coleta de dados da varredura- $Z$ foi baseado no software "zscan_chopper_new", versão 2.0, desenvolvido na linguagem de programação "python" pelo Grupo de Fluídos Complexos do Instituto de Física da USP, que também realiza o controle de deslocamentos do microdeslocador.

O "zscan_chopper_new" se comunica com o osciloscópio e coleta do mesmo os dados do valor de tensão em cada instante de tempo do canal 1, ao qual está conectado o fotodetector $\mathrm{D} 1$, e do canal 2, ao qual está conectado o fotodetector D2.

A figura 18 apresenta uma janela desse software, onde é possível visualizar um menu de comandos da configuração da varredura-Z a ser realizada.

Com a configuração apresentada na figura 18, o microdeslocador percorria a distância de $1 \mathrm{~mm}$ em $1 \mathrm{~mm}$, esperando 1 segundo entre um deslocamento e outro. O número de deslocamentos foi de 120 , ou seja, o deslocamento total da amostra foi de $120 \mathrm{~mm}$. Em cada posição, o software coletava 5 conjuntos de dados do osciloscópio, e os valores de varredura-Z apresentados nesse trabalho correspondem à média desses dados. 


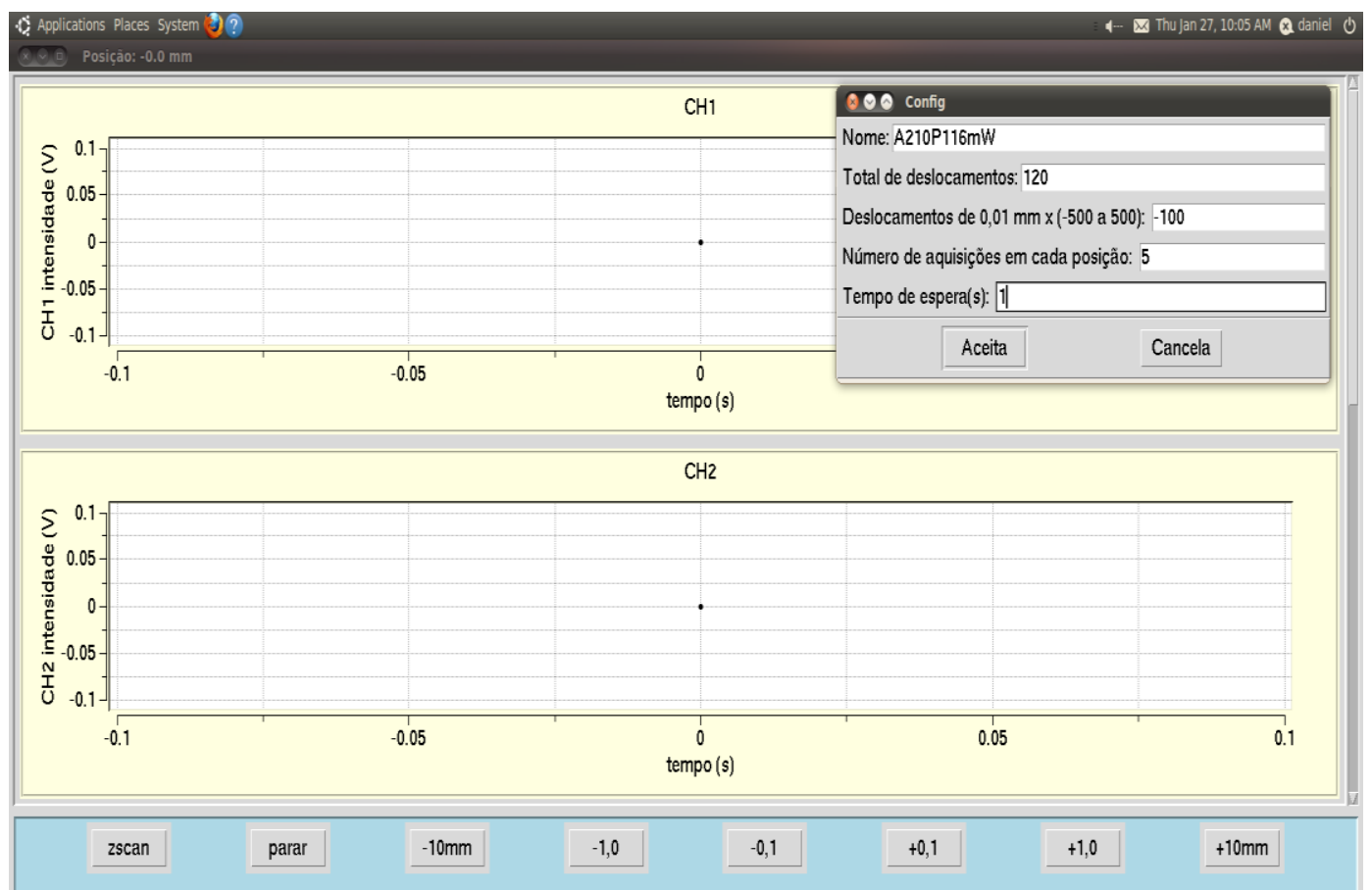
zscan_chopper_new.

Figura 18 - Configuração do arranjo de varredura-Z através do software

A figura 19 apresenta uma janela do "zscan_chopper_new" já com os dados coletados para uma determinada posição $z$. Nela é possível visualizar o sinal elétrico quadrado em função do tempo, tanto para o canal 1 quanto para o canal 2.

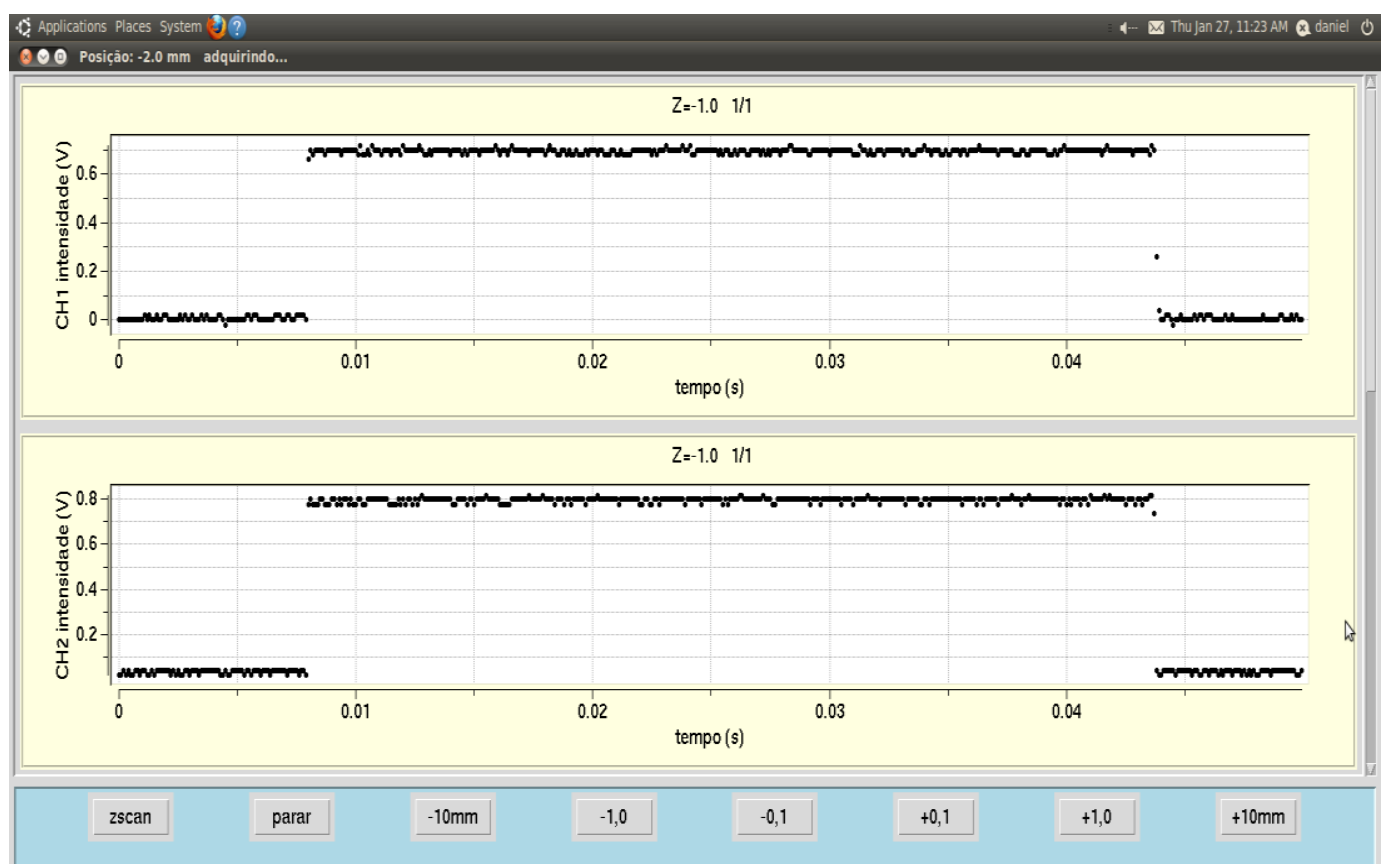

Figura 19 - Gráficos construídos pelo software zscan_chopper_new a partir dos dados coletados do osciloscópio. 


\subsubsection{Medição do Perfil do Feixe e Determinação de $w_{0}$ e $z_{0}$}

Para a obtenção da cintura do feixe $w_{0}$, utilizou-se uma câmera tipo charge coupled device - CCD de silício e o software "BeamView USB" versão 4.4.0, ambos de fabricação da Coherent. A câmera CCD captura a intensidade da radiação luminosa no plano xy, chamado de perfil do feixe, e o software calcula o valor do diâmetro do feixe $(2 w)$ e sua excentricidade, mostrando também um diagrama de cores correspondente a essa distribuição de intensidades, por onde é possível, inclusive, verificar se o perfil do feixe está distorcido ou não. O laser utilizado gera feixes com perfil gaussiano, mas a distorção do perfil pode ocorrer devido ao mau alinhamento dos elementos ópticos do arranjo, ou mesmo a sujeiras ou defeitos nos mesmos. Deve-se buscar, portanto, o melhor alinhamento e limpeza dos elementos para a realização da experiência de varredura-Z.

A figura 20a apresenta imagens capturadas pela câmera em uma determinada posição $z$, onde é possível verificar o comportamento gaussiano das componentes da intensidade no plano xy. A escala de cores segue a seguinte graduação (da intensidade menor para a intensidade maior): violeta, azul, verde, laranja, amarela e vermelha. A figura 20b apresenta a mesma distribuição de intensidade, mas agora, além da escala de cores, a altura (eixo-z da figura) também representa a distribuição de intensidades. Para o exemplo ilustrado nessa figura, 0 perfil do feixe tem o formato elíptico, com excentricidade de 0,848 , o diâmetro em $x$ foi de $736 \mu \mathrm{m}$ e o diâmetro em y foi de $624 \mu \mathrm{m}$.

Movendo a câmera entre vários pontos ao longo do eixo z, obtêm-se o valor de $w$ em cada um desses pontos, e com o ajuste teórico dos dados encontrase o valor da cintura do feixe $\left(w_{0}\right)$. O raio do feixe $w$ se relaciona com $z$ através da relação (SHEIK-BAHAE; SAID; STRYLAND, 1989):

$$
w^{2}(z)=w_{0}^{2}\left(1+\frac{z^{2}}{z_{0}^{2}}\right)
$$




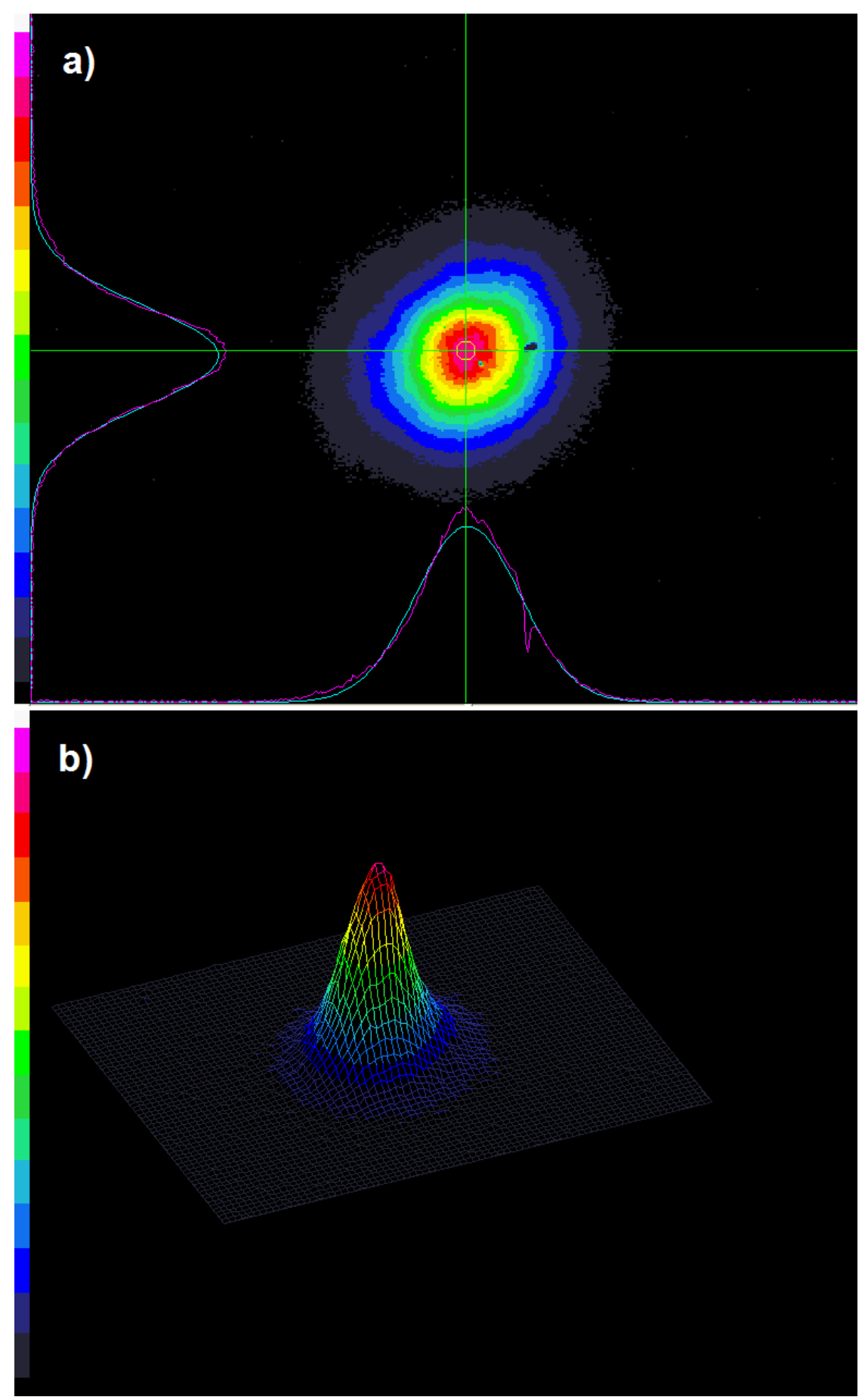

Figura 20 - Perfil de intensidade da luz do laser. Em a), são apresentados a distribuição de intensidade no plano $x y$ e os ajustes de curvas gaussianas nas componentes $x$ e y. Em b), é mostrado um diagrama tridimensional, no qual a altura representa a intensidade.

onde $z_{0}$ é o comprimento de difração do feixe, também chamado de comprimento de Rayleigh, região a partir da cintura onde passa-se do campo próximo (zona de Fresnel) para o campo distante (zona de Fraunhofer). Geometricamente, $z_{0}$ corresponde à distância de $z=0$ até o ponto $z$ onde a área do feixe é o dobro da 
área da cintura do feixe (ou $w=\sqrt{ } 2 w_{0}$ ), conforme mostra a figura 21 (MARTINELLI, 1998; SIEGMAN, 1986).

O comprimento de Rayleigh está relacionado com a área da cintura do feixe através da equação 3.4 (SHEIK-BAHAE; SAID; STRYLAND, 1989):

$$
z_{0}=\frac{\pi w_{0}^{2}}{\lambda}
$$

onde $\lambda$ é o comprimento de onda da luz.

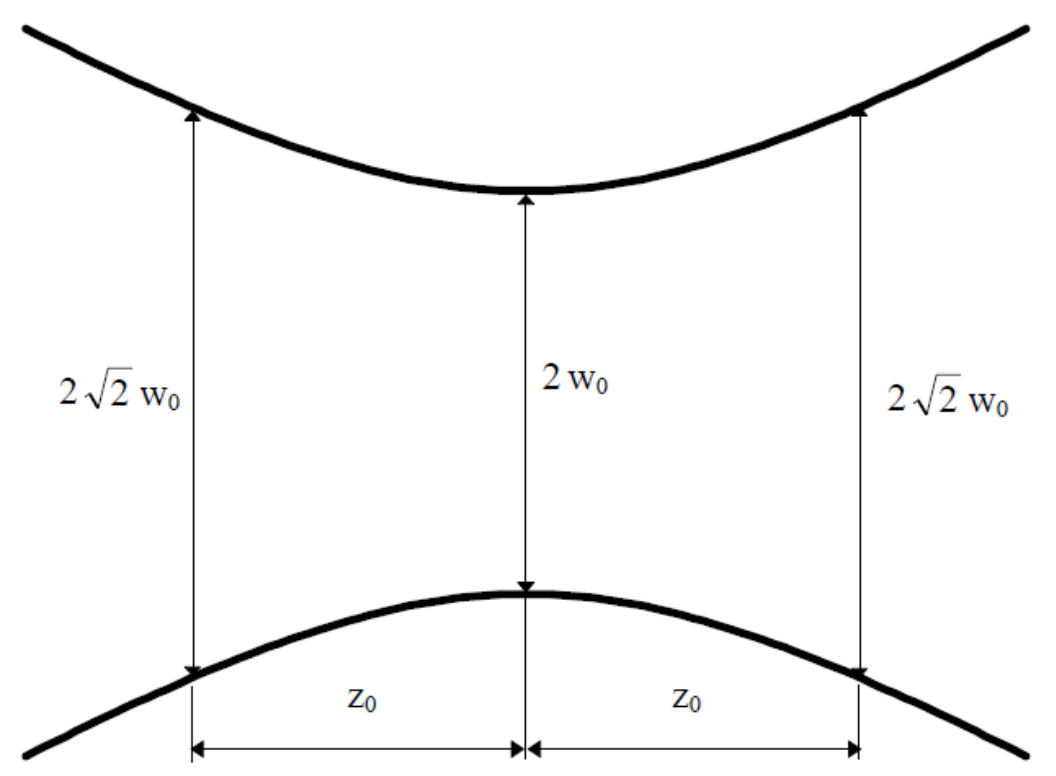

Figura 21 - Relação entre a cintura do feixe $w_{0}$ e o comprimento de Rayleigh $z_{0}$. 


\section{RESULTADOS E DISCUSSÃO}

Neste capítulo serão apresentados os resultados experimentais obtidos através das técnicas de espectrofotometria, perfilometria e varredura- $Z$. Primeiramente, serão apresentados os resultados que caracterizam as amostras: os seus espectros de transmissão, as espessuras dos filmes depositados e seus coeficientes de absorção, o que permitirá o cálculo das espessuras efetivas dos filmes. Após isso, será apresentado um resultado que caracteriza o arranjo de varredura-Z: a medida da cintura do feixe. Por fim, serão apresentados os resultados da varredura-Z juntamente com os ajustes dos modelos teóricos da transmitância normalizada e da lente térmica aos dados experimentais, o que permitirá as medições das propriedades ópticas não-lineares, provenientes de efeitos térmicos, dos filmes de silício amorfo hidrogenado.

\subsection{ESPECTROS DE TRANSMISSÃO}

A figura 22 apresenta os espectros de transmissão dos filmes de Si-a:H. Através do gráfico da figura $22 \mathrm{a}$ pode-se observar 0 comportamento da transmitância em função do comprimento de onda para as amostras depositadas à temperatura de $50^{\circ} \mathrm{C}$, com diferentes fluxos de fosfina. Para as quatro amostras, a transmitância diminui mais acentuadamente nos comprimentos de onda inferiores a cerca de $500 \mathrm{~nm}$, passando de cerca de $70 \%$ em $\lambda \sim 500 \mathrm{~nm}$ para menos de $40 \%$ em $\lambda \sim 400 \mathrm{~nm}$. Isso indica que as amostras absorvem mais a luz nessa região do espectro, que corresponde à luz de cores azul, anil e violeta e à radiação ultravioleta.

$\mathrm{Na}$ figura 22b são apresentados os espectros de transmissão para amostras depositadas com fluxo de fosfina de $10 \mathrm{sccm}$, a diferentes temperaturas de deposição, e na figura 22c são apresentados dois espectros de amostras depositadas à temperatura de $200{ }^{\circ} \mathrm{C}$. A transmitância dessas amostras também 
diminui consideravelmente para $\lambda<500 \mathrm{~nm}$, sendo, portanto, absorvedoras de luz nessa faixa do espectro eletromagnético.
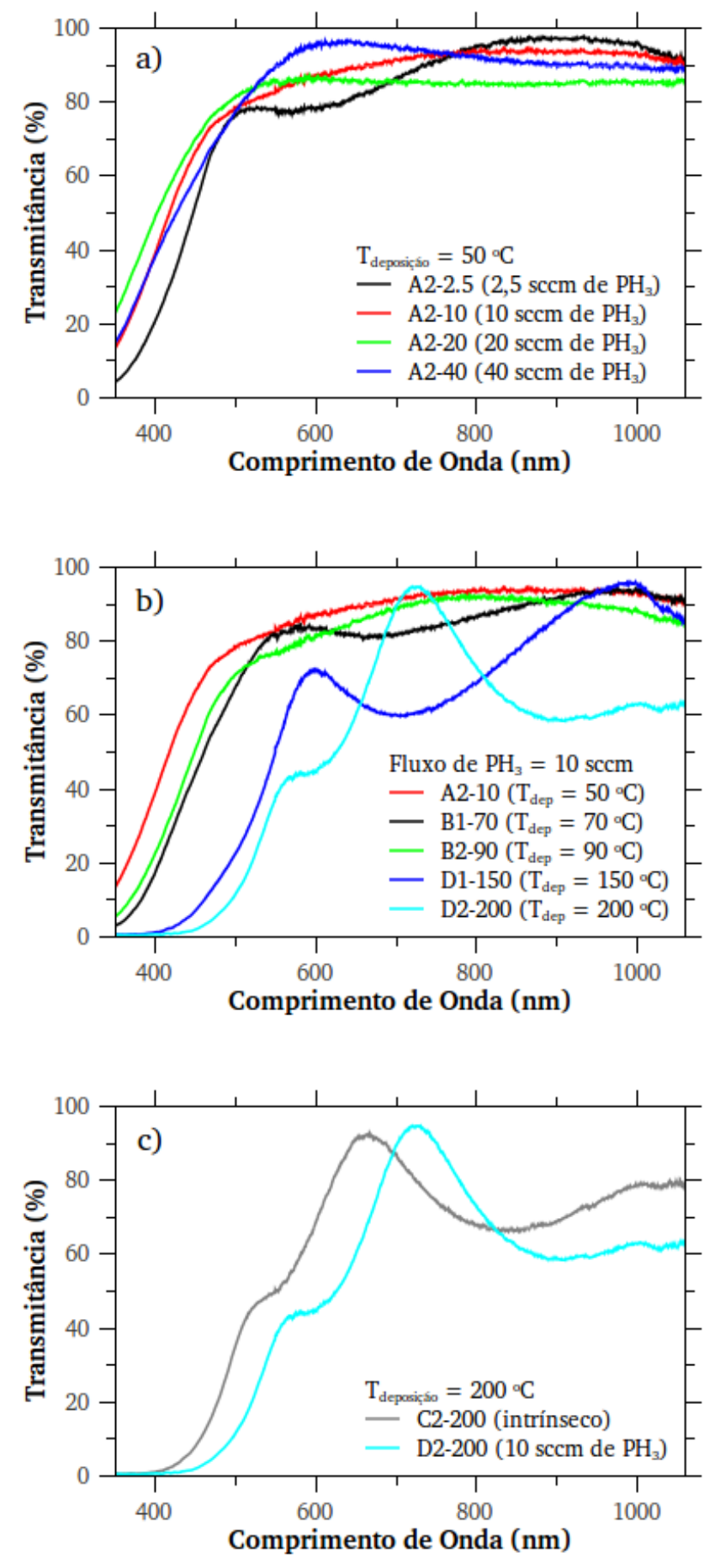

Figura 22 - Espectro de transmissão das amostras. Os parâmetros de deposição foram: a) $T_{\text {dep }}=50^{\circ} \mathrm{C}$ e fluxo de fosfina variando entre 2,5 e $40 \mathrm{sccm}$; b) fluxo de fosfina de 10 sccm e $T_{\text {dep }}$ variando entre $50^{\circ} \mathrm{C} \mathrm{e} 200^{\circ} \mathrm{C}$. Em C), são apresentados os espectros das amostras depositadas a $200{ }^{\circ} \mathrm{C}$ sem dopantes (C2-200) e com fluxo de fosfina de $10 \mathrm{sccm}$ (D2-200). 
A figura 23 traz a imagem de uma das amostras obtidas, onde se pode observar uma coloração alaranjada típica. Todas as amostras obtidas possuem essa coloração alaranjada, embora as amostras C2-200 e D2-200 possuem coloração mais escura que as demais. Esse fato está em conformidade com os espectros de transmissão da figura 22, pois a coloração alaranjada é resultado da absorção das cores verde, azul, anil e violeta pelas amostras.

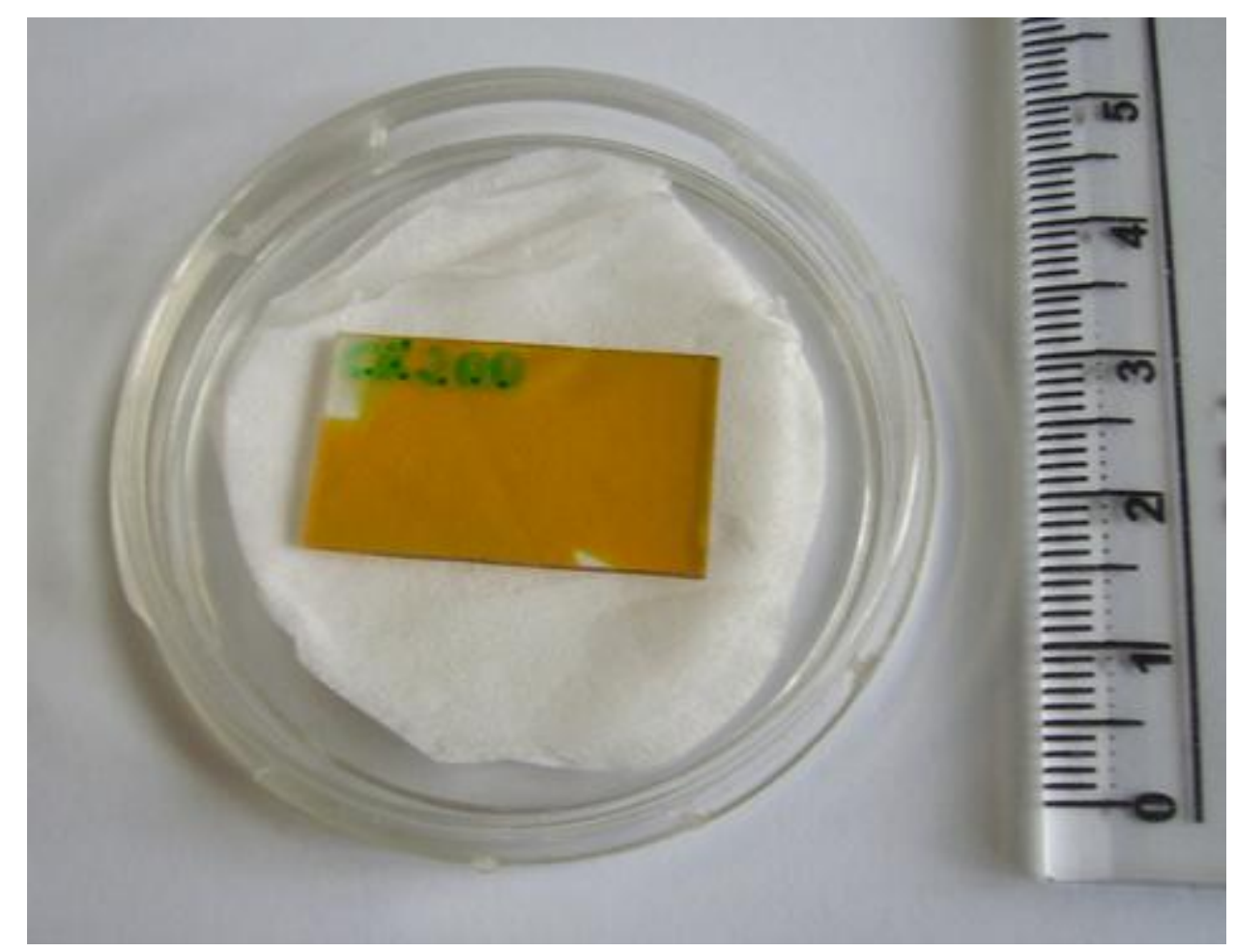

Figura 23 - Imagem de uma amostra de filme fino de Si-a:H depositada a $200{ }^{\circ} \mathrm{C}$.

\subsection{ESPESSURAS E COEFICIENTES DE ABSORÇÃO}

A figura 24 apresenta um gráfico gerado pelo perfilômetro, para a amostra de código D2-200. A ponteira iniciou seu deslocamento horizontal na superfície do vidro, atingindo um degrau de Si-a:H após cerca de $1 \mathrm{~mm}$ de deslocamento. Observa-se que a altura da ponteira passa de cerca de $0 \mathrm{~nm}$ para cerca de $200 \mathrm{~nm}$ após o degrau. A partir daí, o deslocamento horizontal passa a ocorrer sobre a superfície do filme de Si-a:H. 
É possível observar algumas irregularidades na superfície do filme, mas a espessura da amostra ainda assim pode ser determinada. A incerteza foi estimada em cerca de $10 \mathrm{~nm}$ a partir da leitura do gráfico da figura 24 .

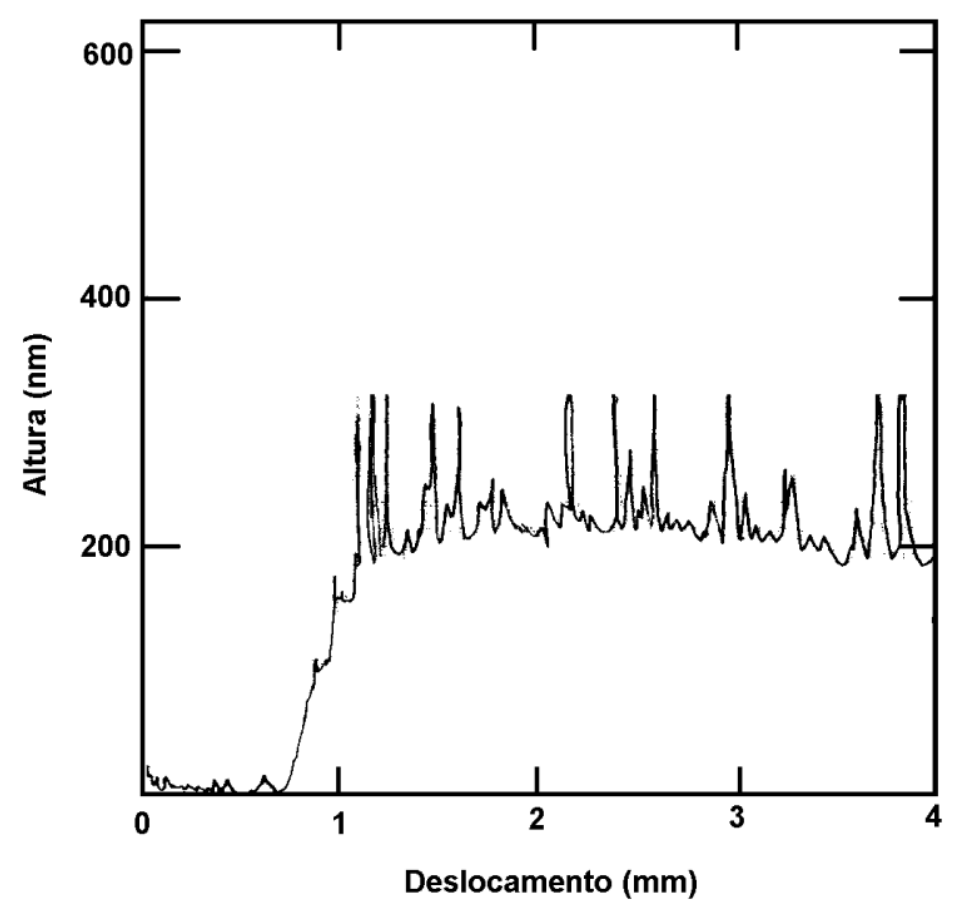

Figura 24 - Gráfico da altura da ponteira do perfilômetro em função do seu deslocamento horizontal. A ponteira iniciou a varredura na superfície do vidro e encontrou um degrau mecânico de Si-a:H após percorrer cerca de $1 \mathrm{~mm}$.

As espessuras das demais amostras também foram medidas e seus valores estão apresentados na tabela 4.1 , juntamente com os valores das suas espessuras efetivas em $532 \mathrm{~nm}$.

Tabela 4.1 - Medidas das espessuras, transmitâncias, coeficientes de absorção linear e espessuras efetivas das amostras de Si-a:H, para o comprimento de onda de $532 \mathrm{~nm}$.

\begin{tabular}{cccccc}
\hline Código da Amostra & $L(\mathrm{~nm})$ & $L_{\text {ef }}(\mathrm{nm})$ & $T(\%)$ & $\alpha\left(10^{4} \mathrm{~cm}^{-1}\right)$ & $E_{g}(\mathrm{eV})$ \\
\hline D2-200 & $200 \pm 10$ & $110,5 \pm 4,9$ & $26,4 \pm 0,8$ & $6,66 \pm 0,48$ & 1,82 \\
D3-150 & $200 \pm 10$ & $127,6 \pm 5,3$ & $37,6 \pm 0,8$ & $4,89 \pm 0,35$ & 1,77 \\
C2-200 & $256 \pm 10$ & $179,9 \pm 6,1$ & $47,1 \pm 0,8$ & $2,94 \pm 0,19$ & 2,01 \\
B2-90 & $260 \pm 10$ & $226,5 \pm 8,1$ & $75,4 \pm 0,8$ & $1,09 \pm 0,10$ & 2,21 \\
B1-70 & $200 \pm 10$ & $177,6 \pm 8,2$ & $78,5 \pm 0,8$ & $1,21 \pm 0,13$ & 2,16 \\
A2-40 & $250 \pm 10$ & $231,8 \pm 8,9$ & $85,8 \pm 0,8$ & $0,613 \pm 0,089$ & 2,07 \\
A2-20 & $180 \pm 10$ & $165,6 \pm 8,7$ & $84,4 \pm 0,8$ & $0,94 \pm 0,13$ & 2,29 \\
A2-10 & $190 \pm 10$ & $171,4 \pm 8,4$ & $81,1 \pm 0,8$ & $1,10 \pm 0,13$ & 2,27 \\
A2-2.5 & $180 \pm 10$ & $159,1 \pm 8,0$ & $77,7 \pm 0,8$ & $1,40 \pm 0,15$ & 2,24 \\
\hline
\end{tabular}


A partir dos espectros de transmissão das amostras e com a utilização da equação 3.2, foram construídos os gráficos dos coeficientes de absorção em função do comprimento de onda para cada amostra de Si-a:H, apresentados na figura 25.
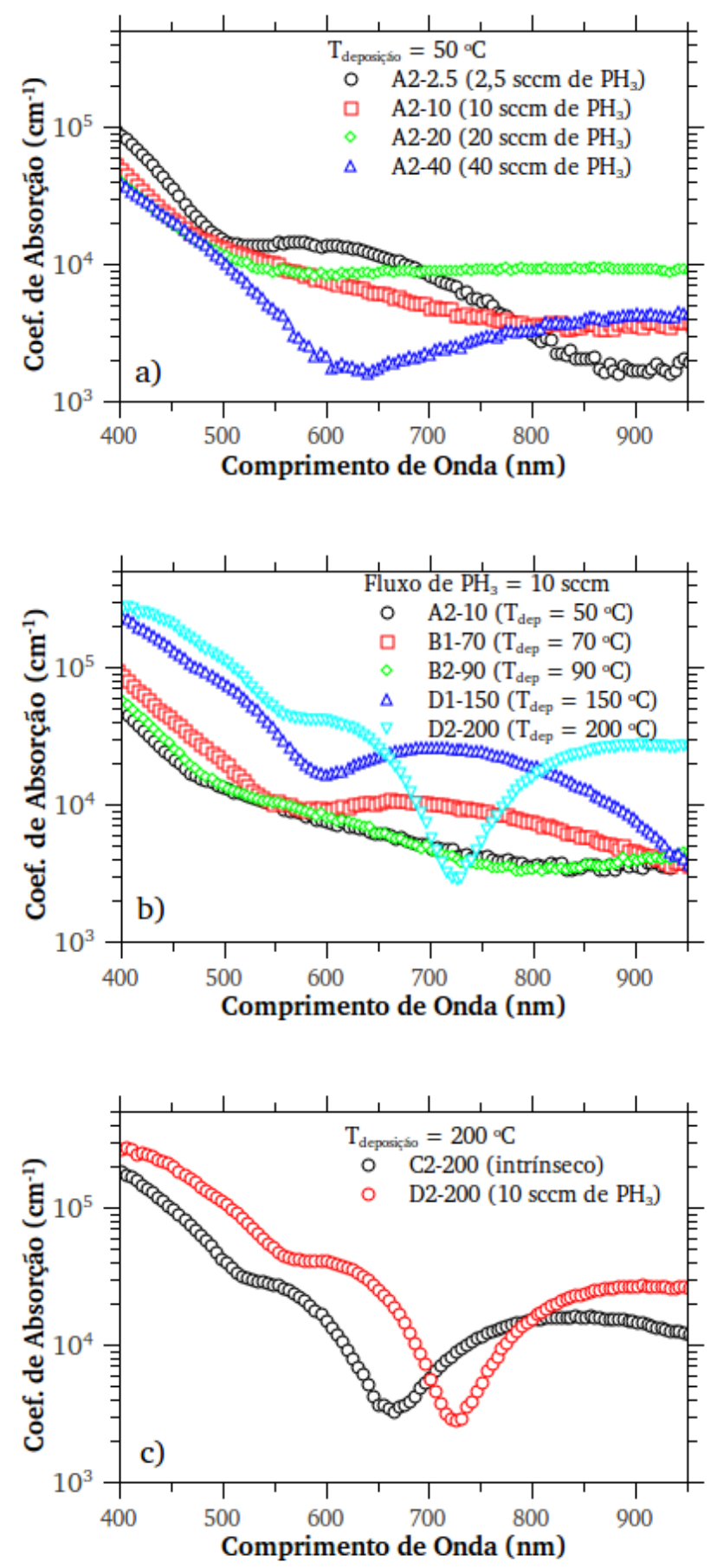

Figura 25 - Coeficiente de absorção das amostras. Os parâmetros de deposição foram: a) $T_{\text {dep }}=50^{\circ} \mathrm{C}$ e fluxo de fosfina variando entre 2,5 e $40 \mathrm{sccm}$; b) fluxo de fosfina de 10 sccm e $T_{\text {dep }}$ variando entre $50^{\circ} \mathrm{C}$ e $200^{\circ} \mathrm{C}$. Em C), são apresentados os espectros das amostras depositadas a $200^{\circ} \mathrm{C}$ sem dopantes (C2-200) e com fluxo de fosfina de $10 \mathrm{sccm}$ (D2-200). 
A análise dos gráficos da figura 25 está em conformidade com a análise dos espectros de transmissão. Pode-se, além disso, comparar esses gráficos com a figura 4, encontrada na literatura (BASS et al., 1995), onde os comportamentos dos mesmos variam entre gráficos típicos de silício policristalino e de silício amorfo. Algumas amostras obtidas, portanto, podem apresentar grãos microcristalinos. Fazse necessário, entretanto, uma análise estrutural das amostras com a técnica de difração de elétrons para saber qual a fração de fase microcristalina elas possuem, o que está além do escopo deste trabalho.

O gráfico de $\left[E_{f} \alpha\right]^{1 / 2} \times E_{f}$, para as amostras de código A2-10 e D3-150, é apresentado na figura 26. Utilizando a equação 2.3, foi realizado um ajuste da equação da reta $\left[E_{f} \alpha\right]^{1 / 2}=A E_{f} B$ nos pontos onde o gráfico é linear e foram obtidos os valores do coeficiente angular A e do coeficiente linear B. A extrapolação da reta com o eixo das energias fornece o valor do gap óptico:

$$
E_{g}=\frac{-B}{A}
$$

Os valores do gaps ópticos calculados dessa forma para as amostras variaram de 1,7 eV a 2,3 eV, e estão em conformidade com os valores encontrados para filmes de Si-a:H depositados anteriormente no LME (NARDES, 2002). A tabela 4.1 apresenta os valores de $E_{g}$ para cada amostra.

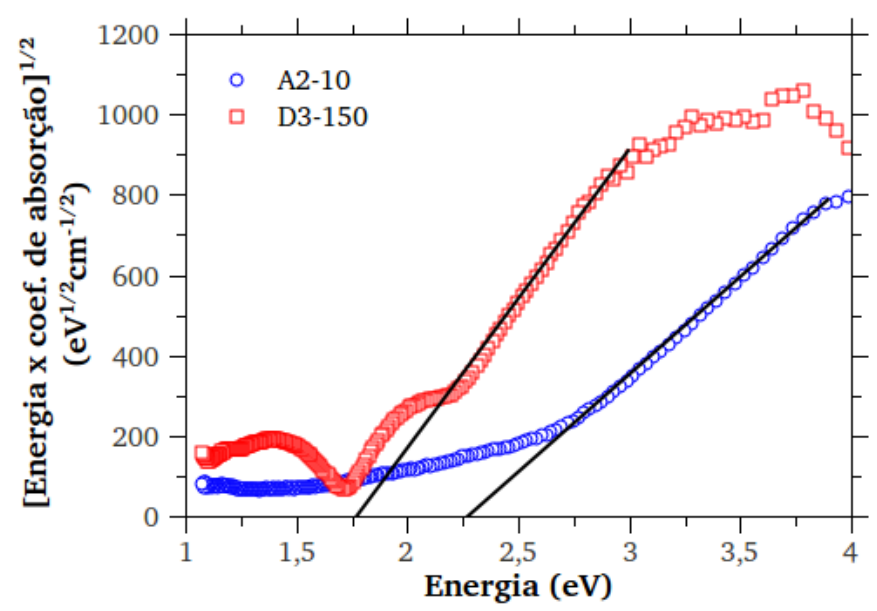

Figura 26 - Determinação do gap óptico $E_{\mathrm{g}}$ segundo o método de Tauc. Na figura são mostradas as extrapolações das retas das amostras que obtiveram menor gap óptico $(1,77$ eV) e maior gap óptico $(2,29 \mathrm{eV})$. 


\subsection{CINTURA DO FEIXE}

A figura 27 apresenta o gráfico com os dados experimentais e ajustes teóricos feitos para a obtenção do valor da cintura do feixe $w_{0}$.
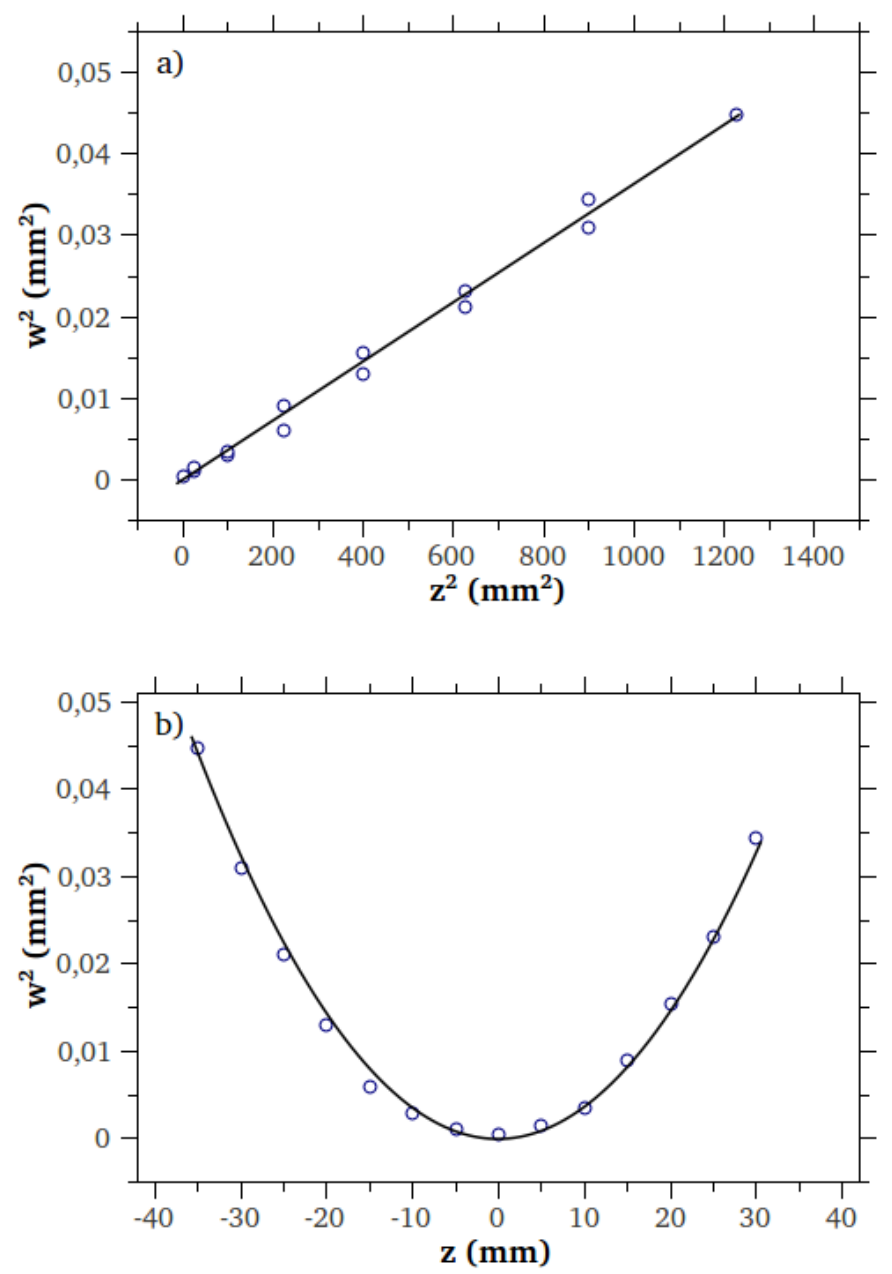

Figura 27 - Determinação da cintura do feixe $w_{0}$ com o ajuste das curvas de $w^{2}$ em função de $z^{2}$ (a) e de $w^{2}$ em função de $z$ (b).

A figura 27a mostra o gráfico de $w^{2}$ em função de $Z^{2}$, o que corresponde, segundo análise da equação 3.3, à seguinte equação de uma reta:

$$
w^{2}\left(z^{2}\right)=A z^{2}+B
$$


onde 0 coeficiente angular corresponde a $A=\left(w_{0} / z_{0}\right)^{2}$ e 0 coeficiente linear corresponde a $\mathrm{B}=w_{0}{ }^{2}$. Através do ajuste da equação 4.2 aos dados experimentais, e utilizando a definição de $z_{0}$ da equação 3.4 , chega-se a:

$$
\begin{gathered}
w_{0}=(28 \pm 1) \mu \mathrm{m} \\
z_{0}=(4,6 \pm 0,4) \mathrm{mm}
\end{gathered}
$$

A figura 27b mostra o ajuste da equação 3.3 no gráfico de $w^{2}$ em função de $z$, onde se obteve os mesmos valores para $w_{0}$ e $z_{0}$.

\subsection{VARREDURA-Z E LENTE TÉRMICA}

\subsubsection{Evolução Temporal dos Pulsos}

A figura 28 apresenta o sinal elétrico do fotodetector D1 (íris fechada) em função do tempo. As medidas apresentadas na figura são da amostra A2-2.5, com a potência da luz incidente de $P=116 \mathrm{~mW}$. Os dados foram coletados do osciloscópio pelo software "zscan_chopper_new". Pela medição do sinal elétrico do fotodetector, pode-se analisar o comportamento da intensidade de luz transmitida através da amostra, que é proporcional ao sinal elétrico do fotodetector. A referência do eixo $z$ é o ponto focal localizado em $z=0$. A referência do tempo é o início do pulso quadrado de luz, onde $t=0$. A lente convergente da varredura-Z estava localizada em $z \sim-150 \mathrm{~mm}$. O fotodetector D1 estava localizado no campo distante, em $z \sim$ $1500 \mathrm{~mm}$.

A figura 28a apresenta a evolução temporal do sinal elétrico do fotodetector D1 devido à luz transmitida através da amostra, quando ela estava posicionada longe do foco (pontos em preto, $z=-52,5 \mathrm{~mm}$ ) e quando ela estava posicionada perto do foco (pontos em vermelho, $z=-6,5 \mathrm{~mm}$ ). Com a amostra longe do foco, o sinal elétrico possui uma forma de onda quadrada, indicando que o pulso 

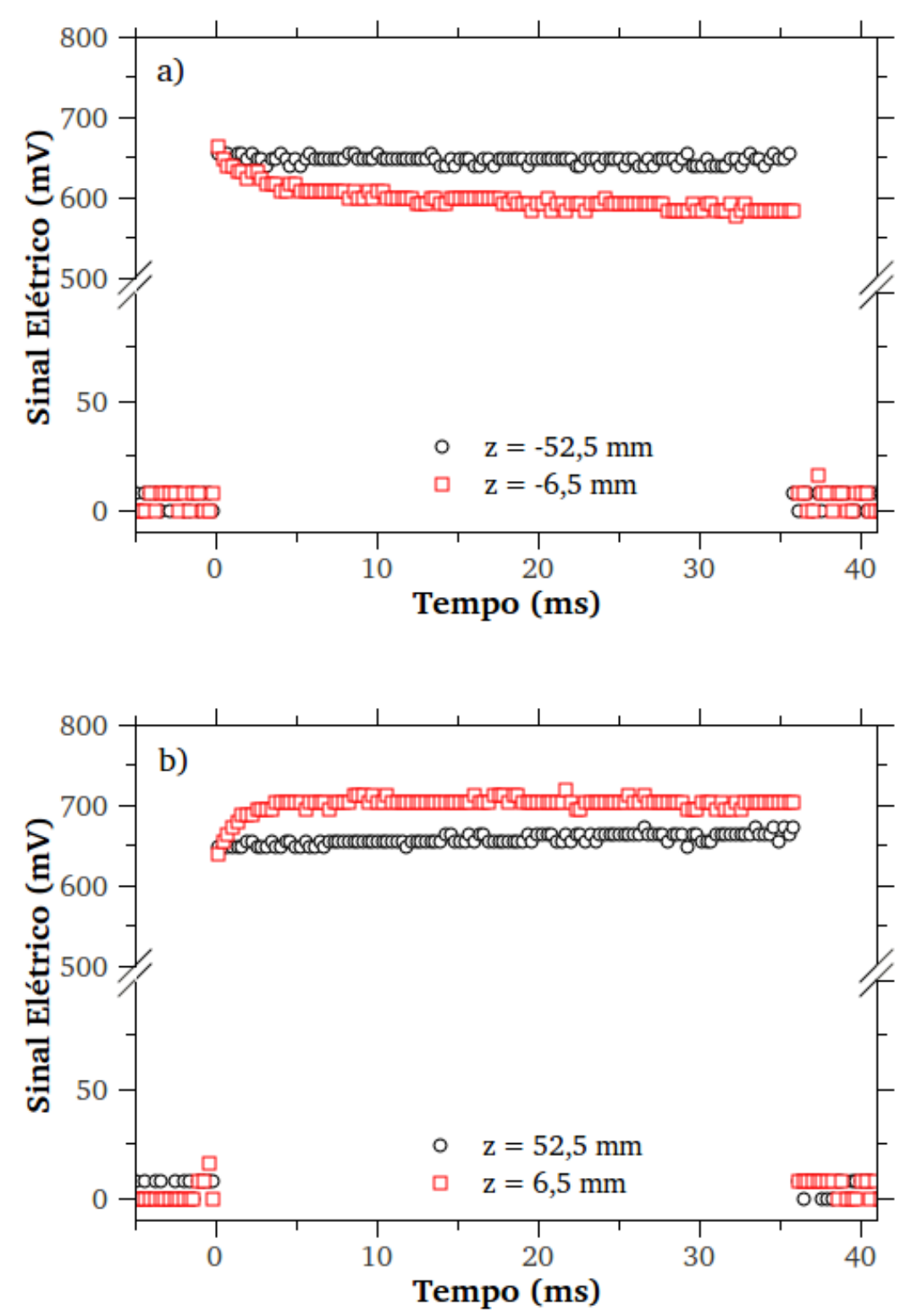

Figura 28 - Evolução temporal do sinal elétrico do fotodetector D1, para a amostra A2-2.5. Os círculos pretos correspondem à medida feita com a amostra posicionada longe do foco, enquanto os quadrados vermelhos correspondem à medida feita com a amostra posicionada próxima do foco. Em a) a amostra estava posicionada antes do foco $(z<0)$, enquanto em b) a amostra estava posicionada após o foco $(z>0)$.

transmitido através da amostra mantém a mesma intensidade desde o instante em que a amostra começa a ser iluminada $(t=0)$ até o instante em que o pulso é bloqueado pelo chopper e a amostra deixa de ser iluminada ( $t=35 \mathrm{~ms}$ ). Nesse caso, a intensidade de luz ainda não é grande o suficiente para causar o aquecimento da amostra e produzir o efeito não-linear de auto-focalização. Com a amostra posicionada perto do foco, pode-se perceber que, no início do pulso $(t=0)$, a 
intensidade de luz que chega no fotodetector é igual à intensidade de luz para posições longe do foco, mas depois de alguns milissegundos o efeito não-linear de auto-focalização começa a ocorrer e o sinal elétrico diminui de intensidade. Esse efeito é o resultado da formação da lente térmica, que ocorre na escala de tempo de milissegundos: a intensidade da luz é suficiente para aquecer a amostra e alterar seu caminho óptico. A mudança no caminho óptico pode ser originada pela mudança do índice de refração com o aumento da temperatura no material juntamente com a mudança da espessura da amostra pela expansão térmica do material.

A figura 28b apresenta a evolução temporal do sinal elétrico do fotodetector D1 devido à luz transmitida através da amostra, quando ela estava posicionada longe do foco (pontos em preto, $z=52,5 \mathrm{~mm}$ ) e quando ela estava posicionada perto do foco (pontos em vermelho, $z=6,5 \mathrm{~mm}$ ), mas agora na região $z$ $>0$. Com a amostra posicionada longe do foco não ocorrem efeitos não-lineares, e o pulso de luz tem a forma quadrada. Com a amostra posicionada perto do foco, o efeito de auto-focalização da luz começa a ocorrer alguns milissegundos após o início do pulso, e desta vez o sinal elétrico do fotodetector aumenta com o passar do tempo. O efeito também é térmico: a intensidade da luz é suficiente para aquecer a amostra e alterar seu caminho óptico.

\subsubsection{Transmitância Normalizada}

A transmitância normalizada em função da posição da amostra é apresentada na figura 29. As medidas da figura foram obtidas com a potência $P=$ $116 \mathrm{~mW}$ para a amostra A2-2.5. Cada ponto do gráfico representa a média de 5 medidas na mesma posição $z$, para diminuir a relação sinal/ruído. A normalização foi realizada segundo a equação 2.7, de forma a apresentar apenas os efeitos que surgem na escala de tempo de milissegundos, ou seja, os gráficos representam a divisão da altura do pulso em $t=30 \mathrm{~ms}$ pela altura do pulso em $t=0$, em cada posição $z$.

A figura 29a apresenta a transmitância normalizada em função de $z$ para o fotodetector D1 (configuração íris fechada). A curva é do tipo vale-pico, indicando 
um comportamento de lente térmica convergente para essa amostra. Aliás, os resultados das varreduras- $\mathrm{Z}$ realizadas em todas as amostras de $\mathrm{Si}-\mathrm{a}: \mathrm{H}$ deste trabalho indicaram o comportamento de lente convergente.
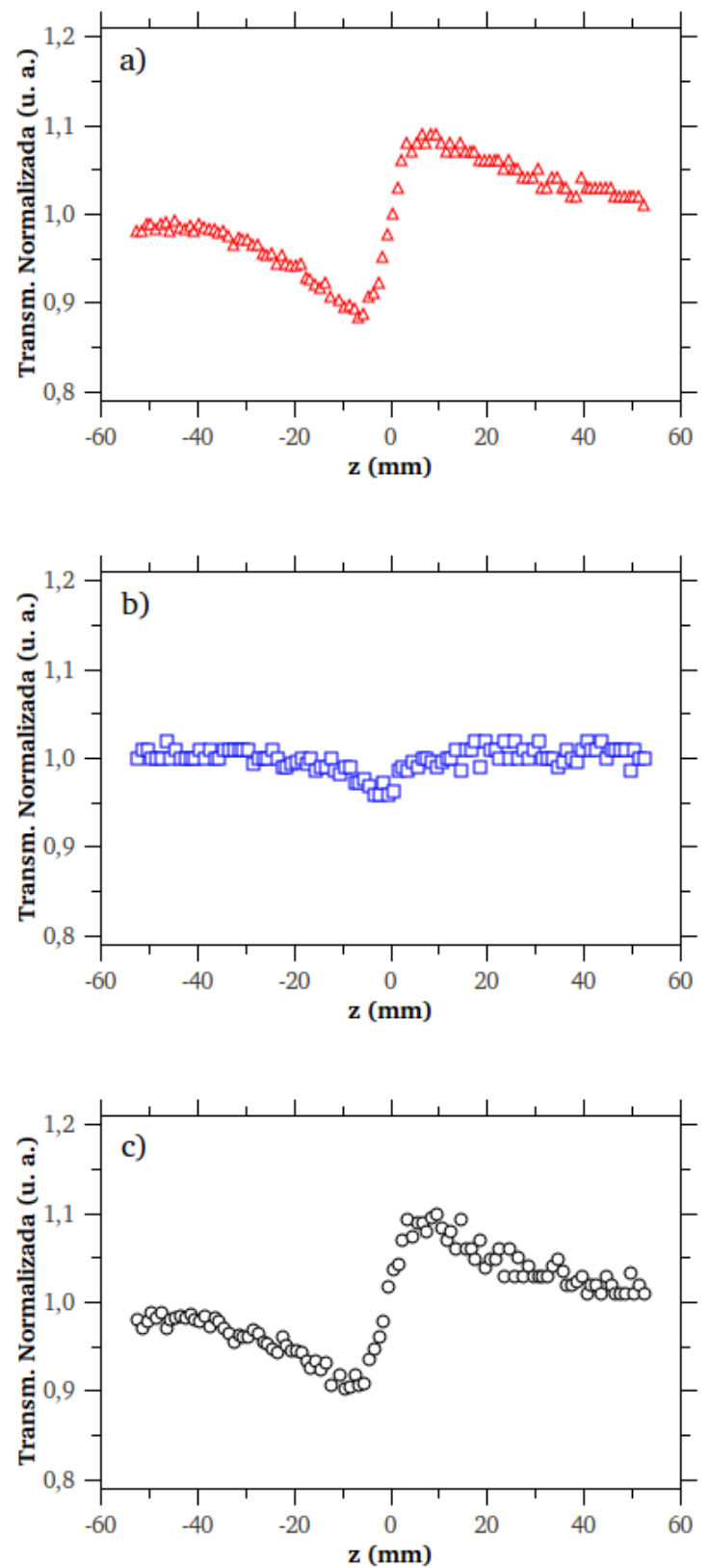

Figura 29 - Resultado da varredura-Z da amostra A2-2.5, com $P=116 \mathrm{~mW}$ e $\lambda=532$ $n m$. Em a), apresenta-se a transmitância normalizada em função da posição $z$ para 0 fotodetector D1 (íris fechada). Em b), apresenta-se a transmitância normalizada em função da posição $z$ para o fotodetector D2 (íris aberta). Em c), apresenta-se a divisão da transmitância normalizada de a) pela de b). 
A figura 29b apresenta a transmitância normalizada em função de $z$ para o fotodetector D2 (configuração íris aberta).

A figura 29c apresenta a divisão do gráfico da figura 29a pelo gráfico da figura 29b. Esse procedimento foi realizado para eliminar as não-linearidades no sinal do fotodetector D1 devido a efeitos não refrativos. Como resultado, pode-se perceber que a simetria da figura 29c é melhor do que a simetria da figura 29a. Os ajustes do modelo teórico da equação 2.8 foram feitos, portanto, nos dados dos gráficos de transmitância normalizada obtidos através do quociente da $T_{\mathrm{N}}$ de D1 pela $T_{\mathrm{N}}$ de $\mathrm{D} 2$.

Para afirmar que o sinal de transmitância normalizada tipo vale-pico é devido ao Si-a:H e não ao substrato de vidro, foi realizada a varredura-Z de uma amostra contendo apenas o substrato de vidro, com o laser na potência de $P=116$ $\mathrm{mW}$ (que é a maior potência utilizada em todas as varreduras- $Z$ deste trabalho). $O$ resultado é apresentado na figura 30: não ocorrem não-linearidades na transmitância da luz pela amostra de vidro, e a transmitância normalizada se mantém constante com o valor $T_{\mathrm{N}}=1$.

De forma semelhante ao que foi feito na figura 29, a figura 30 apresenta a transmitância normalizada para a configuração íris fechada (figura 30a), íris aberta (figura 30b) e o quociente de ambas (figura 30c).

A figura 31 apresenta o que ocorre com o sinal da transmitância normalizada caso a potência utilizada seja demasiadamente alta para a amostra. Os pontos representados por círculos pretos são de uma medida realizada a uma potência adequada de $P=45 \mathrm{~mW}$. Nesse caso, observa-se que a curva é antisimétrica em relação ao ponto $z=0$ e $T_{N}=1$, não apresentando distorções. Além disso, o pico da transmitância normalizada não ultrapassa o valor de 1,2, condição para que o modelo teórico de lente térmica se ajuste bem aos dados experimentais (CUPPO et al., 2002). Já os pontos representados por quadrados vermelhos são da medida realizada a uma potência demasiadamente alta para essa amostra: $P=116$ $\mathrm{mW}$. Além de ultrapassar o limite de $T_{N}=1,2$, a curva apresenta grandes distorções. Conclui-se daí que os resultados da varredura-Z para potências demasiadamente altas não podem ser considerados confiáveis, podendo, inclusive, danificar a amostra. Entretanto, a potência de $116 \mathrm{~mW}$ não foi demasiadamente alta para amostras obtidas com outros parâmetros de deposição, como, por exemplo, a A2- 
2.5. Para essa amostra, a potência de $45 \mathrm{~mW}$ daria um sinal de Varredura-Z muito pequeno, enquanto a potência de $116 \mathrm{~mW}$ foi adequada para a realização da medida, e uma potência muito maior que $116 \mathrm{~mW}$ já seria inadequada. Deve-se, portanto, procurar trabalhar com a potência que produza um pico de transmitância em torno de 1,2.
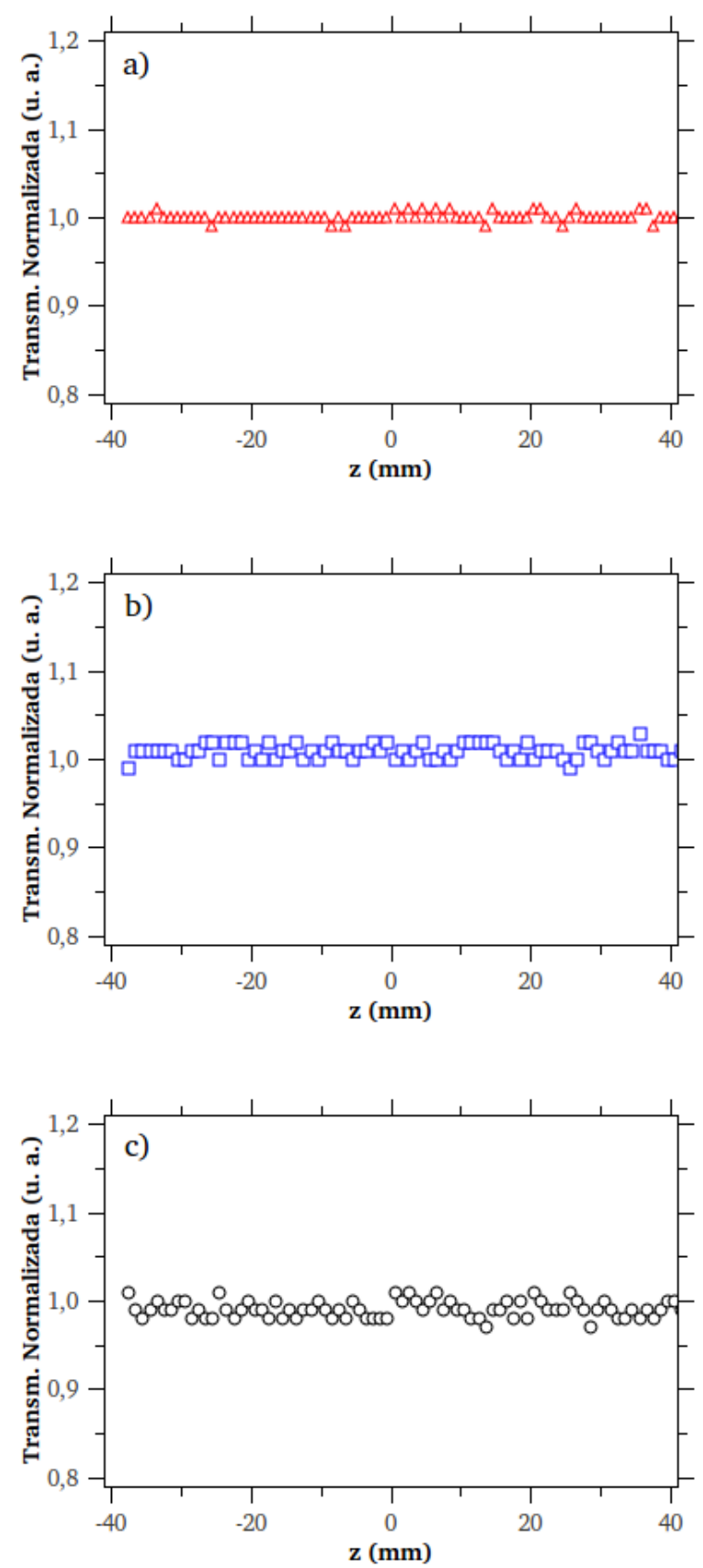

Figura 30 - Resultado da varredura- $Z$ da amostra contendo apenas o substrato de vidro, com $P=116 \mathrm{~mW}$ e $\lambda=532 \mathrm{~nm}$. Em a), apresenta-se a transmitância normalizada em função da posição $z$ para o fotodetector D1 (íris fechada). Em b), apresenta-se a transmitância normalizada em função da posição $z$ para o fotodetector D2 (íris aberta). Em c), apresenta-se a divisão da transmitância normalizada de a) pela de b). 


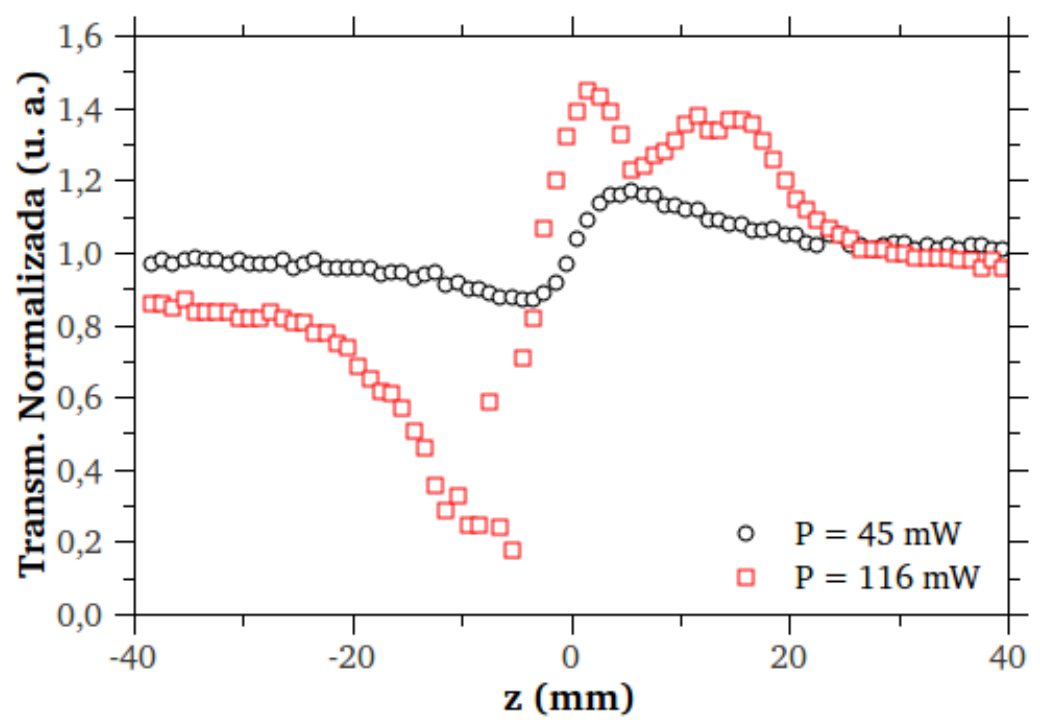

Figura 31 - Resultado da varredura-Z da amostra C2-200, com $\lambda=532 \mathrm{~nm}$. Os círculos pretos correspondem à medida feita com a potência de $45 \mathrm{~mW}$, enquanto os quadrados vermelhos correspondem à medida feita com a potência de $116 \mathrm{~mW}$.

\subsubsection{Desvios de Fase e Tempos Característicos}

A figura 32 apresenta medidas da transmitância normalizada para a amostra A2-2.5, com $P=116 \mathrm{~mW}$. A transmitância normalizada, segundo a equação 2.8, é uma função de $z$ e de $t$.

$\mathrm{Na}$ figura $32 \mathrm{a}$, é mostrado o gráfico da transmitância normalizada em função da posição $z$, para um instante de tempo fixo $t=30 \mathrm{~ms}$. Na figura $32 \mathrm{~b}$, é mostrado o gráfico da transmitância normalizada em função do tempo, para a posição da amostra fixa em $z=-6,5 \mathrm{~mm}$ (perto do foco). Na figura 32c é mostrado o gráfico da transmitância normalizada em função do tempo para a posição da amostra fixa em $z=6,5 \mathrm{~mm}$. Na figura 32a utilizaram-se, como parâmetros fixos de entrada, os valores de $z_{0}=7,65 \mathrm{~mm}$ e $t=30 \mathrm{~ms}$, e obteve-se, como resultado do ajuste da equação 2.8 aos dados experimentais:

$$
\begin{gathered}
\theta=(-0,094 \pm 0,004) \mathrm{rad} \\
t_{\mathrm{c} 0}=(1,0 \pm 0,2) \mathrm{ms}
\end{gathered}
$$



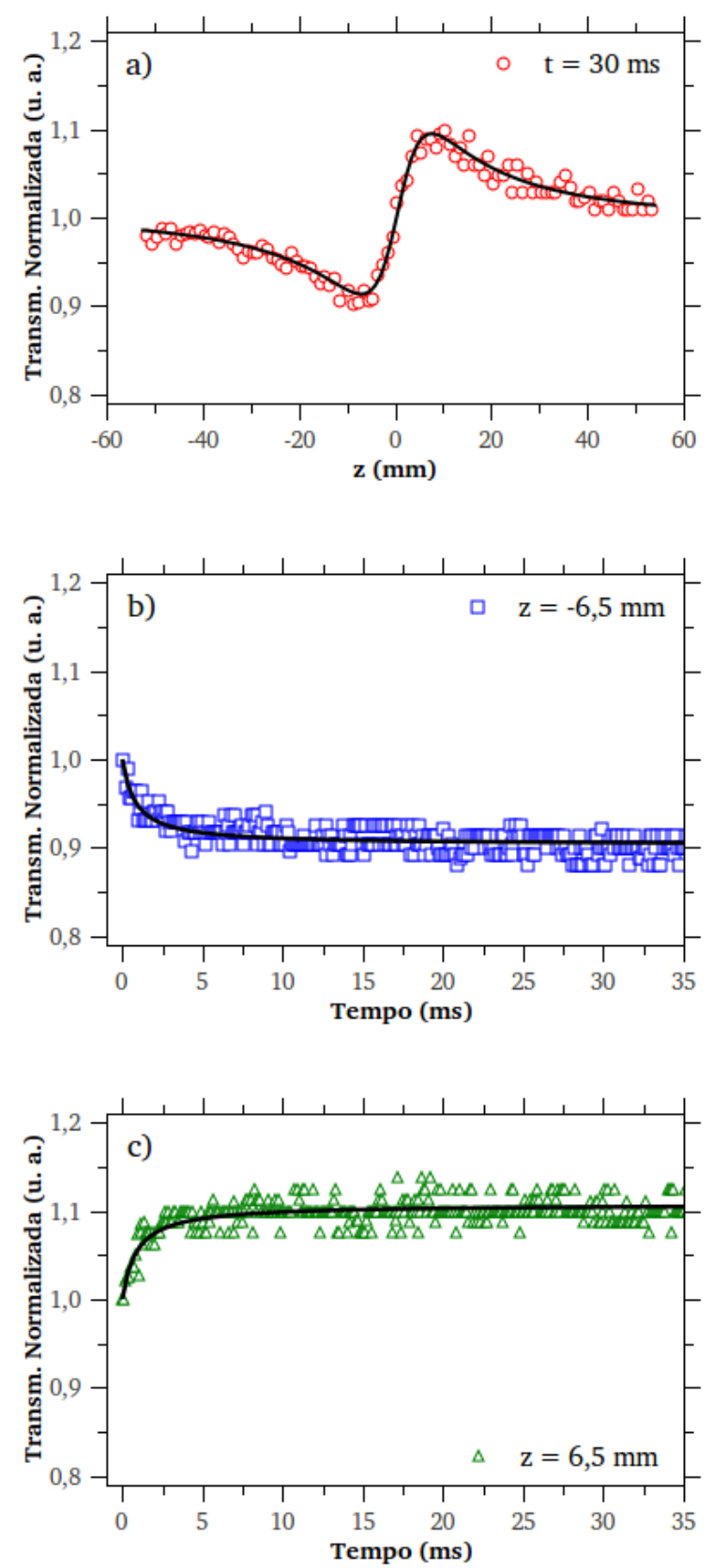

Figura 32 - Ajustes do modelo teórico aos dados de transmitância normalizada para a amostra A2-2.5. Os ajustes são representados pelas linhas contínuas. Em a), $t=\mathbf{3 0} \mathrm{ms} e$ $T_{\mathrm{N}}$ é apresentada em função de $z$. Em b) e c), $z$ é fixo em $-6,5 \mathrm{~mm}$ e $6,5 \mathrm{~mm}$, respectivamente, e $T_{\mathrm{N}}$ é apresentada em função de $t$.

Os valores das incertezas apresentados para $\theta$ e $t_{\mathrm{c} 0}$, que correspondem aos erros dos ajustes teóricos aos dados experimentais, podem estar subestimadas, pois as incertezas devidas à reprodutibilidade das medidas não foram consideradas.

Na figura $32 \mathrm{~b}$, os valores de $z_{0}=7,65 \mathrm{~mm}, z=-6,5 \mathrm{~mm}$ e $t_{\mathrm{c} 0}=1 \mathrm{~ms}$ foram utilizados como parâmetros de entrada, obtendo como resultado o valor: 


$$
\theta=(-0,101 \pm 0,004)
$$

coincidente, dentro da faixa de tolerância, com o valor da figura 32a.

Na figura 32c, os valores de $z_{0}=7,65 \mathrm{~mm}, z=6,5 \mathrm{~mm}$ e $t_{\mathrm{c} 0}=1 \mathrm{~ms}$ foram utilizados como parâmetros de entrada, obtendo como resultado o valor:

$$
\theta=(-0,102 \pm 0,004)
$$

coincidente, dentro da faixa de tolerância, com o valor da figura 32a.

O procedimento de ajuste do modelo teórico realizado na figura $32 \mathrm{a}$ foi repetido para as demais amostras de $\mathrm{Si}-\mathrm{a}: \mathrm{H}$ obtidas. Os resultados são apresentados na tabela 4.2, juntamente com parâmetros da varredura- $Z$ realizada para cada amostra: a potência do laser medidas pelo Power Meter e o valor da cintura do feixe que melhor se ajustou aos dados da varredura-Z. Os valores de $t_{c 0}$ foram cerca de unidades de milissegundos, o que é compatível com o resultado encontrado na literatura (MESSIAS; ZANATTA; CATUNDA, 2004). Os valores de $\theta$ ficaram próximos de $-0,1$ rad.

Tabela 4.2 - Resultados dos ajustes do modelo teórico aos gráficos de transmitância normalizada em função de z. São apresentados os valores do tempo característico $t_{c 0}$ e do desvio de fase $\theta$ obtidos para cada amostra. Também são informados os valores da cintura do feixe e da potência utilizada na varredura- $Z$.

\begin{tabular}{ccccc}
\hline Código da Amostra & $w_{0}(\mu \mathrm{m})$ & $P(\mathrm{~mW})$ & $t c_{0}(\mathrm{~ms})$ & $\theta(\mathrm{rad})$ \\
\hline D2-200 & $29 \pm 1$ & $26,1 \pm 0,5$ & $0,4 \pm 0,2$ & $-0,099 \pm 0,006$ \\
D3-150 & $29 \pm 1$ & $36,3 \pm 0,5$ & $1,0 \pm 0,2$ & $-0,165 \pm 0,008$ \\
C2-200 & $29 \pm 1$ & $45,0 \pm 0,5$ & $2,3 \pm 0,3$ & $-0,158 \pm 0,004$ \\
B2-90 & $32 \pm 1$ & $116 \pm 1$ & $0,7 \pm 0,3$ & $-0,072 \pm 0,004$ \\
B1-70 & $32 \pm 1$ & $116 \pm 1$ & $2,6 \pm 0,6$ & $-0,096 \pm 0,004$ \\
A2-40 & $32 \pm 1$ & $116 \pm 1$ & $3,4 \pm 1,8$ & $-0,052 \pm 0,006$ \\
A2-20 & $32 \pm 1$ & $116 \pm 1$ & $0,4 \pm 0,3$ & $-0,035 \pm 0,006$ \\
A2-10 & $32 \pm 1$ & $116 \pm 1$ & $4,0 \pm 1,8$ & $-0,031 \pm 0,005$ \\
A2-2.5 & $36 \pm 1$ & $116 \pm 1$ & $1,0 \pm 0,2$ & $-0,094 \pm 0,004$ \\
\hline
\end{tabular}




\subsubsection{Propriedades Térmicas e Propriedades Ópticas Não-Lineares}

A partir dos valores obtidos do tempo característico no foco e dos valores da cintura do feixe, chega-se ao valor da difusividade térmica das amostras, com a utilização da equação 2.9. Os valores obtidos foram da ordem de $10^{-3} \mathrm{~cm}^{2} / \mathrm{s}$, o que está em conformidade com valores obtidos pela literatura (MESSIAS; ZANATTA; CATUNDA, 2004). As incertezas das medidas de difusividade foram calculadas por propagação de incertezas.

A figura 33 traz os valores do tempo característico no foco (figura 33a) e da difusividade térmica (figura 33b) para as amostras depositadas a $50{ }^{\circ} \mathrm{C}$, e com o fluxo de fosfina variando de 2,5 a 40 sccm.
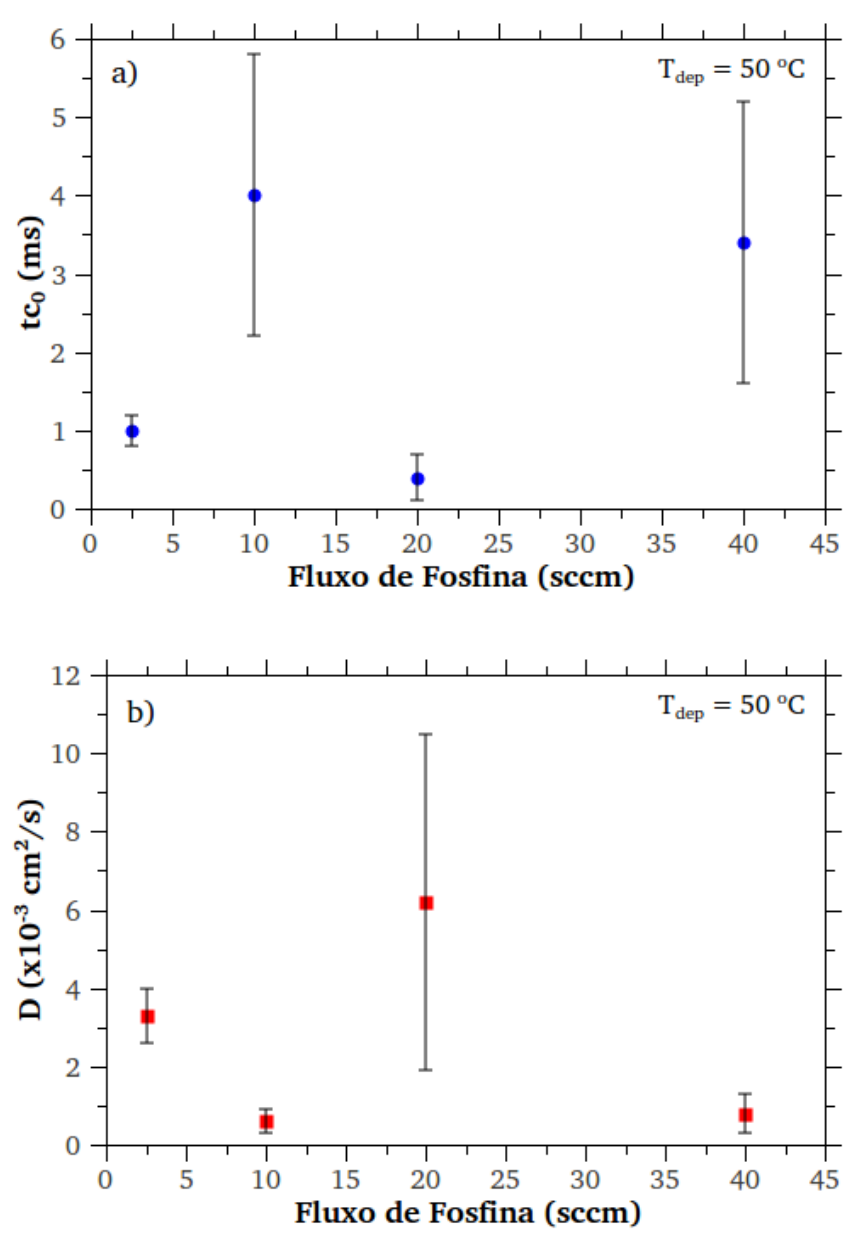

Figura 33 - Medidas do tempo característico no foco e da difusividade térmica para as amostras depositadas a $50^{\circ} \mathrm{C}$. Em a), são apresentados os valores de $t_{\mathrm{c} 0} \mathrm{em}$ função do fluxo de fosfina utilizado na deposição. Em b), são apresentados os valores de $D$ em função do fluxo de fosfina utilizado na deposição. 
Na figura 33a, nota-se que os valores de $t_{\mathrm{c} 0}$ são iguais, considerando-se 0 intervalo de confiança, para as amostras depositadas com fluxo de fosfina de 10 $\mathrm{sccm}$ e de $40 \mathrm{sccm}$, com valor de $t_{\mathrm{c} 0} \sim 4 \mathrm{~ms}$. Já as amostras depositadas com fluxo de fosfina de $2,5 \mathrm{sccm}$ e $20 \mathrm{sccm}$ possuem $t_{\mathrm{co}} \sim 1 \mathrm{~ms}$. O mesmo ocorre com o valor de $D$ : as amostras com fluxo de fosfina de 10 e $40 \mathrm{sccm}$ possuem os valores de difusividade térmica próximos entre si $\left(D \sim 5 \times 10^{-4} \mathrm{~cm}^{2} / \mathrm{s}\right)$, enquanto as amostras depositadas com 2,5 sccm e $20 \mathrm{sccm}$ de fosfina possuem os valores de difusividade térmica próximos entre si $\left(D \sim 4 \times 10^{-3} \mathrm{~cm}^{2} / \mathrm{s}\right)$.

A figura 34 apresenta os valores do tempo característico no foco (figura 34a) e da difusividade térmica (figura 34b) para as amostras depositadas com fluxo de fosfina de $10 \mathrm{sccm}$, e com a temperatura de deposição variando de $50^{\circ} \mathrm{C}$ a 200 ${ }^{\circ} \mathrm{C}$.
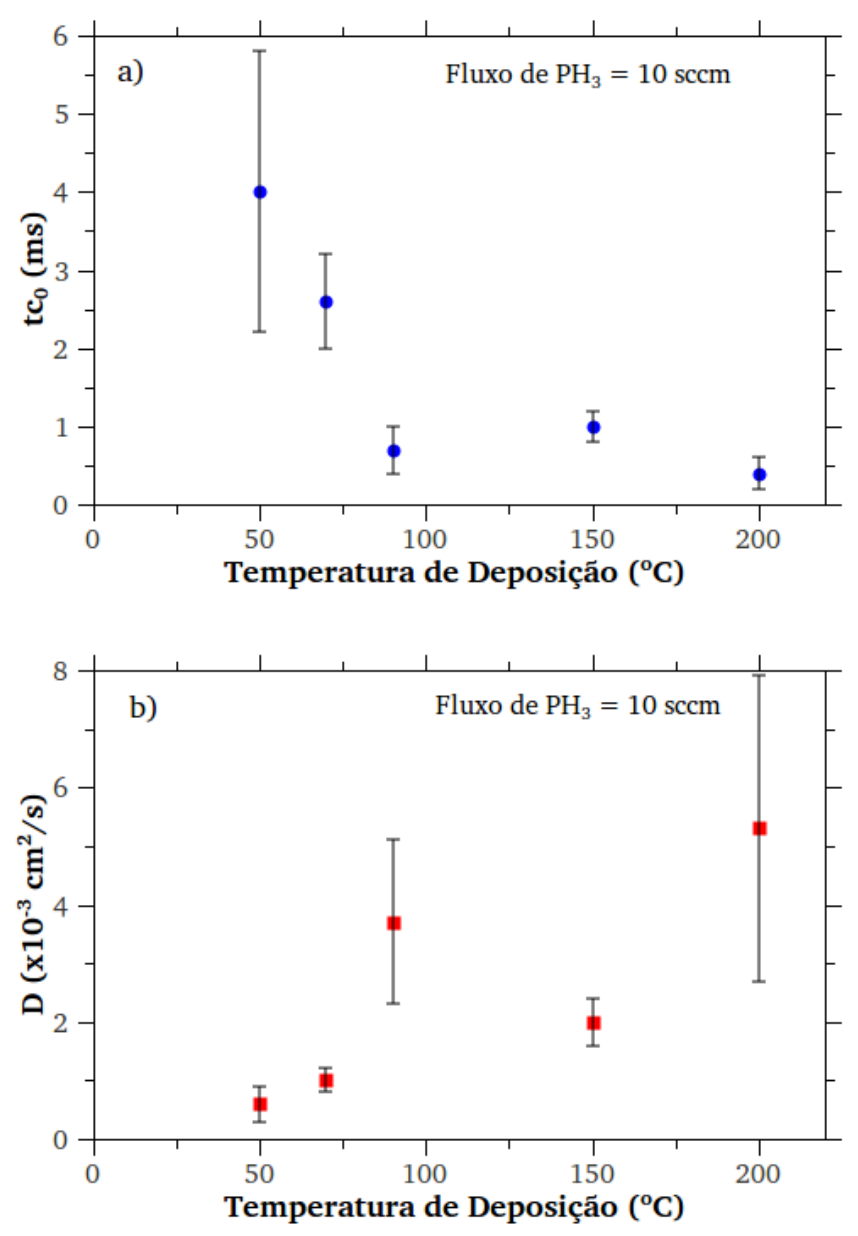

Figura 34 - Medidas do tempo característico no foco e da difusividade térmica para as amostras depositadas com fluxo de fosfina de $10 \mathrm{sccm}$. Em a), são apresentados os valores de $t_{\mathrm{c} 0}$ em função da temperatura de deposição, enquanto em b) são apresentados os valores de $D$ em função da temperatura de deposição. 
$\mathrm{Na}$ figura 34a, nota-se que o tempo característico no foco diminui com o aumento da temperatura de deposição, sendo cerca de $4 \mathrm{~ms}$ para $50{ }^{\circ} \mathrm{C}$ e chegando a menos de $1 \mathrm{~ms}$ para $200{ }^{\circ} \mathrm{C}$. Na figura 34b, nota-se que a difusividade térmica aumenta com o aumento da temperatura de deposição, $5 \times 10^{-4} \mathrm{~cm}^{2} / \mathrm{s}$ para $50{ }^{\circ} \mathrm{C}$ e chegando a mais de $5 \times 10^{-3} \mathrm{~cm}^{2} / \mathrm{s}$ para $200{ }^{\circ} \mathrm{C}$. Se essas dependências forem reprodutíveis com outras amostras a serem medidas por outros trabalhos, tem-se na temperatura de deposição um parâmetro de projeto do tempo de difusão térmica no material, e essa característica pode ser interessante para a engenharia de sensores térmicos. Como o silício cristalino possui uma difusividade térmica maior que a do silício amorfo (MESSIAS; ZANATTA; CATUNDA, 2004), é possível que, com o aumento da temperatura de deposição, as amostras produzidas possuam uma maior fração microcristalina em sua estrutura, e por isso a difusividade térmica aumente. Entretanto, devem ser feitas análises estruturais das amostras para confirmar essa hipótese.

Através da equação 2.11, pode-se calcular o valor da condutividade térmica das amostras. Para isso, foram utilizados os valores de $D$ apresentados nas figuras 33 e 34 e utilizados os valores de $\rho$ e $c_{p}$ da literatura (MESSIAS; ZANATTA; CATUNDA, 2004): $\rho=2,21 \mathrm{~g} / \mathrm{cm}^{3}$ e $c_{p}=0,62 \mathrm{~J} / \mathrm{gK}$. Ressalva-se aqui que, os valores de $\rho$ e $c_{p}$ podem não ser os mesmos para as diferentes amostras, o que exigiria a medição dessas propriedades através de outras técnicas experimentais. Neste trabalho, consideraram-se os valores de $\rho$ e $c_{p}$ iguais para todas as amostras, como uma primeira abordagem para a estimativa do valor de $K$. Utilizando-se desse procedimento, obtêm-se um valor de $K \sim 10^{-3} \mathrm{~W} / \mathrm{Kcm}$. A ordem de grandeza está em conformidade com (MESSIAS; ZANATTA; CATUNDA, 2004). Os valores de $K$ para as diferentes amostras são mostrados na tabela 4.3.

Observa-se que o valor de $K$ da amostra D2-200 foi cerca de 7 vezes maior que o valor da amostra C2-200. A única diferença na deposição de ambas foi a adição de dopantes: a D2-200 foi depositada com $10 \mathrm{sccm}$ de fosfina, enquanto a C2-200 foi depositada sem dopantes. Aparentemente, a adição de dopantes aumenta a condutividade térmica das amostras. Entretanto, as amostras depositadas a $50{ }^{\circ} \mathrm{C}$ não apresentaram esse comportamento: a condutividade não possui relação com o fluxo de fosfina para as amostras A2.5, A2-10, A2-20 e A2-40. 
Algo semelhante ocorre com a difusividade térmica: seu valor para a D2-200 foi cerca de 5 vezes maior que seu valor para a C2-200, mas não há uma relação aparente para a série A. Um estudo com mais amostras se faz necessário para entender melhor esse comportamento.

A tabela 4.3 também apresenta os valores do coeficiente de temperatura do caminho óptico ds/d T, calculados a partir da equação 2.10. Para isso, utilizaramse os valores de $K$ obtidos, juntamente com os valores de $L_{\text {ef }}$ e $\alpha$ da tabela 4.1 e os valores de $P$ e $\theta$ da tabela 4.2. Os valores de $\mathrm{d} s / \mathrm{d} T$ são positivos, indicando um aumento no caminho óptico com o aumento da temperatura causada pela absorção de luz. O caminho óptico representa o produto do índice de refração pela espessura da amostra. Portanto, a priori não é possível saber se a contribuição maior para $\mathrm{d} s / \mathrm{d} T$ provêm de $\mathrm{d} n / \mathrm{d} T$ ou da expansão térmica. Os valores de $\mathrm{d} s / \mathrm{d} T$ obtidos são compatíveis com valores de ds/dT de outros sólidos (JACINTO et al., 2006). Observa-se que o sinal positivo em ds/dT é compatível com o comportamento valepico nas curvas de transmitância normalizada em função de $z$ : a amostra se comporta como uma lente térmica convergente.

A tabela 4.3 apresenta os resultados das propriedades ópticas nãolineares e das propriedades térmicas para as amostras de Si-a:H.

Tabela 4.3 - Propriedades ópticas não-lineares e propriedades térmicas das amostras de Si-a:H.

\begin{tabular}{cccc}
\hline Código da Amostra & $D\left(10^{-3} \mathrm{~cm}^{2} / \mathrm{s}\right)$ & $K\left(10^{-3} \mathrm{~W} / \mathrm{Kcm}\right)$ & $\mathrm{ds} / \mathrm{d} T\left(10^{-7} \mathrm{~K}^{-1}\right)$ \\
\hline D2-200 & $5,3 \pm 2,6$ & $7,2 \pm 3,6$ & $20 \pm 10$ \\
D3-150 & $2,0 \pm 0,4$ & $2,7 \pm 0,5$ & $10,5 \pm 2,2$ \\
C2-200 & $0,9 \pm 0,1$ & $1,3 \pm 0,2$ & $4,59 \pm 0,79$ \\
B2-90 & $3,7 \pm 1,4$ & $5,0 \pm 1,9$ & $6,7 \pm 2,7$ \\
B1-70 & $1,0 \pm 0,2$ & $1,4 \pm 0,3$ & $2,87 \pm 0,71$ \\
A2-40 & $0,8 \pm 0,5$ & $1,0 \pm 0,5$ & $1,68 \pm 0,90$ \\
A2-20 & $6,2 \pm 4,3$ & $8,6 \pm 5,8$ & $8,8 \pm 6,3$ \\
A2-10 & $0,6 \pm 0,3$ & $0,9 \pm 0,4$ & $0,68 \pm 0,33$ \\
A2-2.5 & $3,3 \pm 0,7$ & $4,5 \pm 0,9$ & $8,7 \pm 2,1$ \\
\hline
\end{tabular}




\section{$5 \quad$ CONCLUSÕES}

Neste trabalho, foram obtidos os filmes finos de silício amorfo hidrogenado pela técnica PECVD a temperaturas menores de $200{ }^{\circ} \mathrm{C}$, depositados sobre vidro.

As espessuras dos filmes tiveram cerca de $200 \mathrm{~nm}$. Os valores dos coeficientes de absorção medidos no espectro visível ficaram entre $10^{4} \mathrm{~cm}^{-1}$ e $10^{5}$ $\mathrm{cm}^{-1}$, como esperado para silício amorfo hidrogenado e silício microcristalino hidrogenado. Os valores do gap óptico também ficaram dentro do esperado para o Si-a:H: entre 1,7 eV e 2,3 eV.

Foi possível realizar a experiência de varredura- $Z$ nas amostras, no regime térmico. O tempo de formação do efeito, medido através do tempo característico no foco, foi da ordem de $1 \mathrm{~ms}$. Além dos valores de tempo característico, a varredura- $Z$ também permitiu a medição dos valores da difusividade térmica dos filmes, que foram da ordem de $10^{-3} \mathrm{~cm}^{2} / \mathrm{s}$. Essas características podem ser utilizadas na construção de dispositivos eletrônicos, como sensores termoópticos.

Além disso, foi possível estimar, utilizando valores de $\rho$ e $c_{p}$ da literatura, os valores da condutividade térmica $K$ e do coeficiente de temperatura do caminho óptico $\mathrm{d} s / \mathrm{d} T$.

Observou-se uma dependência entre a temperatura de deposição das amostras, sua difusividade térmica e seu tempo característico: quando a temperatura de deposição era maior, o tempo característico diminuía e a difusividade térmica aumentava.

Não foi encontrada uma dependência entre os valores da condutividade térmica das amostras e o fluxo de fosfina, nem entre os valores da difusividade térmica da amostra e o fluxo de fosfina.

As amostras se comportaram como lente térmica convergente, gerando um sinal de vale-pico na curva de transmitância normalizada da varredura-Z, o que pode ser interpretado como uma variação no caminho óptico $(\Delta s)$ positiva. 


\section{SUGESTÕES PARA TRABALHOS FUTUROS}

Para a continuidade das investigações presentes neste trabalho, sugerese a preparação de mais amostras de Si-a:H depositadas a temperaturas de $50{ }^{\circ} \mathrm{C}$ até $300{ }^{\circ} \mathrm{C}$, e a realização de um estudo mais apurado sobre a dependência com a temperatura de deposição dos valores de $D$ e $t_{c 0}$. Pode-se também estudar com mais detalhes a dependência do fluxo de fosfina com os valores de $D$ e $t_{c 0}$.

Além disso, pode-se realizar um estudo estrutural dos filmes depositados, utilizando técnicas de difração de elétrons e técnicas de microscopia eletrônica. Pode-se também medir com maior precisão os valores de $K$, através das medições de $\rho$ e de $c_{\mathrm{p}}$ para cada amostra com alguma técnica complementar à varredura-Z.

Sugerem-se, também, desenvolvimentos de dispositivos termo-ópticos ou

fotônicos baseados nas características termo-ópticas dos filmes finos de silício, já que o comportamento da transmitância da luz sobre o mesmo é controlado pela intensidade da luz e pelo tempo de exposição. 
AL-DALLAL, S. et al. Optical switching in hydrogenated amorphous silicon-sulfur alloy prepared by glow discharge. Journal of Non-Crystalline Solids, v. 345 e 346, p. 302-305, 2004.

BASS, M. et al. Handbook of Optics - fundamentals, techniques \& design. 2 ed. v.1. New York: McGRAW-HILL, INC, 1995.

BATES, R. Optimizing Parameters for Profiling Measurements, Microelectronic Manufacturing and Testing, p.7 9, 1990.

BOYD, R. W. Nonlinear Optics. 3 ed. Boston: Academic Press Inc, 1992.

CALLISTER, W. D. Jr. Materials Science and Engineering - An Introduction. 7 ed. New York: John Wiley \& Sons, 2007.

CARLSON, D. E.; WRONSKI, C. R. Amorphous Silicon Solar Cells. Applied Physics Letters, v. 28, p. 671-673, 1976.

CARTER, C. A.; HARRIS, J. M. Comparison of models describing the thermal lens effect. Applied Optics, v. 23, n. 3, p. 476-481, 1984.

CUPPO, F. L. S. et al. Thermal-lens model compared with the Sheik-Bahae formalism in interpreting Z-scan experiments on lyotropic liquid crystals. J. Opt. Soc. Am. B, v. 19, n. 6, p. 1342-1348, 2002.

DINU, M.; QUOCHI, F.; GARCIA, H. Third-order nonlinearities in silicon at telecom wavelengths. Applied Physics Letters, v. 82, p. 2954-2956, 2003.

GREEN, W. M. J. et al. Ultra-compact, low RF power, $10 \mathrm{~Gb} / \mathrm{s}$ silicon Mach-Zehnder modulator. Optics Express, v. 15, n. 25, p. 17106-17113, 2007.

GRIFFITHS, D. J. Introduction to Electrodynamics. 3 ed. New Jersey: Prentice Hall, 1999. 
HALINDINTWALI, S. et al. Optical Characterization of a-Si:H and nc-Si:H thin films using the transmission spectrum alone. J. Mater Sci: Mater Electron, v. 18, p. S225S229, 2007.

HASEGAWA, T.; NAGASHIMA, T.; SUGIMOTO, N. Z-scan study of third-order optical nonlinearities in bismuth-based glasses. Optics Communications, v. 250, p. 411-415, 2005.

IKEDA, K.; SHEN, Y.; FAINMAN, Y. Enhanced optical nonlinearity in amorphous silicon and its application to waveguide devices. Optics Express, v. 15, n. 26, p. 17761-17771, 2007.

JACINTO, C et al. Thermal lens and Z-scan measurements: Thermal and optical properties of laser glasses - A review. Journal of Non-Crystalline Solids, v. 352, p. 3582-3597, 2006.

LIN, Q.; PAINTER, O. J.; AGRAWAL, G. P. Nonlinear optical phenomena in silicon waveguides: modeling and applications. Optics Express, v. 15, n. 25, p. 1660416644, 2007.

MARTINELLI, M. Medidas de Efeitos Óticos Não-Lineares por Reflexão de Luz Polarizada. 1998. 162 p. Dissertação (Mestrado) - Universidade de São Paulo, Brasil, 1998.

MESSIAS, D. N.; ZANATTA, A. R.; CATUNDA, T. Thermal lens and non-linear optical absorption study of a-Si:H films. Journal of Non-Crystalline Solids, v. 348, p. 230-234, 2004.

MINAMIKAWA, N.; TANAKA, K. Nonlinear optical properties of hydrogenated amorphous Si films probed by a novel Z-scan technique. Japanese Journal of Applied Physics, v. 45, n. 36, p. L960-L962, 2006.

NARDES, A, M. Propriedades Elétricas de Películas Finas de Ligas de Silício Microcristalino Hidrogenadas Depositadas a Baixas Temperaturas. 2002. 112 p. Dissertação (Mestrado) - Universidade de São Paulo, Brasil, 2002.

NG, T. N. et al. Low Temperature a-Si:H photodiodes and flexible image sensor arrays patterned by digital lithography. Applied Physics Letters, v. 91, p. 063505-1063505-3, 2007. 
OHRING, M. Materials Science of Thin Films - deposition \& structure. 2 ed. San Diego: Academics Press, 2001.

ONMORI, R. K. et al. Photovoltaic effect on $\mu \mathrm{c}-\mathrm{Si}: \mathrm{H}(\mathrm{n}+) / \mathrm{Poly}(\mathrm{o}-\mathrm{methoxyaniline)/a-}$ $\mathrm{Si}: \mathrm{H}(\mathrm{p})$ structures. Synthetic Metals, v. 102, p. 1004-1005, 1999.

RIBEIRO, M. Estudo das Propriedades Estruturais e Ópticas em Materiais Nanoestruturados a Base de Silício. 2009. 150 p. Tese (Doutorado) Universidade de São Paulo, Brasil, 2009.

RODRIGUES, R. J.; FURLAN, R. Design of microsensor for gases and liquids flow measurements. Microelectronics Journal. V. 34, p. 709-711, 2003.

SHEIK-BAHAE, $M$ et al. Sensitivity measurements of optical nonlinearities using a single-beam. IEEE J. Quantum Electron. v. 26, n. 4, p. 760-769, 1990.

SHEIK-BAHAE, M.; SAID, A. A.; STRYLAND, V. High-sensitivity, single-beam $n_{2}$ measurements. Optics Letters, v. 14, n. 17, p. 955-957, 1989.

SIEGMAN, A. E. Lasers. Salsalito: University Science Books, 1986.

SILVA, C. M. Filtro de Interferência Variável e Descrição de uma Aplicação: Dispositivo Multicanal Espectral para Análise Ambiental. 2010. 152 p. Dissertação (Mestrado) - Universidade de São Paulo, Brasil, 2010.

SOGA, D.; ALVES, S.; CAMPOS, A.; TOURINHO, F. A.; DEPEYROT, J.; FIGUEIREDO NETO, A. M. Nonlinear optical properties of ionic magnetic colloids in the femto- and millisecond time scales: change from convergent-to-divergent lenstype behaviors. J. Opt. Soc. Am. B., v. 24, n. 1, p. 49-55, 2007.

SOGA, D. Estudo de Propriedades Não-Lineares de Colóides Magnéticos nas Escalas de Tempo de Mili e Femtossegundos. 2007. 83 p. Tese (Doutorado) Universidade de São Paulo, Brasil, 2007.

SOREF, R. A. The Past, Present, and Future of Silicon Photonics. IEEE J. Sel. Top. Quantum Electron, v. 12, p. 1678-1687, 2006. 
SPEAR, W. E.; LE COMBER, P. G. Electronic Properties of Substitutionally Doped Amorphous Si and Ge. Phylosophical Magazine, v. 33, p. 935-949, 1976.

STERLING, H. F.; SWANN, R. C. G. Chemical Vapour Deposition Promoted by R. F. Discharge. Solid State Electronics, v. 8, p. 653-654, 1965.

STREET, R. A. Hydrogenated Amorphous Silicon. New York: Cambridge University Press, 1991.

SUN, Y.; ROGERS, J. A. Inorganic Semiconductors for Flexible Electronics. Advanced Materials, v. 19, p. 1897-1916, 2007.

TAUC, J. Amorphous and liquid semiconductors, New York:Plenum Press, 1974.

TAUC, J.; GRIGOROVICI, R.; VANCU, A. Optical Properties and Electronic Structure of Amorphous Germanium. Physica Status Solidi, v. 15, p. 627-637, 1966.

VLASOV, Y.; GREEN, W. M. J.; XIA, F. High-throughput silicon nanophotonic wavelength-insensitive switch for on-chip optical networks. Nature Photonics, v. 2, p. 242-246, 2008.

VUOLO, J. H. Visão Humana. Apostila, 2004. 